\title{
Corporal Punishment by Parents and Associated Child Behaviors and Experiences: A Meta-Analytic and Theoretical Review
}

\author{
Elizabeth Thompson Gershoff \\ Columbia University
}

\begin{abstract}
Although the merits of parents using corporal punishment to discipline children have been argued for decades, a thorough understanding of whether and how corporal punishment affects children has not been reached. Toward this end, the author first presents the results of meta-analyses of the association between parental corporal punishment and 11 child behaviors and experiences. Parental corporal punishment was associated with all child constructs, including higher levels of immediate compliance and aggression and lower levels of moral internalization and mental health. The author then presents a process-context model to explain how parental corporal punishment might cause particular child outcomes and considers alternative explanations. The article concludes by identifying 7 major remaining issues for future research.
\end{abstract}

Corporal punishment has been an integral part of how parents discipline their children throughout the history of the United States (Greven, 1991) and has been a focus of psychological research for decades (e.g., Caselles \& Milner, 2000; Eron, Walder, Huesmann, \& Lefkowitz, 1974; Glueck \& Glueck, 1950; MacKinnon, 1938; J. McCord, 1988b; Sears, 1961; Straus, 1994a). Although a growing number of countries have adopted policies or laws that prohibit parents from using corporal punishment as a means of discipline (Austria, Croatia, Cyprus, Denmark, Finland, Germany, Israel, Italy, Latvia, Norway, and Sweden; Bitensky, 1998; EPOCHUSA, 2000), both support for and use of corporal punishment remain strong in the United States, with $94 \%$ of American parents spanking their children by the time they are 3 or 4 years old (Straus \& Stewart, 1999).

Psychologists and other professionals are divided on the question of whether the benefits of corporal punishment might outweigh any potential hazards; some have concluded that corporal punishment is both effective and desirable (e.g., Baumrind, 1996a, 1996b, 1997; Larzelere, 1996, 2000), whereas others have concluded that corporal punishment is ineffective at best and harmful at worst (e.g., American Academy of Pediatrics, 1998; Lytton, 1997; J. McCord, 1997; Straus, 1994a). This controversy over

Editor's Note. W. Andrew Collins served as the action editor for this article.-NE

I am indebted to Theodore Dix, George Holden, Pamela Miller, Murray Straus, George Knight, Robert Larzelere, Diana Baumrind, and Lawrence Aber for their comments on and assistance with previous versions of this article. Writing of this article was supported in part by a predoctoral University Continuing Fellowship from the University of Texas at Austin and a National Institute of Mental Health-sponsored postdoctoral fellowship through the Program for Prevention Research at Arizona State University.

Correspondence concerning this article should be addressed to Elizabeth Thompson Gershoff, National Center for Children in Poverty, Columbia University, Mailman School of Public Health, 154 Haven Avenue, New York, New York 10032. E-mail: et78@columbia.edu corporal punishment has inspired a series of recent debates among psychological, sociological, and legal scholars about what corporal punishment does and does not do for children (see Donaldson, 1997; Friedman \& Schonberg, 1996; Mason \& Gambrill, 1994; Pervin, 1997).

Despite this controversy and the hundreds of scientific studies invoked on either side of the debate, understanding of the child behaviors and experiences associated with parental corporal punishment has been limited to narrative reviews (e.g., Becker, 1964; Straus, 1994a) and "vote count" summaries of the number of positive and negative effects that accrue from corporal punishment (e.g., Larzelere, 1996, 2000; Steinmetz, 1979). Crucial questions remain unanswered, such as what range of child behaviors and experiences are empirically associated with parental corporal punishment, as well as why, how, and for whom corporal punishment might have such effects. This article provides preliminary answers to these questions by synthesizing the current empirical evidence of, and theoretical explanations for, associations between parental corporal punishment and 11 child behaviors and experiences. In the first half of the article, the empirical evidence linking parental corporal punishment and both positive and negative child constructs is synthesized through meta-analyses. In the second half of the article, I present a process-context model that identifies the processes in the child that might transform the experience of corporal punishment into manifest child behaviors and that suggests types of children and parents for whom and circumstances under which positive or negative associations might be expected. This model is intended to summarize the child processes, contextual influences, and child constructs associated with parental corporal punishment as well as to provide a guide for future research on corporal punishment and its associated child behaviors and experiences. In the final section of the article, I identify seven major issues that need to be addressed in future research to determine the specificity and causal direction of associations between parental corporal punishment and child behaviors and experiences. Taken together, this article summarizes the empirical data on associations between parental corporal punishment and children's behaviors, reviews theoretical work to explain why such 
associations should be expected, and identifies issues that require specific attention in future research.

\section{Meta-Analyses of Parental Corporal Punishment and Associated Child Behaviors and Experiences}

The first step in understanding whether and how parental corporal punishment affects children is to establish to what degree corporal punishment is associated with the child constructs of interest. Toward this end, I present in this section the results of separate meta-analyses of the associations between parental corporal punishment and 11 frequently identified child constructs. Despite the inability of meta-analyses to yield definitive causal conclusions (Cooper \& Hedges, 1994), they do constitute an effective means of establishing whether the associations of interest are present and thus pave the way for further research into causal mechanisms. To underscore the inability of meta-analyses to support causal conclusions, I refer to child "behaviors and experiences" or "constructs" associated with parental corporal punishment rather than to child "outcomes" in the context of the meta-analyses.

\section{Distinguishing Corporal Punishment From Physical Abuse}

Before examining the associations between corporal punishment and child constructs, it is important to establish what is meant by the term corporal punishment. Regarding legal definitions, 48 states and the District of Columbia specify what constitutes corporal punishment in their legal statutes defining child abuse (Davidson, 1997); 29 states assert that corporal punishment encompasses the use of "reasonable" force with some adding qualifiers that it must also be "appropriate" (AL, AK, AZ, CA, CO), "moderate" (AR, DE, SC, SD), or "necessary" (MT, NH, NY, OR, TX, WI). Three states see the need to clarify that corporal punishment is limited to "nondeadly force" (AK, NY, TX; Davidson, 1997). The present article adopts the definition of corporal punishment offered by Straus (1994a). "Corporal punishment is the use of physical force with the intention of causing a child to experience pain but not injury for the purposes of correction or control of the child's behavior" (p. 4).

A frequent criticism of research on corporal punishment is that nonabusive corporal punishment is often confounded with harmful and abusive behaviors, thus preventing conclusions about the effects of everyday spanking (Larzelere, 2000; Baumrind, 1996a). This apparent confound has arisen because the majority of child abuse researchers view corporal punishment and potentially abusive techniques as points on a continuum of physical acts toward children (Gelles \& Straus, 1988; Gil, 1973; Graziano, 1994; Kadushin \& Martin, 1981; Whipple \& Richey, 1997; Wolfe, 1987; Zigler \& Hall, 1989). However, a consensus on where to draw the line between acceptable corporal punishment and dangerous physical abuse is noticeably absent in the United States (Davidson, 1997; Gelles \& Straus, 1988; Hyman, 1997; Whipple \& Richey, 1997; Wolfe, 1987). State laws defining what constitutes physical abuse often specifically include corporal punishment. Davidson (1997) reviewed the state definitions of child maltreatment and found that 12 states (DC, FL, IL, MT, NE, NJ, NY, ND, OH, RI, $\mathrm{SC}, \mathrm{WV}$ ) included the phrase "excessive corporal punishment" in their definitions of child maltreatment; an additional 10 states qualified corporal punishment as constituting abuse when characterized as "cruel" (CT, CO, NE, NM, OH, SD), "unlawful" (CA), "excessive or unreasonable" (WY), "severe" (NJ), "cruel and inhuman" (KS), or "extreme" (ME).

For the purposes of this article, I consider physical abuse to be a potential outcome of corporal punishment. Herein, corporal punishment will be operationally distinguished from physical abuse according to the definition of physical abuse provided by the National Clearinghouse on Child Abuse and Neglect Information (2000), namely:

Physical abuse is characterized by the infliction of physical injury as a result of punching, beating, kicking, biting, burning, shaking or otherwise harming a child. The parent or caretaker may not have intended to hurt the child, rather the injury may have resulted from over-discipline or physical punishment. (What Are the Main Types of Maltreatment? section, para. 2)

Behaviors that do not result in significant physical injury (e.g., spank, slap) are considered corporal punishment, whereas behaviors that risk injury (e.g., punching, kicking, burning) are considered physical abuse. The studies included in the meta-analyses discussed below explicitly targeted parental corporal punishment, rather than parental physical abuse, as potential predictors of child behaviors and experiences. As I describe in detail below, studies that included potentially abusive techniques in their definitions of corporal punishment were excluded from the analyses.

\section{Methodological Concerns in the Measurement of Corporal Punishment}

It is important to acknowledge at the outset that the majority of studies examining links between parental corporal punishment and child behaviors and experiences measure both constructs at the same point in time, thus preventing any conclusions about causality. As I discuss below, even measuring parental corporal punishment at one time point and a child behavior at a future time point may not be sufficient to infer causal direction. True detection of causality may require controlling for the child's rate of the behavior of interest at the first time point as well to account for autocontingency of behavior over time. With these points in mind, the meta-analyses described here do not afford causal conclusions but allow understanding only of whether corporal punishment and child constructs are associated.

In addition, because corporal punishment is used primarily with children younger than 5 years of age (Straus \& Stewart, 1999), because corporal punishment is used rarely by parents (1-2 times per month; Straus \& Stewart, 1999), and because assigning parents to spank or no-spank experimental conditions is untenable, researchers must rely on parent reports of corporal punishment rather than on observations. Although some methods of having parents report their use of corporal punishment, such as nightly phone calls (Holden, Coleman, \& Schmidt, 1995) or detailed daily discipline diaries (Larzelere \& Merenda, 1994), do have high validity, the majority of information on corporal punishment comes from parents' or adolescent and adult children's recollections of frequency of corporal punishment. 


\section{Child Behaviors and Experiences Associated With Parental Corporal Punishment}

The goal of most research on parenting is to identify which practices promote positive and adaptive behaviors in children. However, in the study of parents' use of corporal punishment, much research has been biased toward finding negative child outcomes associated with corporal punishment. The meta-analyses below specifically include a balance of potentially desirable child constructs (immediate compliance, moral internalization, quality of relationship with parent, and mental health) as well as undesirable child constructs (aggression, criminal and antisocial behavior, abuse of own child or spouse, and victim of abuse by own parent). Discussion of why corporal punishment should be associated with such behaviors and experiences is presented briefly here; the hypothesized processes linking the experience of corporal punishment with these constructs are detailed in the process-context model in the second section of the article.

\section{Immediate Compliance}

The primary goal most parents have in administering corporal punishment is to stop children from misbehaving immediately. Laboratory research on learning has confirmed that corporal punishment is indeed effective in securing short-term compliance (Newsom, Flavell, \& Rincover, 1983). Although there are many studies that purport to examine relations between corporal punishment and compliance, most of these studies do not involve observations of whether children comply immediately after corporal punishment is administered. Rather, such studies ask parents how often they typically use corporal punishment and correlate this frequency with parents' reports of how compliant their children are to all forms of discipline (e.g., Lytton, 1977; Minton, Kagan, \& Levine, 1971; Power \& Chapieski, 1986). To assess corporal punishment's effect on short- and long-term compliance separately, the subsequent meta-analysis of immediate compliance only includes studies that measured children's compliance to corporal punishment. Compliance that occurs at a point in time removed from an instance of corporal punishment is considered evidence of internalization.

\section{Moral Internalization}

Although immediate compliance may be a salient goal when parents initiate discipline, promoting the development of children's internal controls is more important to long-term socialization than immediate compliance (Grolnick, Deci, \& Ryan, 1997; Hoffman, 1983; Kohlberg, 1969; Lepper, 1983; Piaget, 1932/ 1965). Moral internalization is defined by Grusec and Goodnow (1994) as "taking over the values and attitudes of society as one's own so that socially acceptable behavior is motivated not by anticipation of external consequences but by intrinsic or internal factors" (p. 4), and it is thought to underlie the development of children's social and emotional competence (Kochanska \& Thompson, 1997). Children's internalization of morals is thought to be enhanced by parental discipline strategies that use minimal parental power, promote choice and autonomy, and provide explanations for desirable behaviors (Kuczynski \& Hildebrandt, 1997). Attribution theorists emphasize that power-assertive methods such as corporal punishment promote children's external attributions for their behavior and minimize their attributions to internal motivations (Dix \& Grusec, 1983; Hoffman, 1983; Lepper, 1983). Additionally, corporal punishment may not facilitate moral internalization because it does not teach children the reasons for behaving correctly, does not involve communication of the effects of children's behaviors on others, and may teach children the desirability of not getting caught (Hoffman, 1983; Grusec, 1983; Smetana, 1997).

\section{Aggression}

The association between corporal punishment and children's aggression is one of the most studied and debated findings in the child-rearing literature (Coie \& Dodge, 1998; Steinmetz, 1979). Over the years, several reviews of the literature have concluded that corporal punishment is associated with increases in children's aggressive behaviors (Becker, 1964; Patterson, 1982; RadkeYarrow, Campbell, \& Burton, 1968; Steinmetz, 1979). Corporal punishment has been hypothesized to predict increases in children's aggression because it models aggression (e.g., Aronfreed, 1969; Bandura \& Walters, 1959; Eron, Walder, \& Lefkowitz, 1971; Walters \& Grusec, 1977); promotes hostile attributions, which predict violent behavior (Dodge, Pettit, McClaskey, \& Brown, 1986); and initiates coercive cycles of aversive behaviors between parent and child (Dishion \& Patterson, 1999; Patterson, Reid, \& Dishion, 1992). Early experiences with corporal punishment may model and legitimize many types of violence throughout an individual's life (White \& Straus, 1981), particularly violence in romantic relationships (Simons, Lin, \& Gordon, 1998). Indeed, in one longitudinal study, parents' use of corporal punishment in childhood was the strongest predictor of adolescents' aggression 8 years later, whereas permissive parenting was not a significant predictor (P. Cohen, Brook, Cohen, Velez, \& Garcia, 1990). It was my expectation that corporal punishment would be associated in the meta-analyses with aggression in childhood as well as in adulthood.

Although aggression is often combined with antisocial behavior to constitute what are typically referred to as externalizing behavior problems (Achenbach, 1991), antisocial behaviors such as stealing are nonviolent and may be related to corporal punishment in different ways than aggression (Huesmann, 1997). In the present meta-analyses, the extent to which children engage in delinquent or illegal behaviors are separated from the extent of their aggressive behaviors.

\section{Delinquent, Criminal, and Antisocial Behavior}

Across decades of research, corporal punishment has been implicated in the etiology of criminal and antisocial behaviors by both children and adults (e.g., Burt, 1925; Glueck \& Glueck, 1964; Hetherington, Stouwie, \& Ridberg, 1971; W. McCord \& McCord, 1959; Patterson \& Stouthamer-Loeber, 1984; West \& Farrington, 1973; Wilson \& Herrnstein, 1985). Attribution theory posits that associations between corporal punishment and child delinquent or antisocial behavior result from an inability of corporal punishment to facilitate children's internalization of morals and values (Hoffman, 1983; Lepper, 1983). Social control theory suggests that parental corporal punishment erodes the parent-child relationship 
and in turn decreases children's motivation to internalize parents' values and those of the society, which in turn results in low self-control (Hirschi, 1969). These same processes may explain the relation between corporal punishment and adult criminality. In Glueck and Glueck's (1950) longitudinal study of delinquency, whether boys experienced a harsh parental disciplinary style predicted their arrest rates at ages 17 through 45 (see also Laub \& Sampson, 1995). J. McCord (1979) also found in her longitudinal study that the extent to which parents were aggressively punitive predicted their children's criminal behavior as adults. The connection between criminal and antisocial behavior in childhood and adulthood is examined here in separate meta-analyses.

\section{Quality of the Parent-Child Relationship}

The potential for parental corporal punishment to disrupt the parent-child relationship is thought to be a main disadvantage of its use (Azrin, Hake, Holz, \& Hutchinson, 1965; Azrin \& Holz, 1966). The painful nature of corporal punishment can evoke feelings of fear, anxiety, and anger in children; if these emotions are generalized to the parent, they can interfere with a positive parentchild relationship by inciting children to be fearful of and to avoid the parent (Bugental \& Goodnow, 1998; Grusec \& Goodnow, 1994; Maccoby \& Martin, 1983; Saarni, Mumme, \& Campos, 1998). If corporal punishment does lead children to avoid their parents, such avoidance may in turn erode bonds of trust and closeness between parents and children (Azrin \& Holz, 1966; Hirschi, 1969; Parke, 1977; Van Houten, 1983).

\section{Mental Health}

Although little theoretical work has been done to identify the processes by which corporal punishment would lead to mental health problems, harsh punishment (including corporal punishment) has been associated significantly with adolescents' depressive symptomatology and distress (McLoyd, Jayaratne, Ceballo, \& Borquez, 1994), even after controlling for age, gender, family socioeconomic status (SES), and history of physical abuse (Turner \& Finkelhor, 1996). Coercive techniques have been associated with decreases in children's feelings of confidence and assertiveness and with increases in feelings of humiliation and helplessness (Baumrind \& Black, 1967; Lasky, 1993). If corporal punishment does have indelible effects on children's mental health, an association between corporal punishment and adult mental health also might be expected. In the meta-analyses I present below, the constructs of child mental health and adult mental health are analyzed separately and include varied indices of poor mental health, including depression, alcoholism, suicidal tendency, and low self-esteem.

\section{Adult Abuse of Own Child or Spouse}

If corporal punishment is associated with a general aggressive tendency in adulthood, this aggression also may manifest in relationships with family members, particularly with a child or spouse. The same processes hypothesized to account for an association between corporal punishment and general aggression also are expected to account for a tendency toward violence against family members. Specifically, if parental corporal punishment leads indi- viduals to view aggression or violence as legitimate (e.g., Aronfreed, 1969; Bandura \& Walters, 1959; Eron et al., 1971; Walters \& Grusec, 1977; White \& Straus, 1981), make external attributions for their behavior (Hoffman, 1983; Lepper, 1983), and attribute hostile intent to the behaviors of others (Dodge et al., 1986), they may be more likely to resort to aggression and violence during conflicts with their children and spouses. A tendency toward intergenerational transmission of aggression in close relationships is evident in a strong tendency for parents who were corporally punished to continue the practice with their own children (Fry, 1993; Herrenkohl, Herrenkohl, \& Toedter, 1983; Holden, Thompson, Zambarano, \& Marshall, 1997; Simons, Whitbeck, Conger, \& $\mathrm{Wu}, 1991)$. Similarly, experience with both average (e.g., spanking) and extreme (e.g., kicking, biting, burning, and beating up) forms of corporal punishment by parents are associated with increases in an individual's likelihood of acting violently with an adult romantic partner (Caesar, 1988; Downs, Miller, Testa, \& Parek, 1992; Sigelman, Berry, \& Wiles, 1984; Straus \& Yodanis, 1996; Swinford, DeMaris, Cernkovich, \& Giordano, 2000).

\section{Becoming a Victim of Physical Abuse}

As stated above, child abuse researchers tend to see corporal punishment and physical abuse on a continuum, such that if corporal punishment is administered too severely or too frequently, the outcome can be physical abuse (Garbarino, 1977; Gil, 1973; Vasta, 1982). The notion of a corporal punishment-physical abuse continuum is corroborated in part by physically abusive parents themselves: Parents who had abused their children revealed that as many as two thirds of their abusive incidents began as attempts to change children's behavior or to "teach them a lesson" (Coontz \& Martin, 1988; Gil, 1973; Kadushin \& Martin, 1981). Unfortunately, use of severe and potentially abusive physical techniques may be more common than has been realized. In a recent study, $16 \%$ of incidents reported by mothers and $21 \%$ of those reported by fathers were rated by independent coders as severe (e.g., use of spoons, sticks, or belts; Nobes, Smith, Upton, \& Heverin, 1999). The potential for the widely used practice of corporal punishment to be associated with a risk for injury to children behooves further research into this connection.

\section{Method}

\section{Sample of Studies}

I used three main sources to identify all articles that examined the associations between parental corporal punishment and child behaviors and experiences and were available through June 2001. The first source was the reference lists of relevant reviews, namely by Becker (1964), Larzelere (1996), Steinmetz (1979), and Straus (1994a). Second, I conducted a computer-based literature search of Psychological Abstracts PsycINFO, Educational Resources Information Center, Social Sciences Index, and Dissertation Abstracts International. Key words used to identify relevant articles were corporal punishment, physical punishment, and spank. The third and final search involved the "ancestry approach" (Johnson, 1993) applied to the reference sections of all retrieved articles, book chapters, and dissertations. In the interest of being exhaustive, qualification for inclusion was not restricted to peer-reviewed journals; I made every attempt to include all relevant and accessible journal articles, book chapters, and dissertations so as to avoid publication biases (Johnson, 1993). 
The abstracts and often the full text of over 300 relevant works, including 63 dissertations, were studied for inclusion in the present metaanalyses. Half of these works did not include data, as they were instead focused on the debate about corporal punishment $(n=69)$, the prevalence of corporal punishment in the United States or abroad $(n=42)$, the antecedents to parents' use of corporal punishment $(n=40)$, attitudes about corporal punishment $(n=21)$, or other issues such as the history of corporal punishment and theories about how it affects children $(n=27)$. Of the 189 studies that did present data on potential effects of corporal punishment, 101 were excluded according to the following criteria: (a) $27 \%$ combined corporal punishment with abusive techniques or only examined abusive behaviors (see Operationalization of Corporal Punishment below); (b) $22 \%$ predicted dependent variables that have not been considered consistently in the literature on corporal punishment (e.g., intelligence; Smith \& Brooks-Gunn, 1997); (c) 22\% did not provide sufficient statistics for calculation of an effect size (e.g., only included betas from regression with other variables; Colder, Lochman, \& Wells, 1997); (d) 17\% combined corporal punishment with other types of discipline (e.g., corporal punishment was grouped with verbal punishment; Brenner \& Fox, 1998); and (e) $12 \%$ did not study corporal punishment administered by parents, used exceptional populations, or were unavailable through interlibrary loan.

A sample of 88 studies, including 8 dissertations, met the above criteria and were included in the analyses. (Multiple articles from the same study were represented in the analyses by the effect size from only one article.) Of the studies included, 67 provided an effect size for a single metaanalysis, 15 provided effect sizes for two meta-analyses, 4 provided three effects sizes, and 2 provided four effect sizes, for a total of 117 effect sizes across the 11 analyses conducted. The total number of participants was 36,309 (studies contributing more than one effect size only counted once), with an average of 413 participants per study and a range of 14 (Chapman \& Zahn-Waxler, 1982) to 4,529 (Straus, 1994a) participants per study. The earliest study was from 1938 (MacKinnon, 1938); 5\% of the studies were from 1950-1959, 10\% from 1960-1969, 10\% from $1970-$ 1979, $25 \%$ from 1980-1989, 47\% from 1990-1999, and $2 \%$ from 2000. The range of studies incorporated in the meta-analyses included 26 nonsignificant effect sizes.

\section{Operationalization of Corporal Punishment}

To be included in the meta-analyses, each study's operationalization of corporal punishment was required to meet Straus' (1994a) definition listed above. Table 1 lists the operationalizations of corporal punishment reported in the 88 studies included in the present meta-analyses. The term spank was used most often to characterize corporal punishment (26\% of the studies) followed by the term physical punishment (24\%). Parents were asked to characterize their use of corporal punishment according to its frequency in $69 \%$ of the studies, according to its severity in $9 \%$, according to both

Table 1

Operationalizations of Corporal Punishment in Sample of Studies $(N=88)$

\begin{tabular}{lc}
\hline \multicolumn{1}{c}{ Operationalization } & \% of all studies \\
\hline Spank & 26 \\
Physical punishment & 24 \\
$\begin{array}{l}\text { Spank or slap/spank or smack/spank or hit/spank } \\
\text { or pinch }\end{array}$ & 20 \\
$\begin{array}{l}\text { Spank or hit with object/slap or hit with object/hit } \\
\text { or hit with object }\end{array}$ & 16 \\
$\begin{array}{l}\text { Corporal punishment } \\
\text { Other (e.g., strike, smack, negative physical } \\
\text { discipline) }\end{array}$ & 8 \\
\hline
\end{tabular}

frequency and severity in 5\%, and only as ever having been used in the child's life in $12 \%$. In only $5 \%$ of studies were immediate child reactions to specific instances of corporal punishment examined.

To ensure that the corporal punishment considered in the meta-analyses did not include possible physical abuse, studies that grouped or compared corporal punishment with techniques that knowingly would cause severe injury to the child were excluded. Examples of excluded definitions of corporal punishment include "whipping, punching, slamming against the wall, tying up" (Bryan \& Freed, 1982, p. 79), "angry abuse, slaps, or beatings" (W. McCord, McCord, \& Howard, 1961, p. 83), and "spanking, slapping, shoving, yanking, kicking, beating severely with object (leaving a mark on the body), hitting firmly but not severely (no mark is left on the body), pulling hair, twisting an ear, making the child kneel on hard objects, making the child stand for a long time, pinching, shaking" (Rohner, Bourque, \& Elordi, 1996, p. 845). Two coders agreed consistently in deciding which studies to exclude on the basis of this criteria $(\kappa=.74, p=$ $.0001)$.

\section{Operationalizations of Child Constructs}

The 11 potential child behaviors and experiences described above and hypothesized to be associated with parental corporal punishment were selected as constructs for separate meta-analyses. The behaviors and experiences measured in childhood were immediate compliance, moral internalization, aggression, delinquent and antisocial behavior, quality of the parent-child relationship, mental health, and likelihood of becoming a victim of physical abuse. Behaviors and experiences measured in adulthood included aggression, criminal and antisocial behavior, mental health, and adult abuse of own child or spouse. Example operationalizations of each of the construct categories are presented in Table 2. As noted above, immediate compliance was restricted to children's responses to particular instances of corporal punishment; compliance measured either longitudinally (e.g., corporal punishment measured at Time 1 and compliance at Time 2) or cross-sectionally (e.g., parents' rate of corporal punishment correlated with children's overall rate of compliance) was considered moral internalization. Two coders agreed 93\% $(\kappa=.92, p=.0001)$ on grouping dependent variables into these categories.

\section{Operationalizations of Moderator Variables}

The age and gender of the target child were reported in the majority of studies and thus were identified as potential moderators. Although race and SES have been used prominently in a few recent studies as moderators of the effects of corporal punishment (e.g., Deater-Deckard, Dodge, Bates, \& Pettit, 1996; Gunnoe \& Mariner, 1997; McLeod, Kruttschnitt, \& Dornfeld, 1994; Straus, Sugarman, \& Giles-Sims, 1997), only $44 \%$ of the studies collected for the meta-analyses reported the racial-ethnic affiliations of their participants, and only $27 \%$ reported their SES. Only 4 of the 90 studies reported parenting style as a possible moderator (DeVet, 1997; Levin \& Sears, 1956; Simons, Johnson, \& Conger, 1994; Straus \& Mouradian, 1998). Such low incidence across the studies in the meta-analyses precluded testing race, SES, or parenting style as moderators.

Seven characteristics of the studies themselves were coded as potential categorical moderators: (a) source of study (journal, book, dissertation); (b) measure of corporal punishment (observation, parent report, child report, child retrospective account, hypothetical [e.g., parent reports likelihood he or she would use spanking to respond to a child's misbehavior described in a vignette], experimental); (c) referent time period (observation, last week, last month, last year, ever, hypothetical, not specified); (d) timing of measure (cross-sectional, longitudinal, retrospective, experimental); (e) index of corporal punishment (frequency, severity, frequency and severity, ever in life, when used); (f) independence of raters (independent, not independent, both); and (g) design of study (within-subjects [all parents reported spanking to varying degrees], between-subjects [parents who 
Table 2

Sample Operationalizations of Child Constructs

\begin{tabular}{|c|c|}
\hline Construct & Sample operationalization(s) \\
\hline \multicolumn{2}{|l|}{ Measured in childhood } \\
\hline Immediate compliance & Obedience to parental directives within 5 s (Day \& Roberts, 1983) \\
\hline Moral internalization & $\begin{array}{l}\text { Resistance to temptation to disobey rules of game when left alone (Burton et al., 1961); behaves altruistically } \\
\text { and makes reparations to peers (Zahn-Waxler et al., 1979) }\end{array}$ \\
\hline Aggression & Nomination by peers (Eron, 1982) \\
\hline Delinquent and antisocial behavior & Self-report of truancy, underage drinking, stealing, or selling drugs (Simons, Johnson, \& Conger, 1994) \\
\hline Quality of parent-child relationship & Observed frequency and quality of contact with mother (Crockenberg, 1987) \\
\hline Mental health & Self-report of depression and lack of purpose in life (DuRant et al., 1994) \\
\hline Victim of physical abuse & Identification of parent as abusive by local Child Protective Services agency (Trickett \& Kuczynski, 1986) \\
\hline \multicolumn{2}{|l|}{ Measured in adulthood } \\
\hline Aggression & Self-report of frequency of aggressive acts (Eron et al., 1991) \\
\hline Criminal and antisocial behavior & State criminal record (J. McCord, 1988a, 1988b) \\
\hline Mental health & Self-report of depressive and alcoholic symptoms (Holmes \& Robins, 1987, 1988) \\
\hline Adult abuse of own child or spouse & $\begin{array}{l}\text { Self-report of abusive techniques used with own child (Straus, 1994a); in therapy for battering spouse } \\
\text { (Caesar, 1988) }\end{array}$ \\
\hline
\end{tabular}

reported spanking were compared with those who did not]). Each of these characteristics was coded by the author for the 88 studies; an independent coder assigned the categorical codes for $22(25 \%)$ of the studies, with interrater agreement at an average kappa of .68 $(p<.0001$, modal agreement $=100 \%$ )

\section{Analyses}

I conducted separate meta-analyses for each of the dependent variables using the DSTAT software (Johnson, 1993), which is based on Hedges's (1981, 1982; Hedges \& Olkin, 1985) formulations of meta-analysis. Summary statistics in each of the target studies are converted into a standardized effect size, $d$, which represents the size of the relation of the independent and dependent variables weighted by the sample size of the study. DSTAT allows for the calculation of $d$ in the case of between-subjects designs (e.g., with $t$ tests) as well as in the case of within-subjects designs (e.g., with correlations). The standardized effect sizes from each of the target studies are combined into a composite mean weighted effect size $\left(d_{+} ;\right.$J. Cohen, 1988) and tested to determine both whether they differ significantly from zero and are consistent as summary statistics. A mean effect size is said to be significant if its $95 \%$ confidence interval does not include 0.00 , a value that indicates no association between the variables of interest. When a study did not report a summary statistic but rather reported effects for subgroups (e.g., boys vs. girls), a single averaged $d$ (weighted by subgroup $n$ ) was calculated consistent with a meta-analytic strategy that treats each study as the unit of analysis to preserve independence of effect sizes (Hunter \& Schmidt, 1990; Light \& Pillemer, 1984). Each study thus contributed only one statistic to each of the 11 meta-analyses.

Categorical tests of moderators typically available in meta-analytic programs only examine main effects and do not control for the explanatory effects of other possible moderators. It is thus necessary to conduct a least squares multiple regression in which each effect size is weighted by the reciprocal of its variance (Johnson, 1993; Knight, Fabes, \& Higgins, 1996). Because the degrees of freedom in the weighted regression procedures in conventional statistical programs are inappropriate (Johnson, 1993), the unstandardized regression weights for each moderator were calculated in a separate statistical package (SPSS was used here) and then corrected in DSTAT. In addition to the overall regression effect $\left(Q_{\mathrm{R}}\right)$ provided by the SPSS multiple regression procedure, DSTAT also calculates a test of model specification $\left(Q_{\mathrm{E}}\right)$ that indicates whether a significant amount of systematic variation remains unexplained in the model (Hedges \& Olkin, 1985; Johnson, 1993).

\begin{abstract}
Results
Meta-Analyses

Table 3 lists the individual studies comprising each metaanalysis and their sample sizes, with participants divided into spank (i.e., parents reported using spanking) and no-spank (i.e., parents did not report using spanking) groups where applicable. Codes for the seven categorical moderator variables, values for the two continuous moderators (mean age of the child and percentage of target children who were female), and individual effect sizes are listed for each study.
\end{abstract}

The results of the 11 separate meta-analyses are summarized in Table 4, including the composite weighted mean effect sizes, their corresponding confidence intervals, and the number of studies and participants in each. All of the composite effect sizes were significant (none of the confidence intervals include zero) and thus parental corporal punishment was associated significantly with each of the 11 child behaviors and experiences. According to J. Cohen's (1988) criteria for judging effect sizes, three of the composite mean weighted effect sizes are small $(-0.09,0.13,-0.33)$, four are small to medium $(0.36,0.42,0.42,-0.49)$, two are medium $(0.57,-0.58)$, one is medium to large $(0.69)$, and one is large (1.13, immediate compliance).

Ten of the 11 meta-analyses indicate parental corporal punishment is associated with the following undesirable behaviors and experiences: decreased moral internalization, increased child aggression, increased child delinquent and antisocial behavior, decreased quality of relationship between parent and child, decreased child mental health, increased risk of being a victim of physical abuse, increased adult aggression, increased adult criminal and antisocial behavior, decreased adult mental health, and increased risk of abusing own child or spouse. Corporal punishment was associated with only one desirable behavior, namely, increased immediate compliance (whether immediate compliance constitutes a meaningful desirable behavior is qualified below).

The direction of association at the level of the individual study was also highly consistent. Chi-square tests comparing the number of individual effect sizes indicating a desirable behavior associated with corporal punishment (e.g., lower levels of aggression) with 
Table 3

Effect Sizes by Study and Child Construct

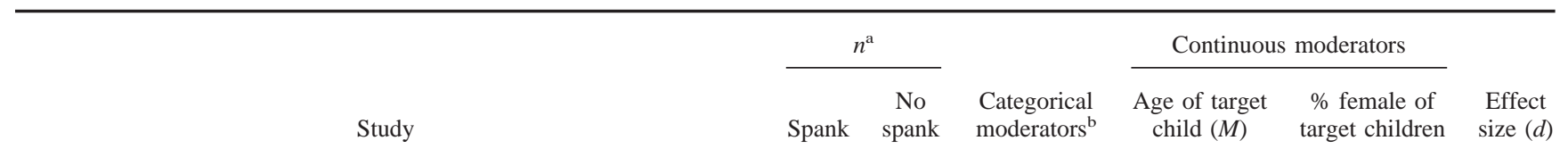

Measured in childhood

Immediate compliance

Bean \& Roberts (1981)

Chapman \& Zahn-Waxler (1982)

Day \& Roberts (1983)

LaVoie (1973)

Roberts \& Powers (1990)

Moral internalization

Aronfreed (1961)

Becker et al. (1962); Becker \& Krug (1964)

Burton, Maccoby, \& Allinsmith (1961)

Crockenberg (1987)

Grinder (1962)

Harvey et al. (1997)

Kandel (1990)

Larzelere \& Merenda (1994); Larzelere et al. (1996)

Lefkowitz et al. (1963); Eron et al. (1971)

Lytton \& Zwirner (1975); Lytton (1977)

MacKinnon (1938)

Minton et al. (1971)

Power \& Chapieski (1986)

Sears et al. (1957)

Zahn-Waxler et al. (1979)

Aggression

Bakshi (1993/1994)

Bandura \& Walters (1959)

Becker et al. (1962); Becker \& Krug (1964)

Deater-Deckard et al. (1996); Bates et al. (1995); Dodge et al. (1994);

Strassberg et al. (1994)

Engfer \& Schneewind (1982)

Eron (1982)

Eron et al. (1974)

Flynn (1999)

Gordon \& Smith (1965)

Gunnoe \& Mariner (1997)

Hall (1994/1995)

Johannesson (1974)

Kandel (1990)

Lefkowitz et al. (1963); Eron et al. (1971)

Levin \& Sears (1956)

Mahoney et al. (2000)

McCabe et al. (1999)

McLeod \& Shanahan (1993)

Radke-Yarrow et al. (1968)

Sears (1961)

Sears et al. (1957)

Simons, Johnson, \& Conger (1994)

Simons et al. (1998)

Singer et al. (1984)

Stattin et al. (1995)

Straus (1990a)

Watson (1989/1990)

Delinquent and antisocial behavior

DuRant et al. (1994)

Frick et al. (1999)

Glueck \& Glueck (1950)

Gove \& Crutchfield (1982)

Gunnoe \& Mariner (1997)

Kahn \& Fua (1995)

J. McCord (1988a, 1988b)

Simons, Johnson, et al. (1993)

Simons, Johnson, \& Conger (1994)

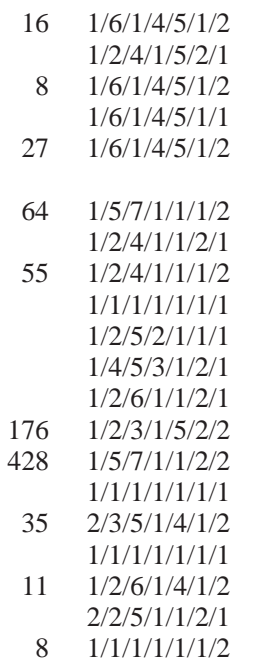$$
\text { . }
$$$$
\begin{array}{r}
4 \\
2 \\
4 \\
15 \\
4 \\
7 \\
7 \\
6 \\
4 \\
2 \\
5 \\
9 \\
7 \\
3 \\
8 \\
3 \\
\hline 2 \\
1 \\
5 \\
2
\end{array}
$$

$3 / 2 / 6 / 1 / 3 / 1 / 1$

$2 / 2 / 5 / 1 / 1 / 1 / 1$

$1 / 2 / 4 / 1 / 1 / 1 / 1$

$1 / 2 / 4 / 2 / 3 / 3 / 1$

$1 / 3 / 4 / 1 / 1 / 3 / 1$

$1 / 2 / 4 / 2 / 1 / 1 / 1$

$2 / 5 / 7 / 2 / 1 / 1 / 1$

$1 / 4 / 5 / 3 / 1 / 2 / 1$

$1 / 5 / 7 / 1 / 1 / 1 / 1$

$1 / 2 / 2 / 2 / 1 / 2 / 1$

$3 / 2 / 4 / 1 / 2 / 1 / 1$

$2 / 2 / 5 / 2 / 1 / 1 / 1$

$1 / 2 / 6 / 1 / 1 / 2 / 1$

$1 / 5 / 7 / 1 / 1 / 1 / 2$

$1 / 2 / 4 / 1 / 2 / 1 / 1$

$1 / 2 / 4 / 1 / 1 / 2 / 1$

$1 / 2 / 6 / 1 / 1 / 1 / 1$

$1 / 2 / 2 / 1 / 1 / 2 / 1$

$2 / 2 / 4 / 1 / 2 / 3 / 1$

$1 / 2 / 4 / 2 / 1 / 3 / 1$

$2 / 2 / 4 / 1 / 1 / 2 / 1$

$1 / 2 / 4 / 1 / 1 / 1 / 1$

$1 / 2 / 5 / 1 / 1 / 1 / 1$

$1 / 2 / 6 / 2 / 1 / 2 / 1$

$2 / 2 / 4 / 2 / 1 / 2 /$

$2 / 2 / 4 / 1 / 4 / 2 / 1$

$3 / 2 / 4 / 3 / 1 / 1 / 1$

$1 / 3 / 6 / 1 / 1 / 2 / 1$

$1 / 3 / 2 / 1 / 1 / 3 / 1$

$1,037 \quad 2 / 2 / 5 / 1 / 4 / 1 / 2$

$1 / 2 / 6 / 1 / 1 / 2 / 1$

$1 / 2 / 2 / 2 / 1 / 3 / 1$

$561 / 2 / 5 / 1 / 4 / 1 / 2$

$31 \quad 2 / 1 / 1 / 2 / 2 / 1 / 2$

$1 / 4 / 5 / 1 / 1 / 2 / 1$

$1 / 2 / 5 / 1 / 1 / 1 / 1$

size $(d)$ 
Table 3 (continued)

\begin{tabular}{|c|c|c|c|c|c|c|}
\hline \multirow[b]{2}{*}{ Study } & \multicolumn{2}{|c|}{$n^{\mathrm{a}}$} & \multirow[b]{2}{*}{$\begin{array}{l}\text { Categorical } \\
\text { moderators }\end{array}$} & \multicolumn{2}{|c|}{ Continuous moderators } & \multirow[b]{2}{*}{$\begin{array}{l}\text { Effect } \\
\text { size }(d)\end{array}$} \\
\hline & Spank & $\begin{array}{l}\text { No } \\
\text { spank }\end{array}$ & & $\begin{array}{l}\text { Age of target } \\
\text { child }(M)\end{array}$ & $\begin{array}{l}\% \text { female of } \\
\text { target children }\end{array}$ & \\
\hline \multicolumn{7}{|c|}{ Measured in childhood (continued) } \\
\hline \multicolumn{7}{|c|}{ Delinquent and antisocial behavior (continued) } \\
\hline Simons et al. (1998) & 113 & & $1 / 2 / 5 / 1 / 1 / 1 / 1$ & 16 & 0 & 0.51 \\
\hline Straus \& Mouradian (1998) & 744 & & $1 / 2 / 4 / 1 / 1 / 2 / 1$ & 9 & 46 & 0.31 \\
\hline Straus et al. (1997) & 910 & & $1 / 2 / 2 / 1 / 1 / 2 / 1$ & 8 & - & 0.56 \\
\hline Wiederhold (1997) & 213 & 195 & $3 / 3 / 6 / 1 / 1 / 2 / 2$ & 15 & 25 & -0.34 \\
\hline \multicolumn{7}{|l|}{ Quality of parent-child relationship } \\
\hline Adams (1995/1996) & 367 & & $3 / 2 / 4 / 1 / 4 / 1 / 1$ & 13 & - & -0.28 \\
\hline Alibrando (1988) & 91 & & $3 / 4 / 4 / 3 / 3 / 2 / 1$ & 7 & 67 & -0.64 \\
\hline Barnett et al. (1998) & 69 & & $1 / 5 / 7 / 1 / 1 / 1 / 1$ & 5 & 55 & -0.69 \\
\hline Crockenberg (1987) & 40 & & $1 / 1 / 1 / 1 / 1 / 1 / 1$ & 2 & 40 & -0.88 \\
\hline DeVet (1997) & 253 & & $1 / 4 / 5 / 3 / 2 / 2 / 1$ & - & 67 & -0.85 \\
\hline Engfer \& Schneewind (1982) & 285 & & $1 / 3 / 4 / 1 / 1 / 1 / 1$ & - & 0 & -1.01 \\
\hline Joubert (1991) & 134 & & $1 / 4 / 5 / 3 / 1 / 2 / 1$ & - & 63 & -0.43 \\
\hline Kandel (1990) & 222 & & $1 / 2 / 6 / 4 / 1 / 2 / 1$ & 7 & - & -0.46 \\
\hline Larzelere et al. (1989) & 157 & & $1 / 4 / 5 / 3 / 1 / 2 / 1$ & - & 86 & -0.40 \\
\hline Magai et al. (1995) & 129 & & $1 / 4 / 5 / 3 / 1 / 2 / 1$ & - & 53 & -0.24 \\
\hline Minton et al. (1971) & 49 & & $1 / 1 / 1 / 1 / 1 / 1 / 1$ & 2 & 0 & -0.28 \\
\hline Schwermer (1994/1995) & 91 & & $3 / 4 / 4 / 3 / 3 / 2 / 1$ & - & 21 & -0.71 \\
\hline Simons, Johnson, \& Conger (1994) & 329 & & $1 / 2 / 4 / 1 / 1 / 2 / 1$ & 13 & 54 & -0.73 \\
\hline \multicolumn{7}{|l|}{ Mental health } \\
\hline Adams (1995/1996) & 367 & & $3 / 2 / 4 / 1 / 4 / 1 / 1$ & 13 & - & -0.29 \\
\hline Coopersmith (1967) & 33 & 30 & $2 / 2 / 4 / 1 / 4 / 2 / 2$ & 12 & - & -0.42 \\
\hline Crockenberg (1987) & 40 & & $1 / 1 / 1 / 1 / 1 / 2 / 1$ & 2 & 40 & -0.62 \\
\hline DeVet (1997) & 253 & & $1 / 4 / 5 / 3 / 2 / 2 / 1$ & - & 67 & -0.57 \\
\hline DuRant et al. (1994) & 225 & & $1 / 3 / 6 / 1 / 1 / 1 / 1$ & 14 & 56 & -1.25 \\
\hline Engfer \& Schneewind (1982) & 285 & & $1 / 3 / 4 / 1 / 1 / 2 / 1$ & - & 0 & -0.65 \\
\hline Goodman et al. (1998) & 307 & 978 & $1 / 2 / 6 / 1 / 1 / 1 / 2$ & 13 & 47 & -0.14 \\
\hline Kandel (1990) & 222 & & $1 / 2 / 6 / 1 / 1 / 2 / 1$ & 7 & - & -0.42 \\
\hline McCabe et al. (1999) & 64 & & $1 / 2 / 6 / 1 / 1 / 1 / 1$ & 12 & 56 & -0.08 \\
\hline McLeod \& Shanahan (1993) & 1,733 & & $1 / 2 / 2 / 1 / 1 / 2 / 1$ & - & - & -0.56 \\
\hline Seagull \& Weinshank (1984) & 5 & 10 & $1 / 2 / 5 / 1 / 1 / 1 / 2$ & 12 & 49 & -2.26 \\
\hline Simons, Johnson, \& Conger (1994) & 332 & & $1 / 2 / 4 / 1 / 1 / 1 / 1$ & 13 & 54 & -0.30 \\
\hline \multicolumn{7}{|l|}{ Victim of physical abuse } \\
\hline Caselles \& Milner (2000) & 60 & & $1 / 5 / 7 / 1 / 1 / 1 / 1$ & 8 & - & 0.98 \\
\hline Chilamkurti \& Milner (1993) & 48 & & $1 / 5 / 7 / 1 / 1 / 1 / 1$ & 8 & 54 & 1.57 \\
\hline Hemenway et al. (1994) & 801 & & $1 / 4 / 5 / 3 / 1 / 2 / 1$ & - & 55 & 0.25 \\
\hline Herzberger et al. (1981) & 24 & & $1 / 3 / 5 / 1 / 1 / 1 / 1$ & 11 & 0 & 0.51 \\
\hline Lahey et al. (1984) & 24 & & $1 / 1 / 1 / 1 / 1 / 1 / 1$ & 6 & 38 & 0.56 \\
\hline Oldershaw, Walters, \& Hall (1986) & 20 & & $1 / 1 / 1 / 1 / 1 / 1 / 1$ & 3 & 50 & 1.51 \\
\hline Straus (1990b) & 1,094 & & $2 / 2 / 4 / 1 / 2 / 2 / 1$ & 10 & - & 0.77 \\
\hline Trickett \& Kuczynski (1986) & 40 & & $1 / 2 / 2 / 1 / 1 / 1 / 1$ & 7 & 40 & 0.37 \\
\hline Webster-Stratton (1985) & 40 & & $1 / 2 / 2 / 1 / 1 / 1 / 1$ & 5 & 28 & 0.32 \\
\hline Whipple $(1989 / 1990)$ & 198 & & $3 / 2 / 2 / 1 / 1 / 1 / 1$ & 6 & 31 & 0.59 \\
\hline
\end{tabular}

Measured in adulthood

Aggression

Eron et al. (1991)

McCranie \& Simpson (1986)

Muller (1996); Muller (1995); Muller (1993/1994)

Riggs \& O'Leary (1996)

Criminal and antisocial behavior

Alibrando (1988)

Baer \& Corrado (1974)

Eron et al. (1991)

J. McCord (1988a, 1988b)

J. McCord (1991)

Mental health

Alibrando (1988)

Hällström (1987)

Holmes \& Robins $(1987,1988)$

Joubert (1991)

Lester (1991)

\begin{tabular}{|c|c|c|c|c|c|}
\hline 335 & & $2 / 5 / 7 / 2 / 1 / 1 / 1$ & 8 & 51 & 0.36 \\
\hline 186 & & $1 / 4 / 4 / 3 / 1 / 2 / 1$ & 16 & 0 & 0.21 \\
\hline 1,536 & & $1 / 4 / 5 / 3 / 2 / 2 / 1$ & - & 70 & 0.77 \\
\hline 345 & & $1 / 4 / 6 / 3 / 1 / 2 / 1$ & - & 62 & 0.12 \\
\hline 91 & & $3 / 4 / 5 / 3 / 3 / 2 / 1$ & 7 & 67 & -0.31 \\
\hline 93 & 107 & $1 / 4 / 5 / 3 / 4 / 2 / 2$ & - & 32 & 0.41 \\
\hline 284 & & $2 / 5 / 7 / 2 / 1 / 1 / 1$ & 8 & 51 & 0.47 \\
\hline 59 & 31 & $2 / 1 / 1 / 2 / 2 / 1 / 2$ & 9 & 0 & 0.29 \\
\hline 165 & 418 & $1 / 1 / 1 / 2 / 2 / 1 / 2$ & 11 & 0 & 0.66 \\
\hline 91 & & $3 / 4 / 4 / 3 / 3 / 2 / 1$ & 7 & 67 & -0.09 \\
\hline 258 & 200 & $1 / 4 / 5 / 3 / 1 / 1 / 2$ & - & 100 & -0.27 \\
\hline 44 & 113 & $1 / 4 / 5 / 3 / 4 / 1 / 2$ & 9 & 48 & -0.84 \\
\hline 134 & & $1 / 4 / 5 / 3 / 1 / 2 / 1$ & - & 63 & -0.12 \\
\hline 131 & 248 & $1 / 4 / 5 / 3 / 4 / 2 / 2$ & - & 0 & -0.11 \\
\hline
\end{tabular}


Table 3 (continued)

\begin{tabular}{|c|c|c|c|c|c|c|}
\hline \multirow[b]{2}{*}{ Study } & \multicolumn{2}{|c|}{$n^{\mathrm{a}}$} & \multirow[b]{2}{*}{$\begin{array}{l}\text { Categorical } \\
\text { moderators }\end{array}$} & \multicolumn{2}{|c|}{ Continuous moderators } & \multirow[b]{2}{*}{$\begin{array}{l}\text { Effect } \\
\text { size }(d)\end{array}$} \\
\hline & Spank & $\begin{array}{c}\text { No } \\
\text { spank }\end{array}$ & & $\begin{array}{l}\text { Age of target } \\
\text { child }(M)\end{array}$ & $\begin{array}{l}\% \text { female of } \\
\text { target children }\end{array}$ & \\
\hline \multicolumn{7}{|c|}{ Measured in adulthood (continued) } \\
\hline \multicolumn{7}{|l|}{ Mental health (continued) } \\
\hline Nettelbladt et al. (1996) & 27 & 42 & $1 / 4 / 5 / 3 / 4 / 2 / 2$ & - & 64 & -0.64 \\
\hline Roy (1978) & 15 & 25 & $1 / 4 / 5 / 3 / 4 / 1 / 2$ & - & 65 & -1.40 \\
\hline Straus \& Kantor (1994); Straus (1995) & 4,523 & & $1 / 4 / 5 / 3 / 1 / 2 / 1$ & 16 & - & -0.07 \\
\hline \multicolumn{7}{|l|}{ Adult abuse of own child or spouse } \\
\hline Caesar (1988) & 26 & 18 & $1 / 4 / 5 / 3 / 4 / 1 / 2$ & - & 0 & 0.51 \\
\hline Carroll (1977) & 41 & 55 & $1 / 4 / 5 / 3 / 1 / 2 / 2$ & - & 60 & 0.42 \\
\hline Simons, Johnson, et al. (1993) & 207 & & $1 / 4 / 5 / 3 / 1 / 2 / 1$ & - & 100 & 0.32 \\
\hline Straus $(1990 b)$ & 2,143 & & $2 / 4 / 5 / 3 / 1 / 2 / 1$ & 10 & - & 0.18 \\
\hline Straus (1994a) & 4,529 & & $2 / 4 / 5 / 3 / 1 / 2 / 1$ & 10 & - & 0.10 \\
\hline
\end{tabular}

Note. Dashes indicate that data were not reported.

${ }^{a}$ Studies with an $n$ in the Spank construct only were within-subjects designs; studies with an $n$ for both the Spank and the No-spank constructs were between-subjects designs.

${ }^{\mathrm{b}}$ The first variable is source of study $(1=$ journal, $2=$ book, $3=$ dissertation $)$; the second variable is measure of corporal punishment $(1=$ observation, $2=$ parent report, $3=$ child report, $4=$ child retrospective, $5=$ hypothetical, $6=$ experimental $)$; the third variable is referent time period $(1=$ observation, $2=$ last week, $3=$ last month, $4=$ last year, $5=$ ever, $6=$ not specified, $7=$ hypothetical $)$; the fourth variable is timing of measure $(1=$ cross-sectional, 2 = longitudinal, $3=$ retrospective, $4=$ experimental); the fifth variable is index of corporal punishment $(1=$ frequency, $2=$ severity, $3=$ frequency and severity, $4=$ ever in life, $5=$ when used); the sixth variable is independence of raters $(1=$ independent, $2=$ not independent, $3=$ both $)$; and the seventh variable is design of study ( $1=$ within-subjects, 2 = between-subjects).

those studies showing an undesirable behavior associated with corporal punishment (e.g., higher levels of aggression) revealed that 9 of the 11 meta-analyses were highly and significantly consistent (see columns 6-8 in Table 4). In each case, the individual effects consistently showed more undesirable child behaviors and experiences associated with corporal punishment. The effect sizes that contribute to the meta-analyses of immediate compliance and adult criminal and antisocial behavior were not significantly consistent. The high $d_{+}$for compliance thus is undermined by its inconsistency: Three studies found corporal pun- ishment associated with higher levels of compliance but two did not.

The balance of desirable and undesirable constructs across all of the studies in the meta-analyses is presented in a stem and leaf plot of the correlation equivalents for each individual effect size in Table 5; undesirable constructs associated with corporal punishment, such as increased aggression or decreased moral internalization, were given a negative sign. As displayed in Table 5, the desirable constructs are sporadic $(n=7)$, whereas the pattern of undesirable constructs is strongly consistent and approximates a

Table 4

Composite Mean Weighted Effect Sizes for Child Constructs

\begin{tabular}{|c|c|c|c|c|c|c|c|c|c|}
\hline \multirow[b]{2}{*}{ Construct } & \multirow[b]{2}{*}{$d_{+}$} & \multirow[b]{2}{*}{$95 \% \mathrm{CI}$} & \multirow[b]{2}{*}{$\begin{array}{l}\text { Studies } \\
(N)\end{array}$} & \multirow{2}{*}{$\begin{array}{l}\text { Participants } \\
\quad(N)\end{array}$} & \multicolumn{2}{|c|}{ Construct association $^{\mathrm{a}}$} & \multirow[b]{2}{*}{$\chi^{2}$} & \multirow[b]{2}{*}{ Mean $Z$} & \multirow[b]{2}{*}{ Tolerance $^{\mathrm{b}}$} \\
\hline & & & & & Desirable & Undesirable & & & \\
\hline \multicolumn{10}{|l|}{ Measured in childhood } \\
\hline Immediate compliance & 1.13 & $0.86, \quad 1.41$ & 5 & 170 & 3 & 2 & 0.20 & 8.09 & 600 \\
\hline Moral internalization & -0.33 & $-0.40,-0.26$ & 15 & 2,285 & 2 & 13 & $8.07 * * *$ & -9.65 & 7,723 \\
\hline Aggression & 0.36 & $0.33, \quad 0.38$ & 27 & 12,326 & 0 & 27 & $27.00 * * * *$ & 27.33 & 201,197 \\
\hline Delinquent and antisocial behavior & 0.42 & $0.38, \quad 0.45$ & 13 & 7,016 & 1 & 12 & $9.31 * * *$ & 21.89 & 29,887 \\
\hline Quality of parent-child relationship & -0.58 & $-0.64,-0.52$ & 13 & 2,216 & 0 & 13 & $13.00 * * * *$ & -18.96 & 22,419 \\
\hline Mental health & -0.49 & $-0.53,-0.44$ & 12 & 4,884 & 0 & 12 & $12.00 * * *$ & -21.53 & 24,655 \\
\hline Victim of physical abuse & 0.69 & $0.62, \quad 0.76$ & 10 & 2,349 & 0 & 10 & $10.00 * * * *$ & 18.48 & 12,609 \\
\hline \multicolumn{10}{|l|}{ Measured in adulthood } \\
\hline Aggression & 0.57 & $0.51, \quad 0.63$ & 4 & 2,402 & 0 & 4 & $4.00 * *$ & 19.20 & 2,178 \\
\hline Criminal and antisocial behavior & 0.42 & $0.31, \quad 0.52$ & 5 & 1,248 & 1 & 4 & 1.80 & 7.96 & 581 \\
\hline Mental health & -0.09 & $-0.13,-0.06$ & 8 & 5,851 & 0 & 8 & 8.00 *** & -4.80 & 538 \\
\hline Adult abuse of own child or spouse & 0.13 & $0.10, \quad 0.17$ & 5 & 7,019 & 0 & 5 & $5.00 * *$ & 7.91 & 574 \\
\hline
\end{tabular}

Note. $\quad \mathrm{CI}=$ confidence interval.

${ }^{a}$ Values represent the number of comparisons reflecting an association with either desirable or undesirable behaviors and experiences. ${ }^{\mathrm{b}}$ Values represent tolerance for future null results.

$* * p<.05$. $* * * p<.01$. ***** $p<.001$. 
Table 5

Stem and Leaf Plot of Correlations Between Parental Corporal Punishment and All Child Behaviors and Experiences $(N=117)$

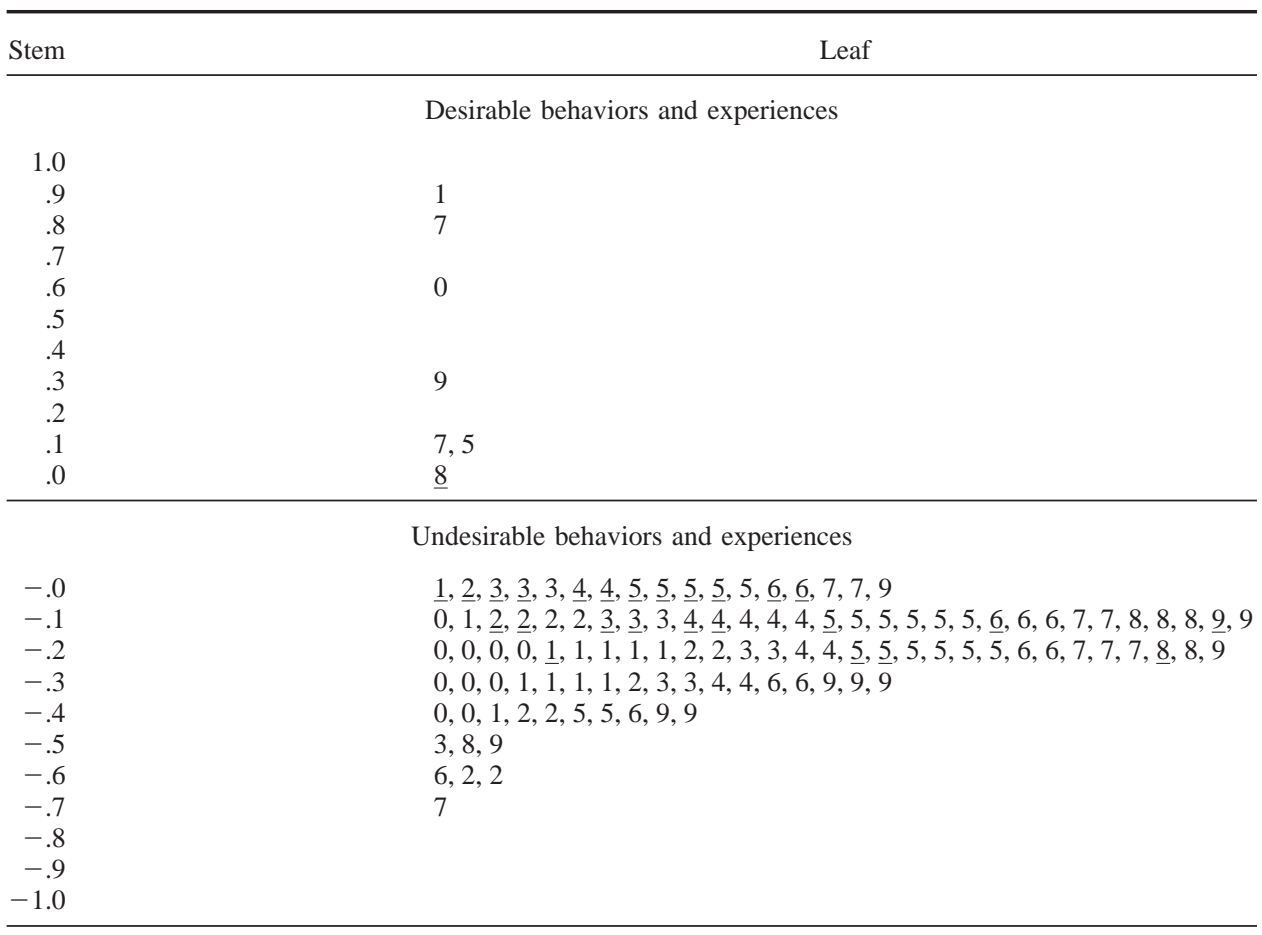

Note. Nonsignificant correlations are underlined.

normal distribution ( $n=110)$; a median correlation of -.25 for the undesirable constructs corresponds to a medium effect size ( $\mathrm{J}$. Cohen, 1988). Seventy-eight percent of the individual effect sizes are significant; of these significant effect sizes, only $7 \%$ represent desirable constructs. Table 5 verifies that the significant composite mean effect sizes were not biased by a few studies finding undesirable associations - the overwhelming majority of individual effect sizes represent undesirable child constructs associated with corporal punishment.

Finally, Table 4 also addresses a problem commonly discussed with regard to meta-analyses, namely, retrievability bias, or the "file drawer problem" (Rosenthal, 1979, 1991). The problem of contrary unpublished findings is particularly germane to the topic of corporal punishment because there may be a bias in scientific journals towards publishing only negative effects of corporal punishment. By calculating the number of unretrieved studies containing null results that have to exist in file drawers throughout academia before the overall probability of Type I error can be lowered to a minimum acceptable level of significance (such as $p=.05$ ), one can determine how tolerant the effect sizes are to the "file drawer threat" (Rosenthal, 1979, 1991). The large mean $Z$ scores and tolerances for future null results presented in Table 4 indicate that each of the mean effect sizes is highly tolerant to the threat of file drawers filled with nonsignificant results. In most cases, several thousand published or nonpublished studies not used in these meta-analyses would have to exist before the present effect sizes would become nonsignificant. These robust tolerances to null results are striking given that half of the meta-analyses involved fewer than 10 studies.

\section{Moderator Analyses}

After documenting significant composite mean weighted effect sizes, it is important to determine the conditions under which the associations between corporal punishment and the 11 child behaviors and experiences may vary. However, the majority of the meta-analyses in this article are based on too few studies to conduct moderator analyses because there were more moderators to test than there were effect sizes to test them (Johnson, 1993). Compared with the nine moderators tested, the meta-analyses for immediate compliance, adult aggression, adult criminal and antisocial behavior, adult mental health, and adult abuse of own child or spouse do not include 10 or more studies. I rejected the possibility of conducting moderator analyses by combining effect sizes across all 11 constructs because doing so would violate conceptual distinctions among them. In the interest of gaining a preliminary understanding of the factors that moderate the effects of corporal punishment on children, I conducted moderator analyses on a composite of the five child behaviors that are closest conceptually: child aggression, adult aggression, child delinquent and antisocial behavior, adult criminal and antisocial behavior, and adult abuse of own child or spouse. Studies that contributed to more than one of these individual behaviors $(n=7)$ were averaged accounting for the correlation between the measures in DSTAT. Hereafter, these combined studies are referred to as the aggression composite.

I conducted a weighted multiple regression with all of the potential moderators, recoding the seven categorical variables as indicator variables for the regression (see Table 6). The resulting large number of moderator variables (20) resulted in five variables 
Table 6

Partial Multiple Regression Coefficients for Study Qualities Predicting the Association of Parental Corporal Punishment With the Aggression Composite $(n=22)$

\begin{tabular}{|c|c|c|}
\hline Predictor & $B$ & $\beta$ \\
\hline Age of target child $(M)$ & $0.02 *$ & .15 \\
\hline Percentage of target children who are female & $-1.68^{* * * * *}$ & -.81 \\
\hline \multicolumn{3}{|l|}{ Source } \\
\hline Journal & $-0.89 * * * *$ & -1.24 \\
\hline Book & $-0.55 * *$ & -.75 \\
\hline \multicolumn{3}{|l|}{ Measure of corporal punishment } \\
\hline Parent report & $0.21 *$ & .28 \\
\hline Child retrospective & $-0.77 * * * *$ & -.51 \\
\hline \multicolumn{3}{|l|}{ Referent time period } \\
\hline Observation & $-1.99 * * * *$ & -1.31 \\
\hline Last week & $1.38 * * * *$ & .64 \\
\hline Last year & $-0.56^{* * * * *}$ & -.47 \\
\hline \multicolumn{3}{|l|}{ Timing } \\
\hline Longitudinal & 0.10 & .14 \\
\hline \multicolumn{3}{|l|}{ Index of corporal punishment } \\
\hline Severity & 0.10 & .09 \\
\hline Frequency and severity & $0.31 * *$ & .28 \\
\hline \multicolumn{3}{|l|}{ Raters of corporal punishment and aggression } \\
\hline Different & 0.01 & .02 \\
\hline Same & 0.16 & .23 \\
\hline \multicolumn{3}{|l|}{ Design } \\
\hline Between-groups & $-1.56^{* * * * *}$ & -1.07 \\
\hline Intercept & 3.06 & \\
\hline Overall $R^{2}$ & .86 & \\
\hline Overall regression effect $\left(Q_{\mathrm{R}}\right)$ & $251.49 * * * *$ & $d f=15$ \\
\hline Test of model specification $\left(Q_{\mathrm{E}}\right)$ & $41.13 * * * *$ & $d f=6$ \\
\hline
\end{tabular}

$* p<.10 . \quad * * p<.05 . \quad * * * * p<.001$.

being dropped from the model for being collinear with other variables. Furthermore, only 22 studies had reported data for each moderator category, thus barely meeting the requirement that the number of studies be larger than the number of moderators tested (Hedges \& Olkin, 1985). The large number of categories and the collinearity between some of the subcategories across molar categories (e.g., observation as a subcategory of "measure of corporal punishment" and of "referent time period") meant that five of the potential predictors were not estimated in the model.

The significant overall regression effect $\left(Q_{\mathrm{R}}\right)$ indicates that the moderators together account for a significant amount of variance in the aggression composite effect sizes. However, the significance of the test of model specification $\left(Q_{\mathrm{E}}\right)$ means that systematic variation remains in the regression model and thus the moderators examined here do not fully account for the association between parental corporal punishment and the aggression composite. The two continuous predictors included in the model, namely the gender and age of the children included in the studies, were both significant, although age was only significant at the level of a trend. The more girls included in a study sample, the less corporal punishment was associated with aggression and antisocial behavior. In addition, as the mean age of the children in the study increased, the association between corporal punishment and aggressive and antisocial behaviors increased. To further explicate this finding, the mean effect size was determined for four mean age groups: preschool (1-5 years), grade school (6-9 years), middle school (10-12 years), and high school (13-16 years). The mean effect size was found to be larger when the mean sample age fell in the middle school group $(M=0.55, S D=0.58)$ than when the mean sample age fell in the preschool $(M=0.44, S D=0.36)$, grade school $(M=0.43, S D=0.33)$, or high school $(M=0.45$, $S D=0.54$ ) groups, indicating a curvilinear association.

For the categorical moderators recoded as indicator variables for the regression analysis, the regression analysis suggests that certain aspects of individual studies moderate the strength of associations between corporal punishment and child behaviors, such as the source of the study, the design of the study, and the specific ways it operationalized corporal punishment (the reporter, the referent time period, and how corporal punishment was indexed). Post hoc $t$ tests of difference in mean effect sizes between subcategories of the same variable (e.g., between-subjects vs. withinsubjects designs) were computed with the Bonferonni correction for simultaneous tests. With this conservative criterion for rejecting the null hypothesis imposed and with the small number of studies, none of the subcategories was significant. Thus, the conclusion of these moderator analyses must be that specifics of how corporal punishment is defined do not moderate the associations between corporal punishment and child aggression and antisocial behavior but that the age and gender of the child do appear to moderate the direction of these associations.

\section{Discussion}

\section{What Can Be Concluded From the Meta-Analyses}

The primary conclusion from the meta-analyses of these 88 studies conducted over the last 62 years is that parental corporal punishment is associated significantly with a range of child behaviors and experiences, including both short- and long-term, individual- and relationship-level, and direct (physical abuse) and indirect (e.g., delinquency and antisocial behavior) constructs. Although it is related with immediate compliance, corporal punishment is associated with 10 undesirable constructs. The effect sizes tended to be medium in size (per J. Cohen, 1988) and were remarkably consistent $-94 \%$ of the individual effect sizes represented undesirable behaviors or experiences. Each of the composite effect sizes was robust to the file drawer threat, such that it is highly unlikely that hundreds, if not thousands, of unpublished or future studies with contrary results exist to alter the composite effect sizes.

The child constructs with the two largest effect sizes are also the starkest contrast; immediate compliance is a highly desirable behavior, whereas physical abuse is a highly undesirable experience. That these two disparate constructs would show the strongest links to corporal punishment underlines the controversy over this practice: There is general consensus that corporal punishment is effective in getting children to comply immediately (Newsom et al., 1983; Larzelere, 2000; Baumrind, 1996a), but at the same time there is caution from child abuse researchers that corporal punishment by its nature can escalate into physical maltreatment (e.g., Gelles \& Straus, 1988; Gil, 1973; Graziano, 1994; Wolfe, 1987; Zigler \& Hall, 1989).

Three remaining issues qualify the overall positive relation of parental corporal punishment to children's immediate compliance. First, the studies constituting the mean effect size for immediate compliance were not consistent; two of the five individual studies 
found corporal punishment to be linked with decreased compliance. This inconsistency argues for caution in accepting that corporal punishment and immediate compliance are favorably associated. Further research is needed to address the inconsistency in findings to date.

Second, three of the five studies in the meta-analysis of immediate compliance only included target children who had been referred for conduct disorder (Bean \& Roberts, 1981; Day \& Roberts, 1983; Roberts \& Powers, 1990). That corporal punishment may be effective in gaining compliance among highly disobedient and disruptive children is consistent with previous findings that high parental control (including corporal punishment) is associated with better child behavior for children high in temperamentally based resistance to control (Bates, Pettit, Dodge, \& Ridge, 1998; Kochanska, 1993, 1995, 1997a). However, two of these three studies found small, negative associations between parental corporal punishment and immediate compliance, which underscores again the need for additional research to resolve these inconsistent findings.

Third, although immediate compliance is often a valid shortterm goal for parents, their long-term goals are that children continue to comply in the future and in their absence (Kuczynski, 1984). Immediate compliance can be imperative when children are in danger, yet successful socialization requires that children internalize moral norms and social rules (Grusec \& Goodnow, 1994); in and of itself, immediate compliance does not imply internalization (Hoffman, 1983; Lepper, 1983). Consistent with previous research that power assertion impedes children's moral internalization (Brody \& Shaffer, 1982; Hoffman, 1983; Zahn-Waxler, Radke-Yarrow, \& King, 1979), the studies examined here found corporal punishment to be associated overall with decreases in children's moral internalization, operationalized as their long-term compliance, their feelings of guilt following misbehavior, and their tendencies to make reparations upon harming others. These findings illustrate that whether success is achieved by corporal punishment may depend on the goals parents have (an idea developed in more depth in the model below).

The lack of post hoc differences among the subcategories of the categorical moderators indicates no significant associations between study qualities and the strength of the association between corporal punishment and the aggression composite. However, characteristics of the sample of target children were found to moderate this association. The finding that studies whose samples averaged 10 to 12 years of age tended to report stronger associations between corporal punishment and the aggression composite is consistent with previous research (Frick, Christian, \& Wootton, 1999) and supports Deater-Deckard and Dodge's (1997) assertion that the effects of corporal punishment on children may be nonlinear, with corporal punishment having differential effects on children at different stages of development. Why this middle school-age group should evidence this difference is unclear. Corporal punishment is less normative with children of school age (Straus, 1994a), and thus corporal punishment delivered when children are in grade school may have stronger effects than when children are of preschool age. Alternatively, it may be that middle school children who are high in aggression elicit more corporal punishment from frustrated parents than do children in preschool, for whom parents have lower expectations for behavioral control. Stronger associations among middle school-age children than among grade school- and preschool-age children may also reflect cumulative effects of exposure to parental corporal punishment. The smaller association for high school children may reflect the fact that corporal punishment of high school students is fairly rare (P. Cohen \& Brook, 1995; Frick et al., 1999; S. Jackson et al., 1999; Straus \& Stewart, 1999) and that children of high school age have greater independence and may be more strongly affected by peer and other nonparental influences (Berndt, 1996).

The stronger association between corporal punishment and the aggression composite for boys may also be accounted for by child effects; because boys tend to exhibit aggression more than girls (Maccoby \& Jacklin, 1974; Parke \& Slaby, 1983), they may also elicit more corporal punishment from parents than do girls. However, as I discuss below, boys in general tend to receive more corporal punishment than girls (Day, Peterson, \& McCracken, 1998; Giles-Sims, Straus, \& Sugarman, 1995; Maccoby \& Jacklin, 1974; Mahoney, Donnelly, Lewis, \& Maynard, 2000; Rohner, Kean, \& Cournoyer, 1991; Smith \& Brooks-Gunn, 1997; Straus \& Stewart, 1999). Taken together, these findings constitute a chicken-and-egg problem: Are boys spanked more because they are aggressive, or are they more aggressive because they are spanked more? Longitudinal studies beginning in infancy are needed to resolve these questions.

The meta-analyses have confirmed a strong association between parental corporal punishment and parental physical abuse of these same children, confirming fears of many researchers that corporal punishment and physical abuse are closely linked. Currently in the United States, approximately 13 out of every 1,000 children under the age of 18 have experienced some form of abuse or neglect, $21 \%$ of whom have suffered physical abuse (U.S. Department of Health and Human Services, 2001). Child abuse in any form is a tragedy and deserves our best prevention efforts, and thus the potential for corporal punishment to escalate into physical abuse must be seriously considered at the levels of scientific research and public policy.

\section{What Cannot Be Concluded From the Meta-Analyses}

First and foremost, statistical meta-analyses cannot overcome the psychological tenet that findings of correlation do not prove causation. Because these meta-analyses are based primarily on correlational studies, parental corporal punishment cannot be identified definitively as the cause of these child behaviors and experiences, with the exception of immediate compliance. For some of the child behaviors considered in the meta-analyses, it is conceivable that the causal direction is reversed from what might be expected, such that children are driving the associations (e.g., aggressive children tend to elicit more corporal punishment from their parents). In addition, there might also be a third variable that predicts both parents' use of corporal punishment and child behaviors, such as parents' inconsistent style of discipline. Both of these possibilities are developed more in the process-context model. Meta-analyses will never be able to rule out completely such alternative explanations; potential study designs that would allow causal conclusions about parental corporal punishment are discussed later in this article.

Particular caution must be used when drawing conclusions from the child behaviors measured in adulthood. Although adult aggression, criminality, mental health, and likelihood of abusing own 
family members were each significantly associated with parental corporal punishment experienced in childhood, only three studies (Eron, Huesmann, \& Zelli, 1991; J. McCord, 1988a, 1988b; J. McCord, 1991) used a prospective design. This reliance on retrospective methods, as well as the inability to control for the range of factors that intervene between the measures of parental corporal punishment and adult constructs, prevents researchers from definitively tracing the constructs to the parent action. Furthermore, the continuity of children's behavioral tendencies across adulthood may account for associations with corporal punishment. Childhood aggression remains the best predictor of aggression in adulthood (Eron, Huesmann, Dubow, Romanoff, \& Yarmel, 1987; Lefkowitz, Eron, Walder, \& Huesmann, 1977); it may be that the third variable of childhood aggression predicts both parental corporal punishment and adult aggression, or it may be that corporal punishment predicts childhood aggression, which in turn persists as aggression in adulthood.

These meta-analyses focused on corporal punishment, and their findings should not be extended unequivocally to other forms of punishment, such as time-out or withdrawal of privileges. Effective parenting includes firm and consistent punishment for misbehaviors (Baumrind, 1996b; Grusec \& Goodnow, 1994; Walters \& Grusec, 1977), and thus the results of these analyses should not be construed as suggesting that parents should refrain from all forms of punishment. Indeed, a permissive parenting style devoid of any punishments is likely to increase, not decrease, children's noncompliant and antisocial behaviors (Patterson, 1982).

The strong and consistent results of the meta-analyses should not lead researchers to abandon future studies of corporal punishment. On the contrary, much more research is needed on the moderators of associations between corporal punishment and child behaviors and experiences. Very little is known about the conditions under which, or the children and parents for whom, corporal punishment may or may not be associated with these constructs. Unfortunately, the regression moderator analyses of the aggression composite reported here were inconclusive-although potential moderators were identified, nonsignificant post hoc tests preclude any substantive conclusions. It does appear that middle school-age children and boys of all ages are more likely to evidence higher rates of aggression associated with parental corporal punishment, but the design aspects of the studies themselves could not be confirmed as moderators, in part because so few studies qualified for the moderator analysis. Definitive conclusions regarding the conditions under which corporal punishment is most likely to be associated with these constructs await future research.

Finally, the results from these meta-analyses do not imply that all children who experience corporal punishment turn out to be aggressive or delinquent; a variety of parent, child, and situational factors not examined here have the potential to moderate the associations between corporal punishment and child behaviors. Like the majority of statistical analyses, meta-analyses examine aggregates of people; the association between corporal punishment and the particular behaviors of any individual child may or may not follow the patterns found here. The presence of corporal punishment may make certain behaviors more likely but clearly not inevitable. Other complex aspects of the parent-child relationship and context probably play an important role but are not yet well understood. The fact that over $90 \%$ of Americans are spanked as children (Straus, 1994a; Straus \& Stewart, 1999) and most are not violent and criminal adults contradicts an assertion that corporal punishment necessarily has negative effects on children. The parent-child relationship is complex, and the mere fact that parents use corporal punishment is unlikely to be entirely responsible for how a child develops and behaves.

\section{A Process-Context Model of Direct, Mediated, and Contextually Moderated Effects of Parental Corporal Punishment on Children}

The meta-analyses described above confirm that parental corporal punishment and certain child behaviors and experiences are significantly associated, yet because most of the included studies are correlational, the meta-analyses cannot confirm whether corporal punishment definitively causes the child constructs. In this section of the article, I endeavor to explain how parental corporal punishment might cause particular child outcomes and consider alternative explanations for associations between corporal punishment and child behaviors and experiences. Indeed, regardless of whether corporal punishment has been argued to have positive (e.g., Larzelere, 1996; Baumrind, 1996a) or negative (Straus, 1994a) effects, most research on and discussions of corporal punishment assumes that the direction of effect is primarily from parent to child. However, the assumption that corporal punishment predicts child behaviors, up to now, has not developed into a thorough understanding of why or how parental corporal punishment might have such effects. Therefore, in this section I use causal language (e.g., outcomes, effects) to describe potential relations among parental corporal punishment and child behaviors and experiences.

In this section of the article, I summarize the theoretical and empirical work that identifies the likely means by which corporal punishment affects children. The appreciation of both mediators and moderators of behavior is essential for developmental models (Eddy, Dishion, \& Stoolmiller, 1998); accordingly, the processcontext model presented here focuses on how and why parental corporal punishment may affect children, what effects it may have, as well as when, whether, and for whom corporal punishment may have positive or negative effects on children. The model hypothesizes that parental corporal punishment affects children primarily by initiating and shaping emotional and cognitive processes in the children (see Figure 1, Path A), which in turn predispose them to engage in certain behaviors or have particular experiences (Path B). Therefore, the observable effects of corporal punishment on children's behaviors such as aggression are speculated to be mediated through internal cognitive and affective processes. The behaviors and experiences listed in Figure 1 are those that have been examined most consistently in the literature, and thus the mediational processes identified here are those that apply to these potential outcomes. It is important to note, however, that a range of other potential outcomes of corporal punishment has been examined (e.g., IQ: Smith and Brooks-Gunn, 1997; achievement: Cherian, 1994; sexual attitudes: Miller, McCoy, Olson, \& Wallace, 1986) and may also be explained by the mediational processes outlined here. One exception to the pathway of mediated corporal punishment effects is in the case of physical child abuse (Path C), in which a direct link exists between the parent behavior of corporal punishment and the child's experience of physical abuse by that same parent. Contextual factors, depicted in the model as 


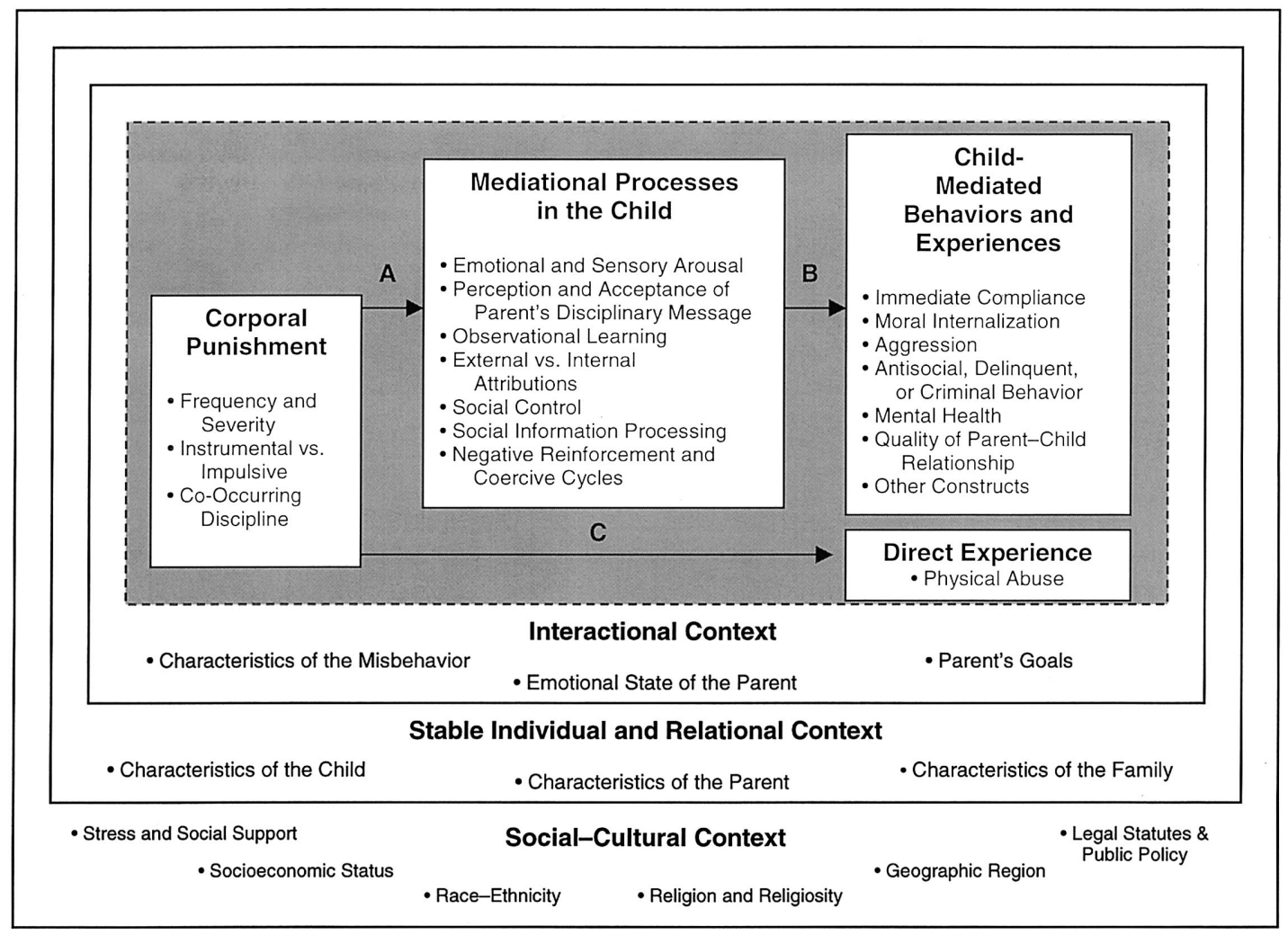

Figure 1. A model of processes and contexts hypothesized to determine how parental corporal punishment may affect child behaviors and experiences.

comprising nested levels of influence, can serve both as predictors of whether corporal punishment is used in the first place as well as moderators of the processes linking corporal punishment and child constructs.

The hypothesized mediational child processes incorporate a range of theoretical perspectives, including those of social learning theory (Bandura, 1973, 1977), attribution theory (Lepper, 1983), social information processing theory (Dodge, 1986), social control theory (Hirschi, 1969), social interactional theory (Patterson, 1982, 1997; Patterson et al., 1992), behavior genetics (Plomin, DeFries, \& Loehlin, 1977; Reiss, 1995; Scarr, 1992; Scarr \& McCartney, 1983), and the perception-acceptance model of Grusec and Goodnow (1994). The conceptualization of contextual influences on the association between corporal punishment and child behaviors and experiences owes much to Bronfenbrenner's $(1977,1986)$ ecological systems framework as well as to pathways and processes identified by Belsky (1984, 1993), McLoyd (1990), Parke and Buriel (1998), and Straus (1994a). The complexity of the model is in line with the current understanding that children's behaviors are the product of a combination of factors, not the least of which is parents' behavior, but which also include heredity, extrafamilial environments, and the broader context of the family (Collins, Maccoby, Steinberg, Hetherington, \& Bornstein, 2000).

\section{Corporal Punishment}

The act of corporal punishment itself is different across parents-parents vary in how frequently they use it, how forcefully they administer it, how emotionally aroused they are when they do it, and whether they combine it with other techniques. Each of these qualities of corporal punishment can determine which childmediated processes are activated and, in turn, which outcomes may be realized.

\section{Frequency and Severity}

The widespread use of the term corporal punishment belies considerable variation in how it is practiced by parents. Parents may use corporal punishment frequently, such as several times a week, or rarely, such as once a year. Parents can administer mild spankings with a hand or severe beatings with a paddle. For some parents, a spanking may consist of one slap on a child's buttocks, whereas for others it involves repeated slaps. The range of behaviors subsumed under the term corporal punishment is suggested by the variety of terms parents use to describe the practice, such as spank, smack, slap, pop, beat, paddle, punch, whup or whip, and hit (Davis, 1996; Mosby, Rawls, Meehan, Mays, \& Pettinari, 1999). No one doubts that the effects of corporal punishment depend on its frequency and severity, yet some studies ask only if parents have ever used corporal punishment (e.g., 15\% of the studies used in the meta-analyses), most operationalize corporal punishment only in terms of the frequency of its occurrence (e.g., $65 \%$ of studies in the meta-analyses), and few ask parents about both frequency and severity (e.g., 5\% of the studies in the metaanalyses). Additional research is needed to determine if frequency, 
severity, or an interaction between the two is most responsible for positive or negative effects of corporal punishment.

\section{Instrumental Versus Impulsive}

When corporal punishment is planned, controlled, and not accompanied by strong parental emotion, it is said to be instrumental; when it is spur-of-the-moment and accompained by feelings of anger and possibly by feelings of being out of control, corporal punishment is said to be impulsive (Holden \& Miller, 1997; Straus \& Mouradian, 1998). Instrumental corporal punishment is likely a regular part of the disciplinary repertoire for parents with favorable attitudes toward corporal punishment. Because it is used routinely, children may be more accepting of and compliant with instrumental corporal punishment. In contrast, impulsive corporal punishment can be thought of as that used by parents who do not use corporal punishment regularly and instead use it only as a last resort-when other disciplinary methods fail to secure child compliance and thus when parents are frustrated and angry. Children who experience sporadic instances of impulsive corporal punishment may become fearful of or angry at their parents. Holden and Miller (1997) have shown that parents who use corporal punishment in an impulsive manner have low expectations for its use in securing compliance or respect for authority, and Straus and Mouradian (1998) found that such parents rate their children high in antisocial behavior, although their study did not test the possibility that child antisocial behavior elicits more impulsive corporal punishment. The instrumental-impulsive distinction has been used to differentiate discipline from abuse (Vasta, 1982); the question of whether any impulsive corporal punishment can be considered normative and nonabusive awaits further research.

\section{Co-Occurring Discipline}

Perhaps the most significant shortcoming of research on corporal punishment to date is the failure to recognize that it rarely occurs in isolation; rather, corporal punishment typically is combined with reasoning, threats, time-out, withdrawal of privileges, or other techniques (Grusec \& Kuczynski, 1980). Whether compliance or other child constructs can be attributed to corporal punishment per se or to the other techniques used, or even to a combination of both, has rarely been studied. A notable exception is the work by Larzelere and his colleagues (Larzelere, 1986; Larzelere \& Merenda, 1994; Larzelere, Sather, Schneider, Larson, \& Pike, 1998), who have found that reasoning "backed-up" by a form of punishment, such as corporal punishment, is highly effective at preventing future misbehavior. In addition, parents who use corporal punishment frequently also tend to be verbally abusive toward their children (e.g., insulting, swearing, threatening; A. P. Jackson, Gyamfi, Brooks-Gunn, \& Blake, 1998; Vissing, Straus, Gelles, \& Harrop, 1991), and the combination of corporal punishment and verbal aggression may magnify associations between corporal punishment and child aggression, delinquency, and interpersonal problems (Vissing et al., 1991). More studies are needed that examine corporal punishment in conjunction with other types of discipline.

\section{Direct Experience: Physical Abuse}

The meta-analytic finding that parents' use of corporal punishment is significantly associated with their risk of abusing their children challenges the claim that corporal punishment and physical abuse are distinct phenomena (e.g., Strassberg, Dodge, Pettit, \& Bates, 1994). Rather, this finding supports the notion that corporal punishment and physical abuse are two points along a continuum, such that if corporal punishment is administered too severely or too frequently, it crosses the line into physical abuse (Garbarino, 1977; Gelles \& Straus, 1988; Gil, 1973; Kadushin \& Martin, 1981; Straus \& Kantor, 1994; Vasta, 1982; Wolfe, 1987; Zigler \& Hall, 1989). That abusive parents often recall abusive incidents as beginning with instrumental corporal punishment (Coontz \& Martin, 1988; Gil, 1973; Kadushin \& Martin, 1981) confirms this connection. Indeed, many abuse prevention efforts explicitly target the reduction of parents' reliance on corporal punishment as a goal (e.g., Azar, 1989; Olds et al., 1997; Thompson, Ruma, Brewster, Besetsney, \& Burke, 1997; Wolfe, Sandler, \& Kaufman, 1981).

Although characteristics of the child (e.g., gender), the parent (e.g., stress level), or the child's misbehavior (e.g., aggression toward the parent) may increase the likelihood of abuse because they create strong feelings of anger or frustration in the parent, they do so as moderators rather than mediators. Whether corporal punishment results in physical abuse to a child is determined by how hard and how long the parent hits the child and thus is not mediated by any processes in the child (Figure 1, Path C). The task for researchers is to determine the exact conditions under which corporal punishment is transformed into abuse. Stress, lack of support, and dispositions toward hostility have been suggested as catalysts (Belsky, 1993; Vasta, 1982), but studies of specific instances of abuse that began as corporal punishment are needed to identify specific child-, parent-, family-, and society-level factors that can be targeted for prevention efforts. Child abuse is multiply determined (Parke \& Lewis, 1981; Wolfe, 1987), but the link between corporal punishment and physical abuse demonstrated here behooves future research to determine why, when, and for whom the purposeful use of corporal punishment may end in unintentional physical child abuse.

\section{Mediational Processes and Associated Child Behaviors and Experiences}

Parents' administration of corporal punishment is hypothesized to initiate several potential mediational processes in the child. The processes are not mutually exclusive and rather may be implicated in child behaviors independently or in conjunction with one another. Because the processes invoked may predispose particular child behaviors and experiences, I discuss potential child constructs in the context of these mediational processes.

\section{Emotional and Sensory Arousal}

Sequential analyses of mother-child interactions have revealed that the emotions children feel from moment to moment in part determine whether they will comply with parents' controls (Gershoff \& Dix, 2001). Children experiencing positive moods and emotions are more receptive to parents' controls than children experiencing negative moods (Lay, Waters, \& Park, 1989; Londerville \& Main, 1981; Maccoby \& Martin, 1983; Parpal \& Maccoby, 1985; Stayton, Hogan, \& Ainsworth, 1971). In contrast, feelings of pain or anger can motivate children toward resistance of and 
retaliation against those responsible for the mismatch between children's goals and actual events, whereas feelings of fear or distress can motivate children to withdraw from the situation at hand (Frijda, 1986; Lazarus, 1991). Although "minimally sufficient" emotional arousal in the child elicits the attention and concern that facilitates moral internalization (Hoffman, 1983; Kochanska, 1993, 1994; Larzelere \& Merenda, 1994; Lepper, 1983), strong negative emotions may lead children to ignore the disciplinary message and to resent and avoid the parent who delivered it. Negative emotions lead children to focus on themselves, an effect that is counterproductive when parents want children to understand how their behaviors may negatively impact others (Eisenberg et al., 1988).

Pain. In using corporal punishment, parents inflict momentary pain to stop children's misbehaviors. On feeling pain, children stop the misbehavior either to get the painful stimulus to stop or to restore a sense of security with the parent (Grusec \& Goodnow, 1994). However, in addition to its utility in inducing immediate compliance, pain from corporal punishment can initiate other unintended effects. Pain typically provokes a motivation to escape the painful stimulus (Azrin et al., 1965), which in the case of corporal punishment is the parent; thus, children who are corporally punished may be more likely to withdraw from or avoid their parents (Aronfreed, 1969; Parke, 1977). This response may be especially likely when a child realizes the parent intended for the child to feel pain (Lazarus, 1991). If pain causes children to flee from their parents after corporal punishment, corporal punishment can have the unintended effect of undermining parents' attempts to socialize children after a spanking (Newsom et al., 1983). In an experimental demonstration of this idea, adults who were negative and punishing toward children were most effective at generating immediate compliance but were avoided in a later play situation and were rated by the children as least preferred (Redd, Morris, \& Martin, 1975).

Anger. Corporal punishment can elicit anger from children either because their goals have been frustrated or because they feel they were punished unfairly or inappropriately (Izard, 1991; Lazarus, 1991; Saarni et al., 1998). In the immediate sense, children's aggression is not attack but counterattack behavior (Patterson, 1982). Children's anger at being spanked may cause them to lash back at their parents either as a reflex (elicited aggression) or to try to stop the spanking (operant aggression; Azrin \& Holz, 1966; Berkowitz, 1983; Crick \& Dodge, 1996; Dollard et al., 1939; Newsom et al., 1983; Ulrich, 1966). Sequential analyses have confirmed that when mothers use hitting to punish their children, children tend to respond with aggression themselves (Snyder \& Patterson, 1986). Persistent feelings of anger also can incite resentment of the parent, which may manifest in decreases in the quality of the parent-child relationship or declines in the child's mental health. Over time, parents can become associated with painful corporal punishments and may elicit retaliatory aggression from children (Berkowitz, 1983). Children who view their parents as dispensers of painful stimuli may fear and resent them, feelings that may slowly erode bonds of trust and closeness established between parents and children in early childhood.

Fear and distress. For a discipline technique to be effective, it must evoke some emotional arousal or distress in the child to ensure that he or she attends to the disciplinary message (Hoffman, 1983; Lepper, 1983). Indeed, one study found that children shown a fear-inducing film were more compliant with a harsh adult than children shown a pleasant film (Carlsmith, Lepper, \& Landauer, 1974). The capacity for corporal punishment to evoke fear or distress is thought to constitute a main reason for its effectiveness in achieving child compliance (Maccoby \& Martin, 1983). When corporal punishment occurs in the context of a warm parent-child relationship, it can function as love withdrawal, such that fear of losing a parent's love can impel children to comply in the short run with parents' wishes so as to restore a loving relationship (Maccoby \& Martin, 1983; Parke, 1977; Parke \& Walters, 1967). There is some evidence for the motivating effects of fear and distress resulting from corporal punishment: Children delay repeating a misbehavior longer if they responded to corporal punishment of that misbehavior with high distress (Larzelere \& Merenda, 1994). The elicitation of fear or distress may have unintended consequences, however. In their fear that the painful punishment will recur, children may bypass cognitive processing and internalization of the parent's message in favor of an immediate strategy of avoidance (Bugental \& Goodnow, 1998; Grusec \& Goodnow, 1994; Maccoby \& Martin, 1983; Saarni et al., 1998). If parental corporal punishment compels children to avoid their parents consistently, it can undermine parents' abilities to socialize children after corporal punishment and can erode bonds of trust and closeness established between parents and children in early childhood, both of which can undermine parents' ability to influence children's future behavior (Azrin \& Holz, 1966; Parke, 1977; Van Houten, 1983).

\section{Perception and Acceptance of Parents' Disciplinary Message}

Children who understand and accept parents' disciplinary requests will be more likely to comply with them and, as a result, to behave in socially appropriate ways (Grusec \& Goodnow, 1994). Although corporal punishment draws attention to their message (Hoffman, 1983), if parents do not clearly verbalize their message, children may misperceive it. For example, a parent who spanks a child for running into the street intends for the child to learn that such a behavior is dangerous, yet the child may interpret the parent's response to mean that he or she should not run into the street when the parent is around. The emotional arousal described above in particular may prevent children from attending to or understanding the parent's message.

If and when the parent's message from corporal punishment is perceived accurately, children must accept the message (Grusec \& Goodnow, 1994). Children who believe that their parents are acting in their best interests (Dix, 1992), who see the discipline as appropriate to the misdeed (Grusec \& Goodnow, 1994), or who see their parents' use of force as legitimate (Baumrind, 1997; Gunnoe \& Mariner, 1997; Lewis, 1981) will be inclined to accept their parents' message. Furthermore, children who have positive or secure relationships with their parents will be most likely to view their caregivers' use of control as legitimate (Bretherton, Golby, \& Cho, 1997; Deater-Deckard \& Dodge, 1997). In the same fashion, hostile parent-child relationships can incline children toward accepting corporal punishment because exposure to corporal punishment and coercive cycles may foster an acceptance of these styles as an acceptable means of dealing with problems (Rutter, Giller, \& Hagell, 1998). If the use of corporal punishment is normative in 
the family's culture, children will be inclined to view their parents' use of corporal punishment as legitimate (Deater-Deckard \& Dodge, 1997; Gunnoe \& Mariner, 1997); indeed, children in the United States as young as 4 years old adopt their parents' views that corporal punishment is an acceptable form of discipline (Catron \& Masters, 1993).

Children's acceptance of corporal punishment as a moderator of its effects is just beginning to be examined. Preliminary findings from a study conducted in St. Kitts, West Indies (which included potentially abusive techniques and thus was excluded from the meta-analyses), were that children's acceptance of harsh corporal punishment did not attenuate the association between corporal punishment and poor psychological adjustment (Rohner et al., 1991). However, third variable and reverse causation models were not examined. More work on children's acceptance of corporal punishment and of other discipline styles is needed.

\section{Observational Learning}

The most common argument against corporal punishment is that it models aggression (Aronfreed, 1969; Bandura \& Walters, 1959; Eron et al., 1971; S. Feshbach, 1970; Sears, Maccoby, \& Levin, 1957; Walters \& Grusec, 1977). Modeling and imitation are thought to be key learning mechanisms by which children become aggressive (Bandura, 1973, 1977; Parke \& Slaby, 1983). When parents use physical means of controlling and punishing their children, they communicate to their children that aggression is normative, acceptable, and effective- beliefs that promote social learning of aggression (Bandura, 1973; Gelles, 1979; White \& Straus, 1981). Because children see aggression modeled, in the form of corporal punishment, and rewarded, in the form of their own compliance with it, they learn that aggression is an effective way to get others to behave as they want and will be disposed to imitate it (Bandura, 1973; Caldwell, 1977; N. D. Feshbach, 1975; Goode, 1971; Guerra, Nucci, \& Huesmann, 1994; Parke \& Slaby, 1983; Patterson, 1982; J. Ritchie \& Ritchie, 1981; Simons et al., 1998; Straus, 1994b; White \& Straus, 1981). Corporal punishment is a prime candidate for imitation because children are disposed to imitate aggressive models (Bandura \& Huston, 1961; Bandura, Ross, \& Ross, 1961; Fairchild \& Erwin, 1977) and because children want to imitate and please parents whom they care about (Kohlberg, 1969; Kuczynski, Marshall, \& Schell, 1997; Mikulas, 1978).

The argument that children imitate corporal punishment is particularly poignant when children are punished for aggression, because corporal punishment models the very behavior that parents are trying to discourage in their children (Bandura, 1973). Although parents want to teach children not to hit others, the unintended message of their use of corporal punishment is that it is acceptable to hit others when they behave in ways you do not like (Bandura, 1969; Sears et al., 1957). Despite the risk of imitation, parents use corporal punishment more in response to children's aggression than to any other child misbehavior (Frude \& Gross, 1979; Grusec \& Kuczynski, 1980; Holden et al., 1995; Kelder, McNamara, Carlson, \& Lynn, 1991; Socolar \& Stein, 1995; Zahn-Waxler \& Chapman, 1982).

\section{External Versus Internal Attributions}

According to attribution theory, attributing compliance to internal rather than external sources is an integral part of children's internalizing norms and morals, a process that occurs only in the absence of strong pressure (Hoffman, 1983; Grusec \& Goodnow, 1994; Lepper, 1983; Maccoby, 1980). When children are subject to strong external pressure, they are less internalized, less intrinsically motivated, and more likely to attribute their prosocial behavior to the external force (Dix \& Grusec, 1983; Lepper, 1973; see also review by Grolnick et al., 1997). Children's internal attributions for their behavior (i.e., internalization), and resulting socialemotional competence, are thought to be enhanced by parental discipline strategies that use minimal parental power, promote choice and autonomy, and provide explanations for desirable behaviors (Kuczynski \& Hildebrandt, 1997). Parents must strive to use minimally sufficient force that evokes the arousal and motivation to comply with their requests and avoid overly sufficient force that provides children an external source to which they may attribute their compliance (Lepper, 1983). Because it involves physical force by the parent, corporal punishment thus may interfere with children's internalization of norms and morals by providing salient external controls to which children can attribute their compliance (Hoffman, 1983; Lepper, 1983). Additionally, corporal punishment may not facilitate internal attributions because it does not teach children the reasons for behaving correctly and does not involve communication of the effects of children's behaviors on others (Smetana, 1997). Thus, corporal punishment can impel children to avoid misbehaviors in order to avoid future punishment but cannot on its own teach children the responsibility to behave independently in morally and socially acceptable ways (Hoffman, 1983; Grusec, 1983).

\section{Social Control}

Social control theory (Gottfredson \& Hirschi, 1994; Hirschi, 1969) contends that how parents socialize and discipline their children is a strong determinant of whether children develop the self-control that prevents them from engaging in aggressive or criminal behavior. Parents' use of harsh punishment, including corporal punishment, is thought to prevent moral internalization by eroding the attachment bond between parent and child; children who do not feel an attachment bond to their parents will fail to identify with them and internalize the parents' values and those of the society, which in turn will result in low self-control (Hirschi, 1969). In turn, individuals low in self-control ignore potential long-term costs and engage in aggressive, antisocial, and criminal acts because they provide immediate and easy gratification of desires (Gottfredson \& Hirschi, 1990, 1994, 1995; Hirschi, 1969; Sampson \& Laub, 1994). Thus, parents' use of corporal punishment can initiate feelings of low self-control in children, which may predispose children toward aggressive, antisocial, and delinquent or criminal behaviors.

\section{Social Information Processing}

Social information processing theory proposes that children approach situations with both biologically determined capabilities as well as expectations derived from past experiences (Crick \& 
Dodge, 1996; Dodge, 1986). How children respond to social cues is a function of how children encode, represent, and process social information (Crick \& Dodge, 1996; Dodge, 1986); children who attribute hostile intent to the behaviors of others tend to retaliate with their own aggression (Dodge, 1980; Dodge \& Coie, 1987; Dodge \& Somberg, 1987; MacKinnon-Lewis et al., 1994). Applied to parental corporal punishment, social information processing theory suggests that experience with corporal punishment affects how children process information about the behaviors and intentions of others (Dodge et al., 1986). Experience with harsh treatment from parents is hypothesized to bias each step of children's social information processing such that harshly treated children will be hypervigilant to hostile cues, attribute hostile intent to others, access more aggressive potential responses, and evaluate aggression as achieving social benefits (Dodge et al., 1986). Support for this explanation comes from research with a sample of 5 -year-olds, in which the contemporaneous association between parental corporal punishment and increased child aggression was mediated significantly by deficits in children's social information processing (Weiss, Dodge, Bates, \& Pettit, 1992). A similar mediational role for social information processing has been found for the relation between the experience of physical harm from parents and later aggression (Dodge, Bates, \& Pettit, 1990; Dodge, Pettit, Bates, \& Valente, 1995).

\section{Negative Reinforcement and Coercive Cycles}

Parental corporal punishment has the potential to initiate coercive cycles of parent and child behavior (Patterson, 1982). The main assertions underlying coercion theory are that aversive behaviors tend to elicit aversive reactions from others and that aggressive behavior is governed by its consequences (Dishion \& Patterson, 1999; Patterson, 1982; Patterson et al., 1992; Snyder, 1995). When aversive acts are rewarded, the likelihood that they will recur is increased (Patterson, 1982). Reward in the case of coercive cycles comes in the form of negative reinforcement, such as the cessation of child misbehavior (for the parent) or of parental corporal punishment (for the child). Thus, if a parent contingently punishes a child's misbehavior with corporal punishment and the child complies, the parent's use of corporal punishment is negatively reinforced by the cessation of the child's misbehavior and the child's compliance is negatively reinforced by the cessation of the parent's corporal punishment. In such a scenario, operant learning principles predict the future occurrence both of parental corporal punishment and of children's compliance to it (Patterson, 1982; Snyder, 1995). However, these same principles can lead to undesirable coercive cycles. For example, if a parent uses corporal punishment only out of frustration after being unsuccessful with a series of other discipline techniques (in a similar fashion to that described as impulsive above), corporal punishment may be unsuccessful at gaining compliance because the child may continue to defy because he or she views such punishment as unreasonable and coercive. In such a case, the parent may then give up and stop using corporal punishment because it too has been unsuccessful. When children succeed in getting parents to cease their aversive punishment in such ways, the children's own aversive behaviors are negatively reinforced (Patterson, 1982). Thus, coercion can be used effectively or ineffectively, and coercive exchanges can in- fluence the behaviors of both the aggressor and the victim simultaneously (Patterson, Dishion, \& Bank, 1984).

Several research methods have been used to illustrate coercion theory principles. In sequential analyses, parents' use of coercive methods, including corporal punishment, to punish antisocial children's hostile or aggressive behaviors has been found to increase by $50 \%$ the likelihood that children would continue to engage in aversive behaviors (Patterson, 1982). In longitudinal analyses, coercive discipline, including corporal punishment, has been found to predict children's antisocial behaviors 2 years later (Patterson et al., 1992). Similarly, mothers' observed use of coercive techniques with their 5-year-olds predicted teacher and mother ratings of children's externalizing behavior problems 1 year later, even after controlling for behavior ratings at age 5 (Pettit, Bates, \& Dodge, 1993). Further understanding of the mechanics of coercion, particularly when it is successful and when it is not, requires more sequential analyses of observational or parent diary data.

\section{Interactional Context}

Although parenting is relatively consistent, parents' behaviors do vary across time and across situations (Holden \& Miller, 1999). Characteristics of the immediate interaction between parent and child can determine whether parents choose to use corporal punishment and to some extent may influence which child processes are initiated and which outcomes are realized.

\section{Characteristics of the Misbehavior}

Parents' decisions to use corporal or other punishments depend on the type and severity of children's misbehaviors as well as on the attributions parents make about children's responsibility for the misbehavior (Dix \& Grusec, 1985; Dix, Ruble, \& Zambarano, 1989; Grusec, Dix, \& Mills, 1982; MacKinnon-Lewis et al., 1994; Nix et al., 1999). Parents are more likely to use corporal punishment if the child's behavior is aggressive or is a threat to their own or others' safety (e.g., Catron \& Masters, 1993; Culp, Culp, Dengler, \& Maisano, 1999; Flynn, 1998; Grusec \& Kuczynski, 1980; Holden et al., 1995; Peterson, Ewigman, \& Vandiver, 1994; Socolar \& Stein, 1995; Zahn-Waxler \& Chapman, 1982). Children themselves view corporal punishment as more justifiable as a response to misbehaviors involving harm to self or others than to simple disobedience (Catron \& Masters, 1993; Siegal \& Cowen, 1984). Parents are also more likely to use power assertion if they attributed to the child understanding of the rules violated, the capability to act appropriately, and responsibility for the misbehavior (Dix et al., 1989; Pinderhughes, Dodge, Bates, Pettit, \& Zelli, 2000). When they perceive children to be at fault, parents rate harsh corporal punishment (e.g., hitting with an object such as a belt) as less severe than if children were not at fault (Rodriguez \& Sutherland, 1999). If children display escalated disobedience (i.e., knowingly disobey after being reprimanded), parents are more likely to use corporal punishment (Gershoff, Miller, \& Holden, 1999; Holden, Miller, \& Harris, 1999; Peterson et al., 1994; K. L. Ritchie, 1999). What time of day the child misbehaves may determine whether corporal punishment is used, as a majority of spankings occur between 5 p.m. and bedtime (Holden et al., 1995). 
The type of misbehavior also may determine the effectiveness of corporal punishment in suppressing undesirable child behavior. Parents themselves recognize the specificity in the effectiveness of corporal punishment; parents believe that corporal punishment is more effective at suppressing misbehaviors involving safety (e.g., running away from a parent in a crowded parking lot) than at preventing children from disobeying moral (e.g., hitting a friend) or social norms (e.g., interrupting a parent on the phone; Gershoff et al., 1999).

\section{Emotional State of the Parent}

The emotions parents experience during interactions with their children influence how they perceive and in turn react to child misbehaviors (Dix, 1991); if their emotional arousal is too strong, parents are less able to regulate their emotions and in turn their behavior (Dix, 1991; Patterson, 1982; Vasta, 1982). When parents are upset or highly emotionally aroused, they tend to make negative attributions about their children's misbehaviors and to select power assertion, such as corporal punishment, as their response (Dix, Reinhold, \& Zambarano, 1990; Pinderhughes et al., 2000). Indeed, corporal punishment is used most often when parents are angry (S. Jackson et al., 1999; Peterson et al., 1994) or when parents report experiencing one or more episodes of frustration or aggravation with their children on a typical day (Wissow, 2001). Proponents of corporal punishment in the popular press make conflicting recommendations about what type of parent emotion should accompany corporal punishment for maximum effect. Dobson $(1970,1996)$ argued that corporal punishment should be followed immediately by displays of affection for the child accompanied by explanations of why the misbehavior was wrong, whereas Rosemond (1994) argued that parents should be angry when they spank so that children will not mistake their parents' disapproval. Whichever emotion "should" accompany corporal punishment, it is most likely that parents use corporal punishment when they experience strong negative emotions such as anger.

\section{Parents' Goals}

An important predictor of whether parents will use corporal punishment for a specific misbehavior is the type of goal they have in disciplining their child (Dix, 1992; Hastings \& Grusec, 1998). When parents have short-term socialization goals or parentcentered goals, they are more likely to use power-assertive techniques such as corporal punishment than when they have childcentered or long-term goals (Hastings \& Grusec, 1998; Kuczynski, 1984; Patterson, 1982). For example, when a child is about to stick a metal object into an eletrical socket, the parent's primary goal of stopping the child from engaging in this dangerous behavior may outweigh the long-term goal of teaching the child to recognize and avoid dangerous situations. The findings from the meta-analyses reported above suggest that parents may be successful in realizing their short-term goals for immediate compliance by using corporal punishment but will be less successful when their goals extend toward appropriate behavior in the long-term.

\section{Stable Individual and Relational Context}

During disciplinary interactions, the behaviors of parents and children are determined not only by momentary circumstances but also by stable characteristics of themselves and their families, including their age, their temperament, and their family structure.

\section{Characteristics of the Child}

Age. Parents tend to view corporal punishment as most appropriate for children of preschool age and least appropriate for infants and for children age 5 years and older (Day et al., 1998; Duvall \& Booth, 1979; Flynn, 1998; Rohner et al., 1991; Socolar \& Stein, 1995). As a result, parents' reports of using corporal punishment are negatively related to the age of children (Day et al., 1998; Holden et al., 1995; Loeber et al., 2000; Mahoney, Donnelly, Lewis, \& Maynard, 2000), with rates of corporal punishment dropping off steeply as children age into adolescence (P. Cohen \& Brook, 1995; Frick et al., 1999; S. Jackson et al., 1999; Straus \& Stewart, 1999). Child age has also been linked with the severity of parents' corporal punishment; parents report using more severe forms of corporal punishment (i.e., hit on bottom with object; slap on face, head, or ears; pinch) when children are between 5-8 years old than when they are $0-4$ or 9-17 years old (Straus \& Stewart, 1999).

The age of the child determines his or her cognitive ability to process the disciplinary message implied by the punishment. The moderator analyses of the aggression composite reported above found that the association between corporal punishment and child aggression decreased as the age of the children in the study increased. Given that parents use corporal punishment more often with younger children (Day et al., 1998; Holden et al., 1995), the associations between corporal punishment and child constructs may be stronger in early childhood because corporal punishment is more frequent and consistent. In addition, peers exert an increasing influence on children's behaviors as children age (Berndt, 1996); thus, increasingly rare instances of corporal punishment may have little relation to older children and youths' behaviors, which may be changed more by peer influence than parental discipline. However, there is some competing evidence that parental corporal punishment is associated with more negative effects in older than in younger children (e.g., Gunnoe \& Mariner, 1997; Rothbaum \& Weisz, 1994), and thus the question of when corporal punishment has greatest influence has yet to be decided.

Gender. Parents often have different expectations for the behaviors of boys and girls and as a result react differently to the same behavior depending on the gender of the child exhibiting it (Huston, 1983). Although most child-rearing practices are thought to be used equally with boys and girls (Maccoby \& Jacklin, 1974), some researchers have hypothesized that boys are corporally punished more either because boys engage in behaviors that elicit corporal punishment (e.g., aggression) more than do girls or because parents have gender-based beliefs and expectations about their children, for example that parents want to "toughen up" their boys (Ruble \& Martin, 1998). Findings of gender differences in parents' use of corporal punishment are mixed. In their review, Maccoby and Jacklin (1974) reported that boys received more corporal punishment than girls, a finding replicated in subsequent studies (e.g., Day et al., 1998; Giles-Sims et al., 1995; Mahoney et al., 2000; Rohner et al., 1991; Smith \& Brooks-Gunn, 1997; Straus \& Stewart, 1999). However, in their meta-analyses of differential socialization, Lytton and Romney (1991) found no differences in the corporal punishment meted out to boys or girls by mothers or 
fathers in North America, although they did find that both mothers and fathers in studies from non-Western countries used corporal punishment more often with boys than with girls. A lack of child gender differences in parental corporal punishment also has been reported in a range of studies (e.g., Holden et al., 1995; Minton et al., 1971; Kelley, Sanchez-Hucles, \& Walker, 1993; Statttin, Janson, Klackenberg-Larsson, \& Magnusson, 1995; Strassberg et al., 1994).

The gender of the child also has been hypothesized to moderate the association between corporal punishment and child constructs because children tend to imitate a same-gender model more (Bandura, 1969; Margolin \& Patterson, 1975). Thus, if the parent and child are of the same gender, the effects of corporal punishment on the child will be magnified because modeling is stronger with same-gender dyads (Deater-Deckard \& Dodge, 1997). To support their claim, Deater-Deckard and Dodge (1997) reported stronger correlations between mothers and daughters and between fathers and sons for the association between parental corporal punishment and children's externalizing behavior problems than between mothers and sons and fathers and daughters. However, it has been argued that same-gender imitation is too simplistic an explanation for gender differences in behavior (Huston, 1983).

As a preliminary look at the issue of moderation by child and parent gender, Table 7 lists the six studies (representing a total of 10 constructs) included in the meta-analyses that reported effect sizes separately for each combination of parent and child gender. No consistent pattern of stronger correlations for same-gender dyads compared with different-gender dyads was found. Motherdaughter associations were stronger than father-daughter associations in five cases but weaker in four cases. Similarly, father-son associations were stronger than mother-son associations in three cases but weaker in six cases. These 10 studies do not lend strong support to a same-sex modeling hypothesis for the effects of corporal punishment on children; however, future research is needed to more thoroughly test this hypothesis.

Temperament and genetic contributions. Children's heritable characteristics, with temperament key among them, are thought to affect the types of parenting they receive (Bell \& Chapman, 1986), a phenomenon referred to as an evocative gene-environment correlation (Plomin et al., 1977; Reiss, 1995; Scarr, 1992; Scarr \& McCartney, 1983). Children who are temperamentally high in activity level, low in self-regulation, or high in aggressive tendencies may elicit forceful, coercive controls from caregivers who want to stop undesired, and secure desired, behaviors (Bandura, 1977; Bell \& Chapman, 1986; Belsky, 1984; S. Feshbach, 1970; Patterson et al., 1992; Thomas \& Chess, 1977; Thyer, 1987). Consistent with this hypothesis, experimental studies have found that highly active, aggressive, or conduct-disordered children elicit coercive and power-assertive techniques from their parents (K. E. Anderson, Lytton, \& Romney, 1986; Bell \& Chapman, 1986; Buss, 1981; Lee \& Bates, 1985; Stevens-Long, 1973) and from unfamiliar adults (K. E. Anderson et al., 1986). Similarly, children described by their parents as having fussy or irritable temperaments tend to be spanked more than children reported to have happy or cheerful temperaments (Day et al., 1998). Finally, in two adoption studies, children at genetic risk for antisocial behavior (i.e., their biological parents exhibited antisocial behavior) received more negative parenting, which could include corporal punishment, from adoptive parents than did children not at genetic risk (Ge et al., 1996; O'Connor, Deater-Deckard, Fulker, Rutter, \& Plomin, 1998).

However, there is competing evidence from three longitudinal studies that children's temperamental qualities do not elicit differential amounts of corporal punishment. One study found that infant irritability did not predict mothers' use of corporal punishment when the children were 2 years old (Crockenberg, 1987). In a study of New York families. P. Cohen and Brook (1995) found that parents' use of power-assertive punishment (including corporal punishment) predicted the extent to which their children were diagnosed with conduct disorder 8 and 10 years later, even after controlling for children's early behavior problems, age, gender, and family SES. In cross-lagged analyses across a 6-year span, Kandel and Wu (1995) found that parents' use of punitive punishment at Time 1 predicted children's Time 2 control problems more strongly than children's Time 1 control problems predicted parents' Time 2 use of punitive punishment.

Table 7

Correlations Between Parental Corporal Punishment and Child Constructs as a Function of Whether the Parent and Child Are the Same or Different Gender

\begin{tabular}{|c|c|c|c|c|c|c|c|}
\hline \multirow[b]{2}{*}{ Study } & \multirow[b]{2}{*}{ Child construct } & \multicolumn{2}{|c|}{$\begin{array}{c}\text { Same } \\
\text { gender pairs }\end{array}$} & \multicolumn{2}{|c|}{$\begin{array}{c}\text { Different } \\
\text { gender pairs }\end{array}$} & \multicolumn{2}{|c|}{$\begin{array}{l}\text { Effect size } \\
\text { comparison }\end{array}$} \\
\hline & & $\begin{array}{c}\text { Mother } \\
\text { and daughter }\end{array}$ & $\begin{array}{l}\text { Father } \\
\text { and son }\end{array}$ & $\begin{array}{l}\text { Mother } \\
\text { and son }\end{array}$ & $\begin{array}{c}\text { Father } \\
\text { and daughter }\end{array}$ & Girls & Boys \\
\hline \multirow[t]{2}{*}{ Becker \& Krug (1964) } & Moral internalization & -.36 & -.21 & -.29 & -.15 & $\mathrm{~S}>\mathrm{D}$ & $\mathrm{S}<\mathrm{D}$ \\
\hline & Aggression & .46 & .31 & .31 & .47 & $\mathrm{~S} \approx \mathrm{D}$ & $\mathrm{S} \approx \mathrm{D}$ \\
\hline Flynn (1999) & Aggression & .02 & .35 & .19 & .12 & $\mathrm{~S}<\mathrm{D}$ & $\mathrm{S}>\mathrm{D}$ \\
\hline \multirow[t]{2}{*}{ Joubert (1991) } & Quality of parent-child relationship & -.34 & -.06 & -.09 & -.23 & $\mathrm{~S}>\mathrm{D}$ & $\mathrm{S}<\mathrm{D}$ \\
\hline & Adult mental health & -.11 & -.02 & -.05 & -.04 & $\mathrm{~S}>\mathrm{D}$ & $\mathrm{S}<\mathrm{D}$ \\
\hline Simons, Johnson, \& & Quality of parent-child relationship & -.47 & -.26 & -.29 & -.32 & $\mathrm{~S}>\mathrm{D}$ & $\mathrm{S}<\mathrm{D}$ \\
\hline \multirow[t]{3}{*}{ Conger (1994) } & Aggression & .14 & .03 & .11 & .13 & $\mathrm{~S} \approx \mathrm{D}$ & $\mathrm{S}<\mathrm{D}$ \\
\hline & Delinquency & .01 & .08 & .02 & -.02 & $S \approx D$ & $\mathrm{~S}>\mathrm{D}$ \\
\hline & Child mental health & -.18 & -.14 & -.08 & -.19 & $S \approx D$ & $\mathrm{~S}>\mathrm{D}$ \\
\hline Stattin et al. (1995) & Antisocial behavior & .51 & .48 & .51 & .39 & $\mathrm{~S}>\mathrm{D}$ & $\mathrm{S}<\mathrm{D}$ \\
\hline
\end{tabular}

Note. $\mathrm{S}=$ same-gender dyads; $\mathrm{D}=$ different-gender dyads. 
These conflicting results defy a simplistic unidirectional conclusion and rather point toward a bidirectional, reciprocal association between child temperament and parental corporal punishment. Indeed, in addition to finding genetic-based temperament effects on parenting, Ge et al. (1996) also found reciprocal effects from mothers' discipline to adolescents' antisocial behavior even after controlling for adolescents' genetic risk. Similarly, although parents' punishment was a stronger predictor in the study by Kandel and $\mathrm{Wu}$ (1995), the fact that both the path from parent to child and from child to parent were significant suggests reciprocal relations.

The temperament of the child also can affect children's reactivity to specific parenting behaviors and thereby moderate the effects of parenting on children (Sanson \& Rothbart, 1995). Kochanska (1991, 1993, 1995, 1997a) has proposed that children's temperaments moderate their reactions to parental discipline such that highly anxious children should respond best to techniques that elicit low levels of arousal, whereas children low in anxiety may require forceful techniques deliberately aimed at heightening arousal. For anxious children in particular, parents' subtle techniques foster internalization because they involve optimal arousal and because they deemphasize external justifications for compliance, both of which promote internalization (Kochanska, 1991, 1993). From observations of parent-child interactions, Kochanska $(1995,1997 a)$ has confirmed that relatively fearful children whose mothers use gentle, nonpower-assertive discipline are more likely to exhibit long-term compliance than if their mothers used powerassertive discipline. Because it involves power assertion, corporal punishment may be overbearing and ineffective with fearful children yet appropriately forceful with fearless children (Kochanska, 1993, 1994).

Additional studies have reported results consistent with Kochanska's hypotheses. Predictions for highly fearful children are supported by Colder et al. (1997), who found that parental corporal punishment was associated with the highest levels of teacher-rated aggression among children high in temperamental fearfulness. Predictions for children low in fearfulness are consistent with Bates et al.'s (1998) findings that high parental control (including corporal punishment) was associated with better child behavior for children high in temperamentally based resistance to control. Similarly, hyperactive children in a special education classroom were more able to maintain appropriate behavior when their teachers used consistent negative consequences for inappropriate behavior than when teachers used positive consequences for appropriate behavior (Rosén, O’Leary, Joyce, Conway, \& Pfiffner, 1984). Furthermore, parent training in how to choose child management techniques that complement their children's temperament characteristics has been successful in enhancing parental satisfaction and in depressing child behavior problems (Sheeber \& Johnson, 1994).

Although these studies demonstrate that child temperament may moderate the extent to which corporal punishment is associated with deleterious child constructs, child temperament does not attenuate them. In one study that controlled for children's temperament (Olweus, 1980) and another that controlled for both children's temperament and their earlier levels of aggression (Weiss et al., 1992), parents' use of corporal punishment continued to predict significantly children's later aggression. Particularly strong evidence against a moderating role for child temperament comes from the adoption study by O'Connor et al. (1998) cited above. Al- though an association was found between genetic risk for antisocial behavior and parents' negative control, when genetic risk was partialed out, negative parenting remained significantly associated with children's externalizing behavior (O'Connor et al., 1998). This finding suggests that although genetic-based temperament differences may predict whether corporal punishment is used, once it is used it has the same negative consequences for all children. In other words, child temperament may predict corporal punishment but may not moderate its effects.

\section{Characteristics of the Parent}

Age. Younger parents are both more likely to use corporal punishment than older parents and to use it more frequently (Culp et al., 1999; Day et al., 1998; Giles-Sims et al., 1995; Gunnoe \& Mariner, 1997; Kelley et al., 1993; Straus \& Stewart, 1999; Wissow, 2001; Xu et al., 2000). The increased incidence for younger mothers may be confounded with their lack of experience with children; over $90 \%$ of a sample of low-income adolescent mothers of toddlers reported that they had used corporal punishment for age-appropriate child behaviors, such as the child "wanting to eat other than at mealtime" or the child "not learning quickly enough" (Culp et al., 1999). Future research is needed to explicate this relation.

Gender. The gender of the parent is often linked with use of corporal punishment, with mothers reporting more frequent use (e.g., Day et al., 1998; Gunnoe \& Mariner, 1997; Nobes et al., 1999; S. Jackson et al., 1999; Straus, 1994a; Straus \& Stewart, 1999; Xu, Tung, \& Dunaway, 2000). The greater frequency with which mothers use corporal punishment may be a function of the amount of time spent with the children, for women continue to be the primary caretakers of children even when they work (Biernat \& Wortman, 1991). However, some studies have found no differences in rate of corporal punishment between mothers and fathers (Holden et al., 1999; Wissow, 2001). As mentioned above, the match between the gender of the parent and the gender of the child has been hypothesized to moderate the effects of corporal punishment on children, but as the effect sizes in Table 7 demonstrate, the findings to date are inconsistent.

Temperament and genetic contributions. Parents' own temperaments can predict their likelihood to use corporal punishment. Indeed, parents with tendencies toward aggressive and antisocial behavior tend to report using corporal punishment to a greater extent than do parents without such tendencies (Bank, Forgatch, Patterson, \& Fetrow, 1993). The potential for corporal punishment use to be related to a heritable characteristic has led some to argue that the association between a parent's use of corporal punishment and a child's aggressive behavior may be traced to a shared heritable tendency toward aggressive behavior (Reiss, 1995). Parents with a tendency to be aggressive would be expected both to use corporal punishment more than other parents and to transmit genetically a tendency to be aggressive to their children (Reiss, 1995). In other words, this third variable explanation argues that children may develop behavior problems not because of the corporal punishment they received but because of the aggressive tendencies they inherited from their parents (Belsky, 1997; Wilson $\&$ Herrnstein, 1985). Consistent with this hypothesis, a variety of studies have determined that genetic predispositions account for criminality and antisocial behavior better than do environmental 
influences (Cloninger, Sigvardsson, Bohman, \& von Knorring, 1982; Crowe, 1974; DiLalla \& Gottesman, 1991; Hutchings \& Mednick, 1975). However, the finding reported above that negative parenting remained significantly associated with children's externalizing behavior even after the heritable component was partialed out (O'Connor et al., 1998) suggests that negative parenting is linked to children's emotional and behavior problems over and above the variance explained by shared genetic dispositions. With the increasing attention being paid to genetic contributions to parent and child behavior, the association between parental corporal punishment and child behaviors may be better explicated in future studies.

Psychological functioning. A variety of indices of parents' impaired psychological functioning have been associated with increases in their use of and positive attitudes toward corporal punishment, including whether parents experience negative mood (Holden et al., 1995), experience anxiety or avoidance (Paquette, Bolté, Tucotte, Dubeau, \& Bouchard, 2000), or use legal and illegal drugs (Youssef, Attia, \& Kamel, 1998). Parents' depressive symptomatology repeatedly has been associated with increased reliance on corporal punishment to discipline children (A. P. Jackson et al., 1998; McLoyd et al., 1994; Smith \& Brooks-Gunn, 1997; Webster-Stratton, 1988a; Wissow, 2001). Furthermore, the extent to which mothers' symptoms of anxiety or depression predict children's disruptive behavior problems appears to be mediated by mothers' use of negative control techniques, including corporal punishment (Spieker, Larson, Lewis, Keller, \& Gilchrist, 1999). Depression may precipitate corporal punishment because it biases parents to value parent- over child-centered interactional goals (Dix, Gershoff, \& Miller, 2001) and to make negative attributions about their children's behaviors (Zahn-Waxler, Cole, \& Barrett, 1991). Depression has been found to be the vehicle through which stress affects parenting and in turn children such that maternal depression mediates the association between life stress and harsh discipline (including corporal punishment), which in turn predicts boys' antisocial behavior (Conger, Patterson, \& Ge, 1995).

Parenting style and beliefs. Parents' decisions to use corporal punishment are in part a function of their overall parenting style (Darling \& Steinberg, 1993). Whether corporal punishment is used in the context of a child-centered, responsive, and authoritative parenting style can determine if it achieves positive or negative child constructs (Baumrind, 1967, 1996b). Because parents who spank tend to use other negative techniques such as yelling (Hemenway, Solnick, \& Carter, 1994; Wissow, 2001), some have argued that the negative effects attributed to corporal punishment alone may in fact be a result of a cluster of harmful techniques comprised by a negative parenting style (Darling \& Steinberg, 1993; DeVet, 1997; Levin \& Sears, 1956; Patterson, 1982; Simons, Johnson, \& Conger, 1994; Straus \& Mouradian, 1998). Indeed, corporal punishment has been negatively associated with parents' self-reported rates of reading to, playing with, and hugging their children (Wissow, 2001).

Parents' beliefs about and attitudes toward parenting and child behavior will also influence their decisions whether to use or forgo corporal punishment (Belsky, 1984; Goodnow \& Collins, 1990). The extent to which parents emphasize parental control, expect immediate child obedience, have attitudes that devalue children, have negative perceptions of their parenting role, and endorse the use of corporal punishment each predict whether and how often parents use corporal punishment (Holden et al., 1995, 1999; S. Jackson et al., 1999; McLoyd et al., 1994; Socolar \& Stein, 1995; Straus, 1974; Tremblay, 1995). Parents who use corporal punishment expect it to have more positive and fewer negative consequences (Holden et al., 1997, 1999). In large part, this constellation of beliefs about the appropriateness and effectiveness of corporal punishment is thought to originate from the intergenerational transmission of beliefs and attitudes from parents to their own children (Carroll, 1977; Simons et al., 1991; Rodriguez \& Sutherland, 1999; Widom, 1989). Bidirectional or child effects on parental attitudes have also been identified: Among a group of 39 mothers who had become less in favor of corporal punishment after becoming parents, $89 \%$ reported that their children's negative reactions to being spanked made them less likely to use corporal punishment (Holden et al., 1997).

Parents' overall parenting style is hypothesized to moderate the effects of corporal punishment by changing the nature of the parent-child relationship or the child's willingness to be socialized (Baumrind, 1996a, 1996b, 1997; Darling \& Steinberg, 1993; Grusec, 1997; Kuczynski \& Hildebrandt, 1997; Maccoby \& Martin, 1983). Research confirms that support for the use of corporal punishment and an overall child-oriented parenting style are independent dimensions (Kelley, Power, \& Wimbush, 1992). Corporal punishment used by a warm parent is more likely to achieve positive outcomes because such warmth engenders feelings of trust in and reciprocity toward the parent (Grusec \& Goodnow, 1994; Maccoby, 1980; Maccoby \& Martin, 1983), which in turn may buffer the potential harmful effects of corporal punishment on children's behavior problems (Deater-Deckard \& Dodge, 1997). The presence of warmth in a parenting style has been found to predict more desirable associations between child behaviors and experiences and corporal punishment (e.g., Deater-Deckard \& Dodge, 1997; DeVet, 1997; Kochanska, 1997b; Rohner et al., 1996; Sears et al., 1957; Smith \& Brooks-Gunn, 1997). If it occurs in the context of an overall negative parenting style, corporal punishment is associated with more negative behaviors and experiences (Campbell \& Frabutt, 1999; Olweus, 1980). Furthermore, an inconsistent parenting style may compound the negative effects of corporal punishment. In four separate studies, the inconsistency of parenting predicted children's aggressive or delinquent behaviors, sometimes over and above parents' use of corporal punishment (Agnew, 1983; Glueck \& Glueck, 1964; W. McCord \& McCord, 1959; Simons, Johnson, \& Conger, 1994).

Exceptions to the moderating role of parenting style exist. One study found no interaction between maternal nurturance and use of corporal punishment in predicting children's antisocial behavior (Straus \& Mouradian, 1998). In her longitudinal study of criminality, J. McCord (1997) reported that corporal punishment by mothers and fathers during childhood predicted whether boys would commit serious crimes 30 years later regardless of whether the parents had been rated as warm and affectionate with their sons in childhood. A third study reported that parental support did not moderate the association between frequent corporal punishment and adolescents' distress, although moderation was present at moderate to low levels of corporal punishment (Turner \& Finkelhor, 1996). 


\section{Characteristics of the Family}

When the parent and child are part of a larger family structure, characteristics of the family can affect the likelihood that parents use corporal punishment. As family size increases, support for and use of corporal punishment by parents increase (Flynn, 1994; Hashima \& Amato, 1994; Paquette et al., 2000; Pinderhughes et al., 2000; Sampson \& Laub, 1994; Xu et al., 2000). Particularly important is the quality of the parents' romantic relationship. Partnership in unhappy or conflictual relationships appears to engender parents' use of corporal punishment, with parents in discordant or abusive marriages more likely to use corporal punishment (Dadds, Sheffield, \& Holbeck, 1990; Pinderhughes et al., 2000; Simons, Lorenz, Wu, \& Conger, 1993; Straus \& Kantor, 1987; Webster-Stratton, 1988a; Xu et al., 2000). Marital status itself may also influence parents' use of corporal punishment, presumably because the stress of single parenthood can precipitate a reliance on corporal punishment. Single parents (Loeber et al., 2000; McCabe, Clark, \& Barnett, 1999) and separated or divorced parents (Hetherington, Cox, \& Cox, 1982) have been found to use more corporal and harsh punishment with their children than married parents. This connection between marital status and use of corporal punishment indeed has been related to stress; recently separated mothers experienced more life stress than mothers in intact families, and this stress in turn was associated with more harsh and inept discipline (Forgatch, Patterson, \& Skinner, 1988). However, remarriage alone does not decrease reliance on corporal punishment, as there is some evidence that punitive discipline is more common in stepfamilies (Hashima \& Amato, 1994).

\section{Social-Cultural Context}

Families are embedded within social and cultural systems that can impact patterns of family interaction (Elder, Nguyen, \& Caspi, 1985; Goodnow \& Collins, 1990; McLoyd, 1990; Parke \& Buriel, 1998), in part by dictating the values and skills required by future adult cultural tasks that parents must transmit to their children through socialization (Ogbu, 1981). Thus, a parent's overall style of child rearing, including likelihood to use corporal punishment, is in part determined by the set of parenting beliefs, goals, and expectations inherent in his or her culture's model of parent-child relations (Greenfield \& Suzuki, 1998; Peisner, 1989), sometimes called cultural capital (Xu et al., 2000). In addition to predicting whether parents use corporal punishment, the cultural context can also moderate for whom the practice has positive or negative child constructs. When corporal punishment is both accepted and expected by the community at large, parents may feel justified in administering it and children may view it as normative. In cultures in which a power-assertive parenting style is believed to be in the best interests of the child, corporal punishment may be used instrumentally more than emotionally (Grusec, Rudy, \& Martini, 1997), which, as described above, may predict less negative outcomes (Holden \& Miller, 1997; Straus \& Mouradian, 1998). Social-cultural context may also moderate the effects of corporal punishment by affecting how children emotionally respond to parents' use of corporal punishment (Saarni, 1999). Whether children accept corporal punishment as normative and beneficial will depend largely on whether the larger cultural context deems it acceptable or unacceptable (Deater-Deckard \& Dodge, 1997).

\section{Stress and Social Support}

Stress, assessed by the number of negative life events experienced or by stress specific to the parent-child relationship, has been associated with observations and self-reports of parents' use of physical negative techniques, including corporal punishment (Dumas \& Wekerle, 1995; Forgatch et al., 1988; Paquette et al., 2000; Pianta \& Egeland, 1990; Pinderhughes et al., 2000; Simons, Beaman, Conger, \& Chao, 1993; Webster-Stratton, 1988a; although see McCabe et al., 1999, for contrary findings). Replicated in two separate studies of adolescents, stress from negative life events has been found to predict maternal depression, which in turn predicts harsh discipline (including corporal punishment) and then results in boys' antisocial behavior (Conger et al., 1995). Whether and to what extent stressors negatively impact parenting depend on the social supports available to parents (WebsterStratton, 1990).

Social support is conceptualized as the ways in which interpersonal relationships serve as buffers against potentially stressful experiences or environments (S. Cohen \& McKay, 1984). In the case of parents, social support serves both to make parents feel connected to their community and to promote parents' use of positive (i.e., nonabusive) behavior (Garbarino \& Kostelny, 1995). Social networks support parents by providing instrumental assistance (e.g., money, child care), emotional encouragement, or childrearing advice (Cochran \& Niego, 1995; S. Cohen \& McKay, 1984; Crockenberg, 1988). As a result, social support plays a strong role in moderating associations between economic stress and child outcomes (Conger \& Elder, 1994; Crockenberg, 1988; McLoyd et al., 1994).

Social support is unlikely to have direct effects on child rearing because friends and relatives are not present when day-to-day discipline occurs; rather, social support is more likely to impact parenting indirectly by decreasing parents' levels of depression and stress (Simons, Lorenz, et al., 1993). Social support has rarely been examined as a predictor or moderator of parental corporal punishment directly, yet extant research suggests a relation. A lack of social support has been associated with the incidence of child deaths resulting from maltreatment (Garbarino \& Kostelny, 1995), a finding which implies that the presence of social support may prevent the escalation of corporal punishment into life-threatening abuse. Although not examining corporal punishment per se, several studies have found that mothers who report more social support and more satisfaction with their support are more positive and less controlling during interactions with their children (Crnic, Greenberg, Ragozin, Robinson, \& Basham, 1983; Goldstein, Diener, \& Mangelsdorf, 1996; Jennings, Stagg, \& Connors, 1991; Pianta \& Egeland, 1990). Finally, adolescents' own social support, or the lack thereof, may moderate the effects of physical punishments; adolescents whose peers engage in high levels of problem behavior themselves have lowest levels of problem behaviors if their parents use more behavioral controls (Mason, Cauce, Gonzalez, \& Hiraga, 1996).

\section{SES}

A variety of studies have found a negative association between SES-operationalized as income, education level, and/or job status (Hoff-Ginsberg \& Tardif, 1995)—and parents' use of corporal 
punishment. As SES declines, rates of parents' use of corporal punishment rise (e.g., Bronfenbrenner, 1958; Flynn, 1994; GilesSims et al., 1995; Greenwald, Bank, Reid, \& Knutson, 1997; Gunnoe \& Mariner, 1997; S. Jackson et al., 1999; Kelley et al., 1993; Miller \& Swanson, 1958; Pinderhughes et al., 2000; Rohner et al., 1991; Shumow, Vandell, \& Posner, 1998; Simons, Lorenz, et al., 1993; Straus \& Stewart, 1999; Xu et al., 2000; Youssef et al., 1998). At least one study has found a curvilinear association between SES and use of corporal punishment, with rates of corporal punishment highest for parents in the middle income range $(\$ 20,000-\$ 60,000)$ and with high school but not college educations (Wissow, 2001). In several studies, the increased incidence of both externalizing and internalizing behavior problems exhibited by economically underprivileged children has been found to be mediated through increases in received corporal and other punishments (Bank et al., 1993; Conger et al., 1992; Dodge, Pettit, \& Bates, 1994; Elder et al., 1985; McLeod \& Shanahan, 1993; McLoyd, 1990; McLoyd et al., 1994; Sampson \& Laub, 1994). Two main hypotheses have been posited for a link between low SES and corporal punishment: a stress (spillover) hypothesis and a socialization (linkage) hypothesis.

The stress, or spillover, explanation argues that it is because it is associated with increases in parents' psychological distress that economic hardship leads to more frequent use of corporal punishment (Elder \& Caspi, 1988; McLoyd, 1990; Simons, Lorenz, et al., 1993). There is some evidence that job stress may spur impulsive rather than instrumental uses of corporal punishment (Stolley \& Szinovacz, 1997). Economic stress is associated with both increased parental depression and marital conflict, each of which predicts punitive and hostile parenting associated with adolescent adjustment problems (Conger et al., 1992, 1993). Indeed, associations between SES, stress, and corporal punishment have been found in several studies (Garbarino, Kostelny, \& Barry, 1997; Giles-Sims et al., 1995; A. P. Jackson et al., 1998; McLoyd et al., 1994; Pinderhughes et al., 2000; Simons, Whitbeck, Melby, \& Wu, 1994). Furthermore, stress from low SES can compound the stress associated with being a parent; the association between parenting stress and aversive parenting was higher in economically disadvantaged families than in advantaged families (Dumas \& Wekerle, 1995).

Alternatively, a socialization, or linkage, explanation maintains that the link between low SES and corporal punishment can be explained in the context of a parent fostering values and skills, such as conformity and obedience to authority, required for success in the typical life circumstances the child will likely experience as an adult (Kelley et al., 1992; Kohn, 1977; Luster, Rhoades, \& Haas, 1989; Straus, 1974). Thus, parents of low SES may rely on corporal punishment because they place a premium on children's immediate compliance, either because immediate compliance prepares children for the obedience required in low-status occupations (Kohn, 1977; Straus, 1974) or because the consequences for disobedience in their often more dangerous neighborhoods can be severe (Garbarino et al., 1997; McLeod et al., 1994; Staples \& Johnson, 1993).

One study of parents' experiences at work and at home tested these two explanations and found that both were applicable (Greenberger, O’Neil, \& Nagel, 1994). Support for a stress explanation comes from the finding that lower level (and thus lower paying) work was associated with increases in fathers' psycholog- ical distress, which in turn led to harsher discipline, whereas the finding that parents whose jobs involved greater complexity of work with people were less likely to report using harsh discipline lends support to the linkage explanation (Greenberger et al., 1994). However, a study in the Netherlands found that it was the relation between SES and parents' ability to take their children's perspectives that predicted parents' discipline style rather than the relations between SES and parents' valuation of conformity or autonomy (Gerris, Deković, \& Janssens, 1997). More work is needed to further examine these two pathways by which SES may affect parents' likelihood to use corporal punishment.

Despite findings of SES-based differences in parents' use of corporal punishment specifically or harsh parenting in general, still other studies have found no effect of income or SES on acceptance or use of corporal punishment (e.g., Day et al., 1998; Duvall \& Booth, 1979; Erlanger, 1974; Heffer \& Kelley, 1987; Lahey, Conger, Atkeson, \& Treiber, 1984; Mahoney et al., 2000; McLeod et al., 1994). Findings can even be contradictory within studies. For example, using data from the 1987-1988 National Survey of Families and Households, Stolley and Szinovacz (1997) found a positive association for family income yet a negative association with parent education.

In addition to considering its role as a predictor, researchers have begun investigating the role of SES as a moderator of the associations between parental corporal punishment and child behaviors and experiences. Although not including corporal punishment per se, a controlling parenting style has been associated with reduced exposure to violence in neighborhoods with high homicide rates but with increased risk for exposure to violence in neighborhoods with low homicide rates (Jones, 2000). Similarly, a restrictive and punitive parenting style has been associated with improved cognitive development among low-SES families but not among higher SES families (Baldwin, Baldwin, \& Cole, 1990). However, several studies have found that a family's SES does not moderate the effects of corporal punishment on children (e.g., Kandel, 1990; Straus et al., 1997; Weiss et al., 1992) although there is some evidence that SES moderates the association between parents' general punitiveness and children's prosocial orientation (Knight, Kagan, \& Buriel, 1982).

It is important to note that economic and social discrimination against minorities in the United States has meant that low SES and race-ethnicity are often confounded (Garcia Coll, Meyer, \& Brillon, 1995). As well, many studies of minority parents have focused on the disadvantaged (Garcia Coll, 1990). In some studies, racial differences in the effects of corporal punishment are fully accounted for by SES differences (Dodge et al., 1994). Indeed, European American upper-middle-income mothers tend to report less approval of spanking than did low-income European American and African American mothers and upper-middle-income African American mothers (Heffer \& Kelley, 1987). Future research on corporal punishment should take particular care in examining race-ethnicity and SES differences in conjunction.

\section{Race-Ethnicity}

Parents' ethnicity, defined as a heritage based on nationality, language, and culture (Betancourt \& Lopez, 1993), has been increasingly studied as a possible determinant of corporal punishment, presumably because ethnic differences are confounded with 
cultural differences in parenting values and practices (Mosby et al., 1999; Whaley, 2000). However, the results to date are inconclusive. Although some studies have found that African American or Hispanic American parents use corporal punishment more often than European American parents (e.g., Daro \& Gelles, 1992; Day et al., 1998; Flynn, 1994; Giles-Sims et al., 1995; Loeber et al., 2000; Pinderhuges et al., 2000; Shumow et al., 1998; Smith \& Brooks-Gunn, 1997; Stolley \& Szinovacz, 1997; Straus \& Stewart, 1999), other studies have found that European Americans spank the most (e.g., Escovar \& Escovar, 1985; Straus, 1994a) or that Hispanic Americans or Asian Americans spank the least (e.g., Hashima \& Amato, 1994; Wissow, 2001), and still others have found no differences in frequency between ethnic groups (e.g., Ellison, Thompson, \& Segal, 1995; Hemenway et al., 1994; Stark \& McEvoy, 1970).

The majority of research on ethnic minority families has compared them with European American families to identify betweengroup differences (Parke \& Buriel, 1998), with comparisons of parenting and child development across ethnic groups often implying that one group (i.e., the majority) is optimal or the standard (Cowan, Powell, \& Cowan, 1998). However, variation in discipline practices exists both between and within ethnic groups (Parke \& Buriel, 1998). Indeed, there may be as many differences within SES groups as there are between them. One study of low-income African American mothers found wide variation in parents' use of and attitudes about corporal punishment (Kelley et al., 1992), whereas a second study of working and middle-class African American mothers reported using corporal punishment infrequently and using reasoning and other child-oriented techniques most frequently (Bluestone \& Tamis-LeMonda, 1999).

The idea that corporal punishment may have differential effects in families of disparate racial-ethnic backgrounds also has been explored. A family's racial-ethnic affiliation has been found to moderate the association between corporal punishment and children's aggressive or externalizing behaviors with minority families (Deater-Deckard \& Dodge, 1997). In multiple studies, corporal punishment is positively associated with increased aggression among European American children but negatively or not significantly associated with aggression among African American children (Baumrind, 1972; Deater-Deckard et al., 1996; Gunnoe \& Mariner, 1997).

Yet there are additional results to suggest that the effects of corporal punishment on children are not moderated by race or ethnicity. An authoritative parenting style that deemphasizes parental power has been associated with adolescents' academic achievement regardless of ethnic group, although European American parents were rated higher in authoritative parenting than parents from African, Asian, and Hispanic American ethnic backgrounds (Dornbusch, Ritter, Leiderman, Roberts, \& Fraleigh, 1987). Similarly, a second study found that corporal punishment predicted increases in children's antisocial behavior 2 years later among both European American and minority children (Straus et al., 1997). An interesting finding of reciprocal effects was reported by McLeod et al. (1994); using longitudinal data, they found that African American mothers' corporal punishment was the result rather than the cause of their children's antisocial behavior, whereas European American mothers' corporal punishment and their children's antisocial behavior were reciprocally related. Thus, child antisocial behavior appears to elicit corporal punishment from African American parents and to both elicit and result from corporal punishment by European American parents.

\section{Religion and Religiosity}

The use of corporal punishment to discipline children has been supported by the religious affiliations and beliefs of many Americans (Greven, 1991; Kuczynski \& Hildebrandt, 1997). In particular, a Conservative Protestant affiliation and conservative religious beliefs are associated with more frequent use of corporal punishment (Day et al., 1998; Ellison, Bartkowski, \& Segal, 1996; Gershoff et al., 1999; Giles-Sims et al., 1995; Stolley \& Szinovacz, 1997; Xu et al., 2000). However, there is mounting evidence that parents' religiosity may have effects on parenting distinct from the effects of their specific religious affiliation. In a growing number of studies, parents' religiosity (indexed as either their attendance at religious services or their endorsement of certain religious beliefs) is associated with child-oriented discipline (Kelley et al., 1992) and with positive parent-child relationships (Pearce \& Axinn, 1998; Wilcox, 1998). More research is needed on the extent to which religious affiliation and religiosity may separately and together predict parents' use of corporal punishment.

Little attention has been paid to the potential for parents' religious affiliation to moderate the effects of corporal punishment on children. The two studies to date addressing this question have examined whether parents' perceptions of the effects of corporal punishment vary according to their religious affiliation. In the first study, Conservative Protestant parents attributed fewer negative consequences to corporal punishment than did parents of other religious affiliations (Gershoff et al., 1999). A second study based on data from the National Survey of Families and Households found that Conservative Protestants were least likely to report that corporal punishment had any harmful effects on their children (Ellison, Musick, \& Holden, 1999). Whether religion moderates the effects of corporal punishment on objectively rated child outcomes remains to be determined.

\section{Geographic Region}

Although not systematically studied, the region in which parents live appears to affect the likelihood that they use corporal punishment, suggesting that the region of the country in which families live constitutes a cultural context that either supports or discourages the practice. Corporal punishment is favored most among parents living in the South of the United States and favored least by parents living in the Northeast, even after controlling for demographic factors such as education, income, race, and religious affiliation (Ellison \& Sherkat, 1993; Flynn, 1994; Giles-Sims et al., 1995; Straus \& Stewart, 1999). Consistent with the findings on religious differences in corporal punishment reported above, strong support for corporal punishment has been identified in the region of the South referred to as the Bible Belt (Wiehe, 1990), which includes parts of Alabama, Arkansas, Georgia, Louisiana, Mississippi, North Carolina, Oklahoma, South Carolina, Tennessee, Virginia, and West Virginia. As an analogue to parental corporal punishment, there are also regional differences in rates of corporal punishment in schools (Hyman, 1995). Twenty-seven states have banned the use of corporal punishment in schools; among the 23 states that do permit corporal punishment in schools, 
the 10 states with the highest rates of corporal punishment in schools are primarily from the South (in descending order): Mississippi, Arkansas, Tennessee, Texas, Georgia, Oklahoma, Louisiana, Missouri, and South Carolina (National Coalition to Abolish Corporal Punishment in the Schools, 2001). How the region in which parents reside affects their beliefs about and use of corporal punishment is not well understood. In light of the finding that differences in corporal punishment persist after demographic variables are controlled, further research is needed to determine the source of regional differences and how they are disseminated among a region's residents.

\section{Legal Statutes and Public Policy}

Current U.S. law emphasizes both the rights and interests of parents as well as the "best interests" of children, and in some circumstances the interests of parents and children do not correspond (Garbarino \& Kostelny, 1995; Pagliocca, Melton, Wiesz, \& Lyons, 1995). Individual belief in and use of corporal punishment in the United States is supported by public policies that sanction the use of physical means of disciplining young children and that view children as the property of parents who have the "right" to raise them as they choose (Belsky, 1993; Garbarino, 1977). Although an adult hitting another adult is prosecuted in all states as assault, the use of corporal punishment by parents is legal in all states (Davidson, 1997); however, additional laws in Minnesota allow prosecution of corporal punishment (Bitensky, 1998). Recently Oakland, California, became the first city to consider, although it ultimately rejected, a proposal to make that city the nation's first "no-spanking zone" (Wong, 1999). Twenty-seven states have adopted legislation that prohibits the use of corporal punishment by teachers and guardians other than parents, such as foster parents (National Coalition to Abolish Corporal Punishment in the Schools, 2001), yet the U.S. Supreme Court has upheld the right of teachers to use corporal punishment with their students (Ingraham v. Wright, 1977), including children with disabilities (Lohrmann-O'Rourke \& Zirkel, 1998).

In 1979, Sweden became the first country to ban all corporal punishment of children, including that by parents. The Swedish ban has been particularly effective in changing attitudes about corporal punishment - such that 15 years after the ban only $11 \%$ of the public supports the use of corporal punishment-and in orienting social service intervention towards support and prevention (Durrant, 1999a). Prosecution of parents for assault and abuse against children has remained steady in the years since the ban (Durrant, 1999a), belying fears that the ban would lead to a rash of parents being prosecuted. In addition, counter to fears that a ban on corporal punishment would lead to increases in youth violence and criminal behavior, rates of youth involvement in crime, alcohol and drug use, rape, and suicide decreased in the period after the ban compared with the period before the ban (Durrant, 1999b).

In addition to Sweden, ten countries have banned parents' use of corporal punishment: Austria, Croatia, Cyprus, Denmark, Finland, Germany, Israel, Italy, Latvia, and Norway (Bitensky, 1998; EPOCH-USA, 2000). In each case, the wording of the laws or court rulings indicates that the intent of the lawmakers was to change public attitudes about corporal punishment more than to prosecute parents for using corporal punishment (Bitensky, 1998). It is important to note that both Sweden and Finland accompanied their rulings with national campaigns educating adults and children about discipline techniques that are more effective than and preferable to corporal punishment (Bitensky, 1998). Prohibitions of parental corporal punishment are also being considered by other countries, including the governments of Belgium, Canada, New Zealand, and the United Kingdom (EPOCH-USA, 2000). The United Kingdom's consideration of a ban on parental corporal punishment was prompted by a ruling of the European Court of Human Rights (ECHR) in September 1998. Citing Article 3 of the European Convention on Human Rights protecting individuals from "inhuman or degrading treatment" (Council of Europe, 1998, Prohibition of Torture section) the ECHR ruled that British law did not adequately protect a 9-year-old boy who had been repeatedly beaten by his father with a three-foot long cane and awarded the boy compensatory damages and legal fees (A. v. The United Kingdom, 1998). In response to this ruling, England's Department of Health in January 2000 issued a consultation document entitled "Protecting Children, Supporting Parents: A Consultation Document on the Physical Punishment of Children." In this document, the Department of Health acknowledged that corporal punishment may be harmful to children but did not support a ban on parental corporal punishment. How the United Kingdom will resolve the disagreement between the ECHR ruling and the government's position on parental corporal punishment as "reasonable chastisement" (Department of Health, 2000, p. 15) remains to be seen.

The United Nations Convention on the Rights of the Child (1989) explicitly requires that

parties shall take all appropriate legislative, administrative, social and educational measures to protect the child from all forms of physical or mental violence, injury or abuse, neglect or negligent treatment, maltreatment or exploitation, including sexual abuse, while in the care of parent(s), legal guardian(s) or any other person who has the care of the child. (Article 19, para. 1)

The United Nations Committee on the Rights of the Child (1994) has declared that "corporal punishment of children is incompatible with the convention" (p. 63). Although the President of the United States signed the Convention of the Child in 1995, Congress has not ratified it, and thus the United States is not a party to the Convention (Bitensky, 1998). The United States and Somalia are the only countries that have not ratified the Convention (United Nations Children's Fund, 1999).

\section{Challenges for Future Research on Corporal Punishment}

Although research to date on corporal punishment has enabled the meta-analyses and the specifics of the model described above, firm conclusions regarding the outcomes associated with parental corporal punishment are inhibited by several drawbacks of the research to date. Future research on corporal punishment will need to address these issues to advance understanding of parental corporal punishment and its potential effects on children.

\section{Standardizing the Definition of Corporal Punishment}

To be specific about what is being studied, it will be important for researchers to obtain a clearer understanding of what parents themselves mean by corporal punishment. None of the studies included in the meta-analyses presented above asked parents what 
they meant by corporal punishment but rather provided parents a definition with which to decide whether their behaviors fit. Although the definition by Straus (1994a) used for this article defines the overall category of corporal punishment, researchers still require a detailing of behaviors that fall under this definition. For example, is hitting a child's bottom with a belt corporal punishment or physical abuse? Is corporal punishment restricted to hitting, or is washing a child's mouth out with soap a form of corporal punishment? There is a particular need for information on what other methods are tried first, how long an instance of corporal punishment lasts, how many spanks constitute a spanking, and how hard spanks are delivered. This latter issue is a thorny oneparents differ in their perceptions of what constitutes mild or severe corporal punishment. Research is needed that assesses exactly how hard parents are hitting their children and whether varying degrees of force have varying effects on children.

\section{Standardizing the Measurement of Corporal Punishment}

Measures of corporal punishment abound, ranging from multiple-item instruments to single-item assessments created for the study at hand. The most often used measure of corporal punishment is the Conflict Tactics Scale (Straus, 1990a), which includes spanking and slapping as well as more severe behaviors such as punching, biting, or using weapons; a revised version of the measure has been extended to include questions tapping potential emotional abuse and neglect (Straus, 1999). The Conflict Tactics Scale has been used in at least 10 countries and over 100 studies of parental corporal punishment (Yodanis, Hill, \& Straus, 2001). Duplication of parenting measures both prohibits comparisons across studies and does not take advantage of the large number of existing measures with demonstrated psychometric properties (Dix \& Gershoff, 2001). Because corporal punishment occurs relatively rarely, researchers must rely on parents' selfreports of corporal punishment rather than observations, and thus careful attention needs to be paid to how questionnaire or interview items are worded. Research is needed on the question of whether the time frame parents are asked to consider (e.g., "in the past year" vs. "last week" vs. "an average week") affects the frequency with which they report using corporal punishment. Work is needed to determine whether the constructs associated with corporal punishment are attributable to its frequency, severity, or an interaction between them. In addition, corporal punishment is likely rarely used in isolation but rather before, after, or combined with other types of discipline; more research is needed on the use of corporal punishment in conjunction with other techniques.

\section{Determining Causal Direction}

Psychological research to date has relied on experimental and observational designs to establish causality. Causal conclusions about the effects of parenting on children are hampered by the fact that most research on parenting and its effects on children is correlational or involves "follow-back" designs in which a child problem is identified and then differences between parents in the problem and no-problem groups are examined (Cowan et al., 1998). Correlational designs cannot rule out the possibility that child behavior problems elicit corporal punishment more than corporal punishment causes such problems (Larzelere, Kuhn, \& Johnson, 2000). Because corporal punishment occurs rarely and eludes observation, researchers interested in the effects of corporal punishment need to consider more ingenious methods of establishing causality.

For parental corporal punishment to be identified definitively as a cause of child constructs, a study would need to be conducted that met the following conditions: (a) Corporal punishment and the child construct of interest must be significantly, statistically associated; (b) corporal punishment must be measured at an earlier point in time than the child construct is measured; (c) potential bidirectional (i.e., child $\rightarrow$ parent) associations must be accounted for; and (d) corporal punishment must be isolated from other types of discipline and from overall parenting style as the causal source. The first condition, though necessary, is hardly sufficient, as it describes a majority of the contemporaneous studies included in the meta-analyses above. The second condition of time precedence was met in the 12 longitudinal studies included in the metaanalyses (see Table 3). The third condition of ruling out potential bidirectional patterns of influence has been achieved in several longitudinal studies that have controlled for children's previous behaviors (e.g., Cohen \& Brook, 1995; Crockenberg, 1987; Olweus, 1980; Weiss et al., 1992) or that have controlled for children's Time 1 influences on both their parents and themselves at Time 2 through cross-lagged analyses (e.g., Kandel \& Wu, 1995; O'Connor et al., 1998). The final condition, that of isolating corporal punishment from other types of discipline, will be particularly difficult to meet because although parents use corporal punishment combined with other forms of discipline, such as reasoning, researchers often ask only how often parents use corporal punishment and neglect to ask what other types of discipline they use at the same time as, or just before, using corporal punishment.

Regarding the second and third conditions (those regarding time precedence) in particular, there exist four research methods that have the potential for observing causal directions between parental corporal punishment and child constructs, namely: experimental studies, sequential analyses of parents' reports of corporal punishment, longitudinal studies that control for children's previous behavior, and evaluations of parenting interventions. Although some experimental studies of corporal punishment have been conducted (e.g., Bean \& Roberts, 1981; Day \& Roberts, 1983; Roberts \& Powers, 1990), the ethics of randomly assigning some children to be hit, even by their parents, would challenge most institutional review boards. Even dividing parents who normally use corporal punishment at the same rates into a no-spank and a spank condition may be problematic because it requires finding a group of spanking parents who are open to the idea of not spanking their children, and such parents are likely different from those who think corporal punishment is essential to responsible and effective parenting. Any such experiments also would need to control for key factors that might otherwise distinguish these groups, such as SES, race-ethnicity, and religion. Sequential analyses of parents' reports of corporal punishment and the immediate reactions it evokes in their children have allowed some to draw conclusions about the direction of effects (e.g., Chapman \& Zahn-Waxler, 1982; Larzelere, 1986; Larzelere \& Merenda, 1994; Larzelere et al., 1998; Zahn-Waxler et al., 1979). Longitudinal studies also promise the identification of causal relations (e.g., Eron et al., 
1974; J. McCord, 1988a, 1988b; Simons et al., 1998). Longitudinal models help establish time precedence of parenting behavior, yet they cannot rule out third variable or bidirectional influences (Cowan et al., 1998) unless the design controls for children's initial levels of the behavior of interest. In both sequential and longitudinal methods, controlling for previous behavior, by the children, the parents, or both, increases the likelihood that causal patterns can be isolated (e.g., Cohen \& Brook, 1995; Gunnoe \& Mariner, 1997; Kandel \& Wu, 1995; Larzelere et al., 2000).

Finally, evaluations of parenting interventions that target reductions in use of corporal punishment are another way research might confirm causal associations with child constructs. Decreasing parents' use of corporal punishment is a main goal of many abuse prevention programs (Wolfe, 1991). Through pre- and posttests, evaluations of interventions specifically aimed at reducing corporal punishment have the potential to attribute resulting child constructs to the change in corporal punishment, provided that other factors can be controlled. To date, a range of parenting interventions that deemphasize the use of coercive techniques such as corporal punishment have been associated with improvements in children's behaviors and with decreased likelihood of physical abuse by parents (Baum \& Forehand, 1981; Brenner, Nicholson, \& Fox, 1999; Cowan et al., 1998; Dishion \& Patterson, 1992; Kazdin, 1997; Thompson et al., 1997; Webster-Stratton, 1984, 1988b; Webster-Stratton, Hollinsworth, \& Klopacoff, 1989). However, most parent training programs combine instruction in childmanagement skills with other components such as anger management, problem solving, and stress reduction (e.g., Azar, 1989; Wolfe et al., 1981). Thus, it is difficult to determine if the positive child behaviors that accrue from parent training are attributable to decreases in corporal punishment or rather to increases in other control techniques.

\section{Measuring Mediational Processes in the Child and Moderating Effects of Multiple Contexts}

The process-context model depicted in Figure 1 and described in detail above represents a summary of the field's cumulative understanding of how and under what conditions corporal punishment might have certain effects on children. However, the proposed mediational processes are largely derived from theoretical work, and the particular aspects of contexts proposed to mediate associations between corporal punishment and child outcomes have been examined primarily in separate studies and not as combined influences.

Although researchers must assume that some processes in the child transform the experience of corporal punishment into a manifest behavior, measurement of potential mediational processes is extremely rare. Exceptions include examination of the role of children's arousal in response to corporal punishment and its association with compliance (Larzelere \& Merenda, 1994) and of children's tendencies to make hostile attributions as a mediator between the experience of corporal punishment and engagement in aggressive behavior (Weiss et al., 1992). On the whole, exactly when each type of process is activated and how these processes may interact are entirely unknown. It is clearly impossible to stop disciplinary encounters midstream to ask children how they think or feel about being spanked; however, if it were feasible to videotape an instance of corporal punishment, a method of having children immediately review the videotape and asking them to recall what they were thinking or feeling at that moment (akin to methods used by Gottman \& Levenson, 1985, with married couples and by Gershoff \& Dix, 2001, with parents) might provide the best avenue for examining children's in-time mediational processes. Alternatively, prospective research designs that measure corporal punishment, children's internal processes, and potential child outcomes each at three time points would allow the examination of corporal-punishment-mediational-process-child-outcome contingencies. Clearly this latter method is less preferable because it extends the sequence of interest over months rather than across seconds, but it may provide insights into the role of mediational processes in these complex relations.

The process-context model has identified 12 potential moderational influences on parent-child encounters involving corporal punishment. It is more than likely that some or all of these influences are at work at some level, affecting both when and whether parents use corporal punishment and how children process and react to it. For example, a parent who comes from a religious background that supports the use of corporal punishment (socialcultural context), who is relatively young (stable individual and relational context), and whose disciplinary goal is immediate compliance (interactional context) will be likely to use corporal punishment contingently and instrumentally. Because these contextual factors together likely make corporal punishment a regular occurrence, the child in turn may view corporal punishment as a normal and acceptable form of discipline, react with little emotional arousal, and comply with it fairly consistently. This brief example illustrates the complexity of interrelations involved and the difficulty of isolating moderational influences and mediational processes. The potential combinations of contextual factors are staggering, and thus no research project will ever be able to measure them all. However, with the advent of multilevel modeling (Bryk \& Raudenbush, 1992), it is now possible to analyze nested levels of influences on parent-child interactions; such methods hold the greatest promise for identifying the influences of contexts as moderators of associations between corporal punishment and child behaviors and experiences.

\section{Considering Curvilinear Patterns of Association}

As has been suggested elsewhere (Deater-Deckard \& Dodge, 1997), associations between parental corporal punishment and child behaviors and experiences may follow a curvilinear function, with the most deleterious outcomes observed with frequent or severe levels of corporal punishment. Similarly, the effects of corporal punishment may take a curvilinear pattern with regard to child age; the moderator analyses reported above demonstrate that parental corporal punishment was associated with children's aggressive behaviors more for children in middle school than for older or younger children, a finding replicated in other research (Frick et al., 1999). These issues generate several research questions. Does corporal punishment that is issued rarely and only when parents are angry have more of a negative effect on children than frequent spanking that is controlled and instrumental? If indeed regular spanking does have fewer negative effects than does rare spanking, is it because parents are using it instrumentally rather than impulsively, or is it because it is supported by culture and thus accepted by children? Are certain periods of child devel- 
opment more susceptible to the effects of corporal punishment than are other periods regardless of frequency or severity of the punishment? Longitudinal studies of corporal punishment and its associations with child development are needed to address these questions.

\section{Continuing to Study Diverse Populations}

As the discussion of race-ethnicity effects above suggested, which behaviors are considered normative corporal punishment and which are considered abusive will vary across cultural groups. Studies of corporal punishment with diverse populations need first to demonstrate the measurement equivalence of measures tapping corporal punishment use across racial-ethnic, national, and SES groups. Second, such studies must examine the differential effectiveness of corporal punishment in achieving desirable child constructs across cultural groups. As mentioned above, understanding of cultural differences is stymied by the facts that race-ethnicity and SES are often confounded and that studies of minorities often concentrate solely on the economically disadvantaged. Furthermore, research on religious and geographic region differences is only just beginning. Future research that is sensitive to the culturally based sources of parents' beliefs about and use of corporal punishment is sorely needed.

\section{Balancing Research on Corporal Punishment and Mandated Reporting of Abuse}

In asking parents about their physical discipline of their children, researchers may discover that parents have used techniques that fall under legal definitions of physical abuse. As mandated reporters, psychologists are obligated to report suspected abuse to child protection authorities (Child Abuse Prevention and Treatment and Adoption Reform Act, 1992). However, their likelihood to do so may depend on their beliefs about corporal punishment and abuse. In one study, the more college students approved of corporal punishment, the less likely they were to perceive maltreatment in a series of vignettes and to report such maltreatment to authorities (Ashton, 2001). In light of findings that more than two thirds of psychologists approve of the use of corporal punishment with children (K. A. Anderson \& Anderson, 1976), it is evident there is a need for clearer standards for reporting physical maltreatment and for distinguishing it from corporal punishment.

Because reporting abuse requires breaking agreements of confidentiality, researchers may be hesitant to ask about practices that may be widespread yet fall under the definition of physical abuse (Putnam, Liss, \& Landsverk, 1996). If families are told that any suspicion of child abuse will be reported, they may be less likely to participate, resulting in a biased sample (Egeland, 1991; Lynch, Stern, Oates, \& O'Toole, 1993); however, there are no research studies that have considered whether families at risk for abuse are less likely to participate in research if informed consent statements include obligations to report abuse (Putnam et al., 1996). Although researchers may struggle with reporting issues, children themselves do not; a sample of middle and high school students strongly agreed that investigators should break confidentiality and report suspected physical or sexual abuse to a parent or other concerned adult (Fisher, Higgins-D'Alessandro, Rau, Kuther, \& Belanger, 1996). This finding is a poignant reminder that research- ers who deal with issues regarding parent-to-child violence are beholden to protect the safety of the children they study.

\section{Conclusion}

The focus of the present article has been on understanding whether parental corporal punishment is associated with particular child behaviors and experiences as well as on considering how parental corporal punishment might actually cause such child outcomes. The results of the meta-analyses indicate strong associations between corporal punishment and a range of child behaviors and experiences. The model described above provides a guide for understanding the direct, mediated, and moderated pathways by which corporal punishment might be expected to affect children. As Dishion and Patterson (1999) have argued, effective models of developmental processes should include testable hypotheses, be parsimonious, predict variation in behavior, explain a wide range of phenomena, lead to effective interventions, and be both testable and revisable. Of course, it is impractical, if not impossible, to include and control for all of the potential influences on the associations between parental corporal punishment and child behaviors in any individual study. However, future studies that isolate each of these influences can together provide a richer understanding of parental corporal punishment.

Corporal punishment has been long debated as a method of correcting children, yet other methods of discipline should also be subject to exacting scientific scrutiny. Although corporal punishment was used as the main example throughout the discussion of this model, it is equally applicable to other forms of parental discipline. The potential for other discipline techniques, if misused, to lead to negative child outcomes must also be examined. It is my hope that this model can direct future understanding of all forms of parental discipline.

The role of scientists in the debate over corporal punishment is to establish empirically connections between corporal punishment and potential child outcomes, particularly in longitudinal and prospective studies. It is by examining data and evaluating their conclusions that science progresses and society benefits. The present article is an attempt to analyze systematically the extant data and theory on parental corporal punishment to inform scientific, and ultimately popular, discussion. As a field and as a society, we must separate out the emotionally charged aspects of the debate over corporal punishment so that we can knowledgeably and responsibly recommend or discourage parents' use of corporal punishment with their children.

\section{References}

References marked with an asterisk indicate studies included in the meta-analysis. References marked with a plus sign indicate works that constitute multiple reports from a study already included in the metaanalyses.

A. v. The United Kingdom, Reports 1998-VI, 100/1997/884/1096 (European Court of Human Rights 1998). Retrieved January 10, 2000, from http://hudoc.echr.coe.int/hudoc/ViewRoot.asp?Item =12\&Action = Html\&X $=413033756 \&$ Notice $=0 \&$ Noticemode $=\&$ RelatedMode $=0$

Achenbach, T. M. (1991). Manual for the Child Behavior Checklist/4-18 and 1991 profile. Burlington, VT: University of Vermont, Department of Psychiatry.

*Adams, M. J. (1996). Youth in crisis: An examination of adverse risk 
factors affecting children's cognitive and behavioral/emotional development, children ages 10-16 (Doctoral dissertation, University of Texas at Dallas, 1995). Dissertation Abstracts International, 56(08), 3313A.

Agnew, R. (1983). Physical punishment and delinquency: A research note. Youth and Society, 15, 225-236.

*Alibrando, S. A., Jr. (1988). The effects of corporal punishment and contextual parental characteristics on rebelliousness, neuroticism, and introversion (Doctoral dissertation, Biola University, 1988). Dissertation Abstracts International, 49(04), 1406B.

American Academy of Pediatrics. (1998). Guidance for effective discipline. Pediatrics, 101, 723-728.

Anderson, K. A., \& Anderson, D. E. (1976). Psychologists and spanking. Journal of Clinical Child Psychology, 5, 46-49.

Anderson, K. E., Lytton, H., \& Romney, D. M. (1986). Mothers' interactions with normal and conduct-disordered boys: Who affects whom? Developmental Psychology, 22, 604-609.

*Aronfreed, J. (1961). The nature, variety, and social patterning of moral responses to transgression. Journal of Abnormal and Social Psychology, 63, 223-240.

Aronfreed, J. (1969). The concept of internalization. In D. A. Goslin (Ed.), Handbook of socialization theory and research (pp. 263-323). Chicago: Rand McNally.

Ashton, V. (2001). The relationship between attitudes toward corporal punishment and the perception and reporting of child maltreatment. Child Abuse \& Neglect, 25, 389-399.

Azar, S. T. (1989). Training parents of abused children. In C. E. Schaefer \& J. M. Briesmeister (Eds.), Handbook of parent training: Parents as co-therapists for children's behavior problems (pp. 414-441). New York: Wiley.

Azrin, N. H., Hake, D. F., Holz, W. C., \& Hutchinson, R. R. (1965). Elicitation of aggression by a physical blow. Journal of the Experimental Analysis of Behavior, 8, 55-57.

Azrin, N. H., \& Holz, W. C. (1966). Punishment. In W. K. Honig (Ed.), Operant behavior (pp. 380-447). New York: Appleton-Century-Crofts.

*Baer, D. J., \& Corrado, J. J. (1974). Heroin addict relationships with parents during childhood and early adolescent years. Journal of Genetic Psychology, 124, 99-103.

*Bakshi, A. (1994). Early family experience, chronic peer rejection in school, and overgeneralized social problem solving as predictors of child adjustment at age seven (Doctoral dissertation, University of Tennessee at Knoxville, 1993). Dissertation Abstracts International, 54(09), 4939B.

Baldwin, A. L., Baldwin, C., \& Cole, R. E. (1990). Stress-resistant families and stress-resistant children. In J. Rolf, A. S. Masten, D. Cicchetti, K. H. Nuechternlein, \& S. Weintraub (Eds.), Risk and protective factors in the development of psychopathology (pp. 257-280). New York: Cambridge University Press.

Bandura, A. (1969). Principles of behavior modification. New York: Holt, Rinehart, \& Winston

Bandura, A. (1973). Aggression: A social learning analysis. Englewood Cliffs, NJ: Prentice Hall

Bandura, A. (1977). Social learning theory. Englewood Cliffs, NJ: Prentice Hall.

Bandura, A., \& Huston, A. C. (1961). Identification as a process of incidental learning. Journal of Abnormal and Social Psychology, 63, 311-318

Bandura, A., Ross, D., \& Ross, S. A. (1961). Transmission of aggression through imitation of aggressive models. Journal of Abnormal and Social Psychology, 63, 575-582.

*Bandura, A., \& Walters, R. H. (1959). Adolescent aggression. New York: Ronald Press.

Bank, L., Forgatch, M. S., Patterson, G. R., \& Fetrow, R. A. (1993). Parenting practices of single mothers: Mediators of negative contextual factors. Journal of Marriage and the Family, 55, 371-384.
*Barnett, D., Kidwell, S. L., \& Leung, K. H. (1998). Parenting and preschooler attachment among low-income urban African-American families. Child Development, 69, 1657-1671.

${ }^{+}$Bates, J. E., Pettit, G. S., \& Dodge, K. A. (1995). Family and child factors in stability and change in children's aggressiveness in elementary school. In J. McCord (Ed.), Coercion and punishment in long-term perspectives (pp. 124-138). New York: Cambridge University Press.

Bates, J. E., Pettit, G. S., Dodge, K. A., \& Ridge, B. (1998). Interaction of temperamental resistance to control and restrictive parenting in the development of externalizing behavior. Developmental Psychology, 34, 982-995.

Baum, C. G., \& Forehand, R. (1981). Long term follow-up assessment of parent training by use of multiple construct measures. Behavior Therapy, 12, 643-652.

Baumrind, D. (1967). Child care practices anteceding three patterns of preschool behavior. Genetic Psychology Monographs, 75, 43-88.

Baumrind, D. (1972). An exploratory study of socialization effects on Black children: Some Black-White comparisons. Child Development, 43, 261-267.

Baumrind, D. (1996a). A blanket injunction against disciplinary use of spanking is not warranted by the data. Pediatrics, 98(4, Pt. 2), 828-831.

Baumrind, D. (1996b). The discipline controversy revisited. Family Relations, 45, 405-415.

Baumrind, D. (1997). Necessary distinctions. Psychological Inquiry, 8, 176-182.

Baumrind, D., \& Black, A. E. (1967). Socialization practices associated with dimensions of competence in preschool boys and girls. Child Development, 38, 291-327.

*Bean, A. W., \& Roberts, M. W. (1981). The effect of time-out release contingencies on changes in child noncompliance. Journal of Abnormal Child Psychology, 9, 95-105.

Becker, W. C. (1964). Consequences of different models of parental discipline. In M. L. Hoffman \& L. W. Hoffman (Eds.), Review of child development research (Vol. 1, pp. 169-208). New York: Sage.

${ }^{+}$Becker, W. C., \& Krug, R. S. (1964). A circumplex model for social behavior in children. Child Development, 35, 371-396.

*Becker, W. C., Peterson, D. R., Luria, Z., Shoemaker, D. J., \& Hellmer, L. A. (1962). Relations of factors derived from parent-interview ratings to behavior problems of five-year-olds. Child Development, 33, 509535 .

Bell, R. Q., \& Chapman, M. (1986). Child effects in studies using experimental or brief longitudinal approaches to socialization. Developmental Psychology, 22, 595-603.

Belsky, J. (1984). The determinants of parenting: A process model. Child Development, 55, 83-96.

Belsky, J. (1993). Etiology of child maltreatment: A developmentalecological analysis. Psychological Bulletin, 114, 413-434.

Belsky, J. (1997). Variation in susceptibility to environmental influence: An evolutionary argument. Psychological Inquiry, 8, 182-186.

Berkowitz, L. (1983). Aversively stimulated aggression: Some parallels and differences in research with animals and humans. American Psychologist, 38, 1135-1144.

Berndt, T. J. (1996). Transitions in friendship and friends' influence. In J. A. Graber, J. Brooks-Gunn, \& A. C. Petersen (Eds.), Transitions through adolescence: Interpersonal domains and context (pp. 57-84). Mahwah, NJ: Erlbaum.

Betancourt, H., \& Lopez, S. R. (1993). The study of culture, ethnicity, and race in American psychology. American Psychologist, 48, 629-637.

Biernat, M., \& Wortman, C. (1991). Sharing of home responsibilities between professionally employed women and their husbands. Journal of Personality and Social Psychology, 8, 423-440.

Bitensky, S. H. (1998). Spare the rod, embrace our humanity: Toward a new legal regime prohibiting corporal punishment of children. University of Michigan Journal of Law Reform, 31, 353-474. 
Bluestone, C., \& Tamis-LeMonda, C. S. (1999). Correlates of parenting styles in predominantly working- and middle-class African American mothers. Journal of Marriage and the Family, 61, 881-893.

Brenner, V., \& Fox, R. A. (1998). Parental discipline and behavior problems in young children. Journal of Genetic Psychology, 159, 251-256.

Brenner, V., Nicholson, B. C., \& Fox, R. A. (1999). Evaluation of a community-based parenting program with the parents of young children. Early Child Development and Care, 148, 1-9.

Bretherton, I., Golby, B., \& Cho, E. (1997). Attachment and the transmission of values. In J. E. Grusec \& L. Kuczynski (Eds.), Parenting and children's internalization of values: A handbook of contemporary theory (pp. 103-134). New York: Wiley.

Brody, G. H., \& Shaffer, D. R. (1982). Contributions of parents and peers to children's moral socialization. Developmental Review, 2, 31-75.

Bronfenbrenner, U. (1958). Socialization and social class through time and space. In E. E. Maccoby, T. M. Newcomb, \& E. L. Hartley (Eds.), Readings in social psychology (pp. 400-425). New York: Holt, Rinehart, \& Winston.

Bronfenbrenner, U. (1977). Toward an experimental ecology of human development. American Psychologist, 32, 513-531.

Bronfenbrenner, U. (1986). Ecology of the family as a context for human development: Research perspectives. Developmental Psychology, 22, 723-742.

Bryan, J. W., \& Freed, F. W. (1982). Corporal punishment: Normative data and sociological and psychological correlates in a community college population. Journal of Youth and Adolescence, 11, 77-87.

Bryk, A. S., \& Raudenbush, S. W. (1992). Hierarchical linear models: Applications and data analysis methods. Newbury Park, CA: Sage.

Bugental, D. B., \& Goodnow, J. J. (1998). Socialization processes. In W. Damon (Series Ed.) \& N. Eisenberg (Vol. Ed.), Handbook of child psychology: Vol. 3. Social, emotional, and personality development (5th ed., pp. 389-462). New York: Wiley.

Burt, C. (1925). The young delinquent. New York: Appleton.

*Burton, R. V., Maccoby, E. E., \& Allinsmith, W. (1961). Antecedents of resistance to temptation in four-year-old children. Child Development, 32, 689-710.

Buss, D. M. (1981). Predicting parent-child interactions from children's activity level. Developmental Psychology, 17, 59-65.

*Caesar, P. L. (1988). Exposure to violence in the families-of-origin among wife-abusers and maritally nonviolent men. Violence and Victims, 3, 49-63.

Caldwell, B. M. (1977). Aggression and hostility in young children. Young Children, 32, 4-13.

Campbell, J. J., \& Frabutt, J. M. (1999, April). Familial antecedents of children's overt and relational aggression. Poster presented at the biennial meeting of the Society for Research in Child Development, Albuquerque, NM.

Carlsmith, J. J., Lepper, M. R., \& Landauer, T. K. (1974). Children's obedience to adult requests: Interactive effects of anxiety arousal and apparent punitiveness of adults. Journal of Personality and Social Psychology, 30, 822-828.

*Carroll, J. C. (1977). The intergenerational transmission of family violence: The long-term effects of aggressive behavior. Aggressive Behavior, 3, 289-299.

*Caselles, C. E., \& Milner, J. S. (2000). Evaluations of child transgressions, disciplinary choices, and expected child compliance in a no-cry and a crying infant condition in physically abusive and comparison mothers. Child Abuse \& Neglect, 24, 477-493.

Catron, T. F., \& Masters, J. C. (1993). Mothers' and children's conceptualizations of corporal punishment. Child Development, 64, 1815-1828.

*Chapman, M., \& Zahn-Waxler, C. (1982). Young children's compliance and noncompliance to parental discipline in a natural setting. International Journal of Behavioral Development, 5, 81-94.

Cherian, V. I. (1994). Self-reports of corporal punishment by Xhosa children from broken and intact families and their academic achievement. Psychological Reports, 74, 867-874.

*Chilamkurti, C., \& Milner, J. S. (1993). Perceptions and evaluations of child transgression and disciplinary techniques in high- and low-risk mothers and their children. Child Development, 64, 1801-1814.

Child Abuse Prevention and Treatment and Adoption Reform Act of 1992, Pub. L. No. 102-295, 42 U.S.C.A. § 5101 et seq (1992).

Cloninger, C. R., Sigvardsson, S., Bohman, M., \& von Knorring, A. (1982). Predisposition to petty criminality in Swedish adoptees. Archives of General Psychiatry, 39, 1242-1247.

Cochran, M., \& Niego, S. (1995). Parenting and social networks. In M. H. Bornstein (Ed.), Handbook of parenting: Vol. 3. Status and social conditions of parenting (pp. 393-418). Mahwah, NJ: Erlbaum.

Cohen, J. (1988). Statistical power analysis for the behavioral sciences (Rev. ed.). New York: Academic Press.

Cohen, P., \& Brook, J. S. (1995). The reciprocal influence of punishment and child behavior disorder. In J. McCord (Ed.), Coercion and punishment in long-term perspectives (pp. 154-164). New York: Cambridge University Press.

Cohen, P., Brook, J. S., Cohen, J., Velez, N., \& Garcia, M. (1990). Common and uncommon pathways to adolescent psychopathology and problem behavior. In L. N. Robins \& M. Rutter (Eds.), Straight and devious pathways from childhood to adulthood (pp. 242-258). New York: Cambridge University Press.

Cohen, S., \& McKay, G. (1984). Social support, stress, and the buffering hypothesis: A theoretical analysis. In A. Baum, S. E. Taylor, \& J. E. Singer (Eds.), Handbook of psychology and health: Vol. 4. Social psychological aspects of health (pp. 253-267). Hillsdale, NJ: Erlbaum.

Coie, J. D., \& Dodge, K. A. (1998). Aggression and antisocial behavior. In W. Damon (Series Ed.) \& N. Eisenberg (Vol. Ed.), Handbook of child psychology: Vol. 3. Social, emotional, and personality development (5th ed., pp. 779-862). New York: Wiley.

Colder, C. R., Lochman, J. E., \& Wells, K. C. (1997). The moderating effects of children's fear and activity level on relations between parenting practices and childhood symptomatology. Journal of Abnormal Child Psychology, 25, 251-263.

Collins, W. A., Maccoby, E. E., Steinberg, L., Hetherington, E. M., \& Bornstein, M. H. (2000). Contemporary research on parenting: The case for nature and nurture. American Psychologist, 55, 218-232.

Conger, R. D., Conger, K. J., Elder, G. H., Jr., Lorenz, F. O., Simons, R. L., \& Whitbeck, L. B. (1992). A family process model of economic hardship and adjustment of early adolescent boys. Child Development, 63, $526-541$.

Conger, R. D., Conger, K. J., Elder, G. H., Jr., Lorenz, F. O., Simons, R. L., \& Whitbeck, L. B. (1993). Family economic stress and adjustment of early adolescent girls. Developmental Psychology, 29, 206-219.

Conger, R. D., \& Elder, G. H., Jr. (Eds.). (1994). Families in troubled times: Adapting to change in rural America. New York: Aldine de Gruyter.

Conger, R. D., Patterson, G. R., \& Ge, X. (1995). It takes two to replicate: A mediational model for the impact of parents' stress on adolescent adjustment. Child Development, 66, 80-97.

Coontz, P. D., \& Martin, J. A. (1988). Understanding violent mothers and fathers: Assessing explanations offered by mothers and fathers of their use of control punishment. In G. T. Hotaling, D. Finkelhor, J. T. Kirkpatrick, \& M. A. Straus (Eds.), Family abuse and it consequences: New directions in research (pp. 77-90). Newbury Park, CA: Sage.

Cooper, H., \& Hedges, L. V. (1994). Potentials and limitations of research synthesis. In H. Cooper \& L. V. Hedges (Eds.), The handbook of research synthesis (pp. 521-529). New York: Russell Sage Foundation.

*Coopersmith, S. (1967). The antecedents of self-esteem. San Fransisco: Freeman.

Council of Europe. (1998, November). Convention for the Protection of Human Rights and Fundamental Freedoms as amended by Protocol 
No. 11. Rome, 4.XI.1950. Retrieved January 15, 2001, from http:// conventions.coe.int/Treaty/EN/cadreprincipal.htm

Cowan, P. A., Powell, D., \& Cowan, C. P. (1998). Parenting interventions: A family systems perspective. In W. Damon (Series Ed.) \& I. E. Sigel \& K. A. Renninger (Vol. Eds.), Handbook of child psychology: Vol. 4. Child psychology in practice (5th ed., pp. 3-72). New York: Wiley.

Crick, N. R., \& Dodge, K. A. (1996). Social information-processing mechanisms in reactive and proactive aggression. Child Development, 67, 993-1002.

Crnic, K. A., Greenberg, M. T., Ragozin, A. S., Robinson, N. M., \& Basham, R. B. (1983). Effects of stress and social support on mothers and premature and full-term infants. Child Development, 54, 209-217.

*Crockenberg, S. (1987). Predictors and correlates of anger toward and punitive control of toddlers by adolescent mothers. Child Development, 58, 964-975.

Crockenberg, S. (1988). Social support and parenting. In W. Fitzgerald, B. Lester, \& M. Yogman (Eds.), Research on support for parents and infants in the postnatal period (pp. 67-92). New York: Ablex.

Crowe, R. R. (1974). An adoption study of antisocial personality. Archives of General Psychiatry, 31, 785-791.

Culp, R. E., Culp, A. M., Dengler, B., \& Maisano, P. C. (1999). First-time young mothers living in rural communities use corporal punishment with their toddlers. Journal of Community Psychology, 27, 503-509.

Dadds, M. R., Sheffield, J. K., \& Holbeck, J. F. (1990). An examination of the differential relationship of marital discord to parents' discipline strategies for boys and girls. Journal of Abnormal Child Psychology, 18, $121-129$.

Darling, N., \& Steinberg, L. (1993). Parenting style as context: An integrative model. Psychological Bulletin, 113, 487-496.

Daro, D., \& Gelles, R. J. (1992). Public attitudes and behaviors with respect to child abuse prevention. Journal of Interpersonal Violence, 7 , $517-531$.

Davidson, H. (1997). The legal aspects of corporal punishment in the home: When does physical discipline cross the line to become child abuse? Children's Legal Rights Journal, 17, 18-29.

Davis, P. W. (1996). Threats of corporal punishment as verbal aggression: A naturalistic study. Child Abuse \& Neglect, 20, 289-304.

*Day, D. E., \& Roberts, M. W. (1983). An analysis of the physical punishment component of a parent-training program. Journal of Abnormal Child Psychology, 11, 141-152.

Day, R. D., Peterson, G. W., \& McCracken, C. (1998). Predicting spanking of younger and older children by mothers and fathers. Journal of Marriage and the Family, 60, 79-94.

Deater-Deckard, K., \& Dodge, K. A. (1997). Externalizing behavior problems and discipline revisited: Nonlinear effects and variation by culture, context, and gender. Psychological Inquiry, 8, 161-175.

*Deater-Deckard, K., Dodge, K. A., Bates, J. A., \& Pettit, G. S. (1996). Physical discipline among African American and European American mothers: Links to children's externalizing behaviors. Developmental Psychology, 32, 1065-1072.

Department of Health. (2000, January 18). Protecting children, supporting parents: A consultation document on the physical punishment of children [Electronic version]. Retrieved February 5, 2000, from http:// 193.32.28.83/pub/docs/doh/childpro.pdf

*DeVet, K. A. (1997). Parent-adolescent relationships, physical disciplinary history, and adjustment in adolescents. Family Process, 36, 311-322.

DiLalla, L. F., \& Gottesman, I. I. (1991). Biological and genetic contributions to violence-Widom's untold tale. Psychological Bulletin, 109, $125-129$.

Dishion, T. J., \& Patterson, G. R. (1992). Age effects in parent training outcome. Behavior Therapy, 23, 719-729.

Dishion, T. J., \& Patterson, G. R. (1999). Model building in developmental psychopathology: A pragmatic approach to understanding and intervention. Journal of Clinical Child Psychology, 28, 502-512.
Dix, T. (1991). The affective organization of parenting: Adaptive and maladaptive processes. Psychological Bulletin, 110, 3-25.

Dix, T. (1992). Parenting on behalf of the child: Empathic goals in the regulation of responsive parenting. In I. E. Sigel, A. McGillicuddyDeLisi, \& J. J. Goodnow (Eds.), Parental belief systems (2nd ed., pp. 319-346). Mahwah, NJ: Erlbaum.

Dix, T., \& Gershoff, E. T. (2001). Measuring parent-child relations. In J. Touliatos, B. Perlmutter, \& G. Holden (Eds.), Second handbook of family measurement techniques (2nd ed., pp. 125-142). Thousand Oaks, CA: Sage.

Dix, T., Gershoff, E. T., \& Miller, P. C. (2001). Child orientation and depressive symptoms in mothers. Unpublished manuscript, University of Texas at Austin.

Dix, T., \& Grusec, J. E. (1983). Parental influence techniques: An attributional analysis. Child Development, 54, 645-652.

Dix, T. H., \& Grusec, J. E. (1985). Parent attribution processes in the socialization of children. In I. E. Sigel (Ed.), Parental belief systems (pp. 201-233). Hillsdale, NJ: Erlbaum.

Dix, T., Reinhold, D. P., \& Zambarano, R. J. (1990). Mothers' judgment in moments of anger. Merrill-Palmer Quarterly, 36, 465-486.

Dix, T., Ruble, D. N., \& Zambarano, R. J. (1989). Mothers' implicit theories of discipline: Child effects, parent effects, and the attribution process. Child Development, 60, 1373-1391.

Dobson, J. C. (1970). Dare to discipline. New York: Bantam Books.

Dobson, J. C. (1996). The new dare to discipline. Wheaton, IL: Tyndale House.

Dodge, K. A. (1980). Social cognition and children's aggressive behavior. Child Development, 51, 162-170.

Dodge, K. A. (1986). A social information processing model of social competence in children. In M. Perlmutter (Ed.), Minnesota Symposium on Child Psychology: Vol. 18. Cognitive perspectives on children's social and behavior development (pp. 77-125). Hillsdale, NJ: Erlbaum.

Dodge, K. A., Bates, J. E., \& Pettit, G. S. (1990, December 21). Mechanisms in the cycle of violence. Science, 250, 1678-1683.

Dodge, K. A., \& Coie, J. D. (1987). Social-information-processing factors in reactive and proactive aggression in children's peer groups. Journal of Personality and Social Psychology, 53, 1146-1158.

${ }^{+}$Dodge, K. A., Pettit, G. S., \& Bates, J. E. (1994). Socialization mediators of the relation between socioeconomic status and child conduct problems. Child Development, 65, 649-665.

Dodge, K. A., Pettit, G. S., Bates, J. E., \& Valente, E. (1995). Social information processing patterns partially mediate the effect of early abuse on later conduct problems. Journal of Abnormal Psychology, 104, 632-643.

Dodge, K. A., Pettit, G. S., McClaskey, C. L., \& Brown, M. M. (1986). Social competence in children. Monographs of the Society for Research in Child Development, 51(2, Serial No. 213).

Dodge, K. A., \& Somberg, D. R. (1987). Hostile attributional biases among aggressive boys are exacerbated under conditions of threats to the self. Child Development, 58, 213-224.

Dollard, J., Miller, N. E., Doob, L. W., Mowrer, O. H., \& Sears, R. R. (1939). Frustration and aggression. New Haven, CT: Yale University Press.

Donaldson, C. (Ed.). (1997). Corporal punishment [Special issue]. Children's Legal Rights Journal, 17(4).

Dornbusch, S. M., Ritter, P. L., Leiderman, P. H., Roberts, D. F., \& Fraleigh, M. J. (1987). The relation of parenting style to adolescent academic school performance. Child Development, 58, 1244-1257.

Downs, W. R., Miller, B. A., Testa, M., \& Parek, P. (1992). Long-term effects of parent-to-child violence for women. Journal of Interpersonal Violence, 7, 365-382.

Dumas, J. E., \& Wekerle, C. (1995). Maternal reports of child behavior problems and personal distress as predictors of dysfunctional parenting. Development and Psychopathology, 7, 465-479. 
*DuRant, R. H., Cadenhead, C., Pendergrast, R. A., Slavens, G., \& Linder, C. W. (1994). Factors associated with the use of violence among urban Black adolescents. American Journal of Public Health, 84, 612-617.

Durrant, J. E. (1999a). Evaluating the success of Sweden's corporal punishment ban. Child Abuse and Neglect, 23, 435-448.

Durrant, J. E. (1999b). Trends in youth crime and well-being since the abolition of corporal punishment in Sweden. Youth and Society, 31, 437-455.

Duvall, D., \& Booth, A. (1979). Social class, stress, and physical punishment. International Review of Modern Sociology, 9, 103-117.

Eddy, J. M., Dishion, T. J., \& Stoolmiller, M. (1998). The analysis of intervention change in children and families: Methodological and conceptual issues embedded in intervention studies. Journal of Abnormal Child Psychology, 26, 53-69.

Egeland, B. (1991). A longitudinal study of high-risk families: Issues and findings. In R. H. Starr Jr. \& D. A. Wolfe (Eds.), The effects of child abuse and neglect: Issues and research (pp. 33-56). New York: Guilford Press.

Eisenberg, N., Fabes, R. A., Bustamante, D., Mathy, R. M., Miller, P. A., \& Lindholm, E. (1988). Differentiation of vicariously induced emotional reactions in children. Developmental Psychology, 24, 237-246.

Elder, G. H., Jr., \& Caspi, A. (1988). Economic stress in lives: Developmental perspectives. Journal of Social Issues, 44, 25-45.

Elder, G. H., Jr., Nguyen, T. V., \& Caspi, A. (1985). Linking family hardship to children's lives. Child Development, 56, 361-375.

Ellison, C. G., Bartkowski, J. P., \& Segal, M. L. (1996). Conservative Protestantism and the parental use of corporal punishment. Social Forces, 74, 1003-1028.

Ellison, C. G., Musick, M., \& Holden, G. W. (1999, November). The effects of corporal punishment on young children: Are they less harmful for Conservative Protestants? Paper presented at the annual meeting of the Society for the Scientific Study of Religion, Boston, MA.

Ellison, C. G., \& Sherkat, D. E. (1993). Conservative Protestantism and support for corporal punishment. American Sociological Review, 58, 131-144.

Ellison, C. G., Thompson, T. E., \& Segal, M. L. (1995). Race differences in the parental use of corporal punishment. Unpublished manuscript, University of Texas at Austin.

*Engfer, A., \& Schneewind, K. A. (1982). Causes and consequences of harsh parental punishment. Child Abuse \& Neglect, 6, 129-139.

EPOCH-USA. (2000). Legal reforms: Corporal punishment of children in the family. Retrieved June 30, 2001, from http://www.stophitting.com/ legalReform.php

Erlanger, H. S. (1974). Social class and corporal punishment in childrearing: A reassessment. American Sociological Review, 39, 68-85.

*Eron, L. D. (1982). Parent-child interaction, television violence, and aggression of children. American Psychologist, 37, 197-211.

Eron, L. D., Huesmann, L. R., Dubow, E., Romanoff, R., \& Yarmel, P. W. (1987). Aggression and its correlates over 22 years. In D. Crowell, I. M. Evans, \& C. R. O'Donnell (Eds.), Childhood aggression and violence (pp. 249-262). New York: Plenum Press.

*Eron, L. D., Huesmann, L. R., \& Zelli, A. (1991). The role of parental variables in the learning of aggression. In D. J. Pepler \& K. H. Rubin (Eds.), The development and treatment of childhood aggression (pp. 169-188). Hillsdale, NJ: Erlbaum.

*Eron, L. D., Walder, L. O., Huesmann, L. R., \& Lefkowitz, M. M. (1974). The convergence of laboratory and field studies of the development of aggression. In J. De Wit \& W. W. Hartup (Eds.), Determinants and origins of aggressive behavior (pp. 348-380). The Hague, the Netherlands: Mouton.

${ }^{+}$Eron, L. D., Walder, L. O., \& Lefkowitz, M. M. (1971). Learning of aggression in children. Boston: Little, Brown.

Escovar, L. A., \& Escovar, P. L. (1985). Retrospective perception of parental child-rearing practices in three culturally different college groups. International Journal of Intercultural Relations, 9, 31-49.

Fairchild, L., \& Erwin, W. M. (1977). Physical punishment by parent figures as a model of aggressive behavior in children. Journal of Genetic Psychology, 130, 279-284.

Feshbach, N. D. (1975). The effects of violence in childhood. Journal of Clinical Child Psychology, 2, 28-31.

Feshbach, S. (1970). Aggression. In P. H. Mussen (Ed.), Carmichael's manual of child psychology (Vol. 2, 3rd ed., pp. 159-259). New York: Wiley.

Fisher, C. B., Higgins-D’Alessandro, A., Rau, J. B., Kuther, T. L., \& Belanger, S. (1996). Referring and reporting research participants at risk: Views from urban adolescents. Child Development, 67, 2086-2100.

Flynn, C. P. (1994). Regional differences in attitudes toward corporal punishment. Journal of Marriage and the Family, 56, 314-324.

Flynn, C. P. (1998). To spank or not to spank: The effect of situation and age of child on support for corporal punishment. Journal of Family Violence, 13, 21-37.

*Flynn, C. P. (1999). Exploring the link between corporal punishment and children's cruelty to animals. Journal of Marriage and the Family, 61, 971-981.

Forgatch, M. S., Patterson, G. R., \& Skinner, M. (1988). A mediational model for the effect of divorce in antisocial behavior in boys. In E. M. Hetherington \& J. D. Arasteh (Eds.), Impact of divorce, single parenting, and step-parenting on children (pp. 135-154). Mahwah, NJ: Erlbaum.

*Frick, P. J., Christian, R. E., \& Wootton, J. M. (1999). Age trends in the association between parenting practices and conduct problems. Behavior Modification, 23, 106-128.

Friedman, S. B., \& Schonberg, S. K. (Eds.). (1996). The short- and long-term consequences of corporal punishment [Supplement]. Pediatrics, 98(4, Pt. 2).

Frijda, N. H. (1986). The emotions. New York: Cambridge University Press.

Frude, N., \& Gross, A. (1979). Parental anger: A general population survey. Child Abuse \& Neglect, 3, 331-333.

Fry, D. P. (1993). The intergenerational transmission of disciplinary practices and approaches to conflict. Human Organization, 52, 176-185.

Garbarino, J. (1977). The human ecology of child maltreatment: A conceptual model for research. Journal of Marriage and the Family, 39, 721-735.

Garbarino, J., \& Kostelny, K. (1995). Parenting and public policy. In M. H. Bornstein (Ed.), Handbook of parenting: Vol. 3. Status and social conditions of parenting (pp. 419-436). Mahwah, NJ: Erlbaum.

Garbarino, J., Kostelny, K., \& Barry, F. (1997). Value transmission in an ecological context: The high-risk neighborhood. In J. E. Grusec \& L. Kuczynski (Eds.), Parenting and children's internalization of values: A handbook of contemporary theory (pp. 307-332). New York: Wiley.

Garcia Coll, C. T. (1990). Developmental construct of minority infants: A process-oriented look into our beginnings. Child Development, 61, 270 289.

Garcia Coll, C. T., Meyer, E. C., \& Brillon, L. (1995). Ethnic and minority parenting. In M. H. Bornstein (Ed.), Handbook of parenting: Vol. 2. Biology and ecology of parenting (pp. 189-209). Mahwah, NJ: Erlbaum.

Ge, X., Conger, R. D., Cadoret, R. J., Neidterhiser, J. M., Yates, W., Troughton, E., \& Steward, M. A. (1996). The developmental interface between nature and nurture: A mutual influence model of child antisocial behavior and parent behavior. Developmental Psychology, 32, $574-$ 589.

Gelles, R. J. (1979). Family violence. Beverly Hills, CA: Sage.

Gelles, R. J., \& Straus, M. A. (1988). Intimate violence. New York: Simon \& Schuster.

Gerris, J. R., Deković, M., \& Janssens, J. M. A. M. (1997). The relationship between social class and childrearing behaviors: Parents' perspective 
taking and value orientations. Journal of Marriage and the Family, 59, $834-847$.

Gershoff, E. T., \& Dix, T. (2001). Children's compliance and defiance during sequences of mother-child interaction: Understanding when and with whom particular parental influence techniques work. Manuscript submitted for publication.

Gershoff, E. T., Miller, P. C., \& Holden, G. W. (1999). Parenting influences from the pulpit: Religious affiliation as a determinant of parental corporal punishment. Journal of Family Psychology, 13, 307-320.

Gil, D. G. (1973). Violence against children: Physical abuse in the United States. Cambridge, MA: Harvard University Press.

Giles-Sims, J., Straus, M. A., \& Sugarman, D. B. (1995). Child, maternal, and family characteristics associated with spanking. Family Relations, 44, 170-176.

*Glueck, S., \& Glueck, E. (1950). Unraveling juvenile delinquency. Cambridge, MA: Harvard University Press.

Glueck, S., \& Glueck, E. (1964). Ventures in criminology. Cambridge, MA: Harvard University Press.

Goldstein, L. H., Diener, M. L., \& Mangelsdorf, S. C. (1996). Maternal characteristics and social support across the transition to motherhood: Associations with maternal behavior. Journal of Family Psychology, 10, $60-71$.

Goode, W. J. (1971). Force and violence in the family. Journal of Marriage and the Family, 33, 624-636.

*Goodman, S. H., Hoven, C. W., Narrow, W. E., Cohen, P., Fielding, B., Alegria, M., et al. (1998). Measurement of risk for mental disorders and competence in a psychiatric epidemiologic community survey: The National Institute of Mental Health Methods for the Epidemiology of Child and Adolescent Mental Disorders (MECA) study. Social Psychiatry and Psychiatric Epidemiology, 33, 162-173.

Goodnow, J. J., \& Collins, W. A. (1990). Development according to parents: The nature, sources, and consequences of parents' ideas. Hillsdale, NJ: Erlbaum.

*Gordon, J. E., \& Smith, E. (1965). Children's aggression, parental attitudes, and the effects of an affiliation-arousing story. Journal of Personality and Social Psychology, 1, 654-659.

Gottfredson, M. R., \& Hirschi, T. (1990). A general theory of crime. Stanford, CA: Stanford University Press.

Gottfredson, M. R., \& Hirschi, T. (1994). A general theory of adolescent problem behavior: Problems and prospects. In R. D. Ketterlinus \& M. E. Lamb (Eds.), Adolescent problem behaviors: Issues and research (pp. 41-56). Mahwah, NJ: Erlbaum.

Gottfredson, M. R., \& Hirschi, T. (1995). A control theory interpretation of psychological research on aggression. In R. B. Felson \& J. T. Tedeschi (Eds.), Aggression and violence: Social interactionist perspectives (pp. 47-68). Washington, DC: American Psychological Association.

Gottman, J. M., \& Levenson, R. W. (1985). A valid procedure for obtaining self-report of affect in marital interaction. Journal of Consulting and Clinical Psychology, 53, 151-160.

*Gove, W. R., \& Crutchfield, R. D. (1982). The family and juvenile delinquency. Sociological Quarterly, 23, 301-319.

Graziano, A. M. (1994). Why we should study subabusive violence against children. Journal of Interpersonal Violence, 9, 412-419.

Greenberger, E., O’Neil, R., \& Nagel, S. K. (1994). Linking workplace and homeplace: Relations between the nature of adults' work and their parenting behaviors. Developmental Psychology, 30, 990-1002.

Greenfield, P. M., \& Suzuki, L. K. (1998). Culture and human development: Implications for parenting, education, pediatrics, and mental health. In W. Damon (Series Ed.) \& I. E. Sigel \& K. A. Renninger (Vol. Eds.), Handbook of child psychology: Vol. 4. Child psychology in practice (5th ed., pp. 1059-1109). New York: Wiley.

Greenwald, R. L., Bank, L., Reid, J. B., \& Knutson, J. F. (1997). A discipline-mediated model of excessively punitive parenting. Aggressive Behavior, 23, 259-280.
Greven, P. (1991). Spare the child. New York: Knopf.

*Grinder, R. E. (1962). Parental child-rearing practices, conscience, and resistance to temptation of sixth-grade children. Child Development, 33, 803-820.

Grolnick, W. S., Deci, E. L., \& Ryan, R. M. (1997). Internalization within the family: The self-determination theory perspective. In J. E. Grusec \& L. Kuczynski (Eds.), Parenting and children's internalization of values: A handbook of contemporary theory (pp. 135-161). New York: Wiley.

Grusec, J. E. (1983). The internalization of altruistic dispositions: A cognitive analysis. In E. T. Higgins, D. N. Ruble, \& W. W. Hartup (Eds.), Social cognition and social development (pp. 275-293). New York: Cambridge University Press.

Grusec, J. E. (1997). A history of research on parenting strategies and children's internalization of values. In J. E. Grusec \& L. Kuczynski (Eds.), Parenting and children's internalization of values: A handbook of contemporary theory (pp. 3-22). New York: Wiley.

Grusec, J. E., Dix, T., \& Mills, R. (1982). The effects of type, severity, and victim of children's transgressions on maternal discipline. Canadian Journal of Behavioral Sciences, 14, 276-289.

Grusec, J. E., \& Goodnow, J. J. (1994). Impact of parental discipline methods on the child's internalization of values: A reconceptualization of current points of view. Developmental Psychology, 30, 4-19.

Grusec, J. E., \& Kuczynski, L. (1980). Direction of effect in socialization: A comparison of the parents' versus child's behavior as determinants of disciplinary techniques. Developmental Psychology, 16, 1-9.

Grusec, J. E., Rudy, D., \& Martini, T. (1997). Parenting cognitions and child constructs: An overview and implications for children's internalization of values. In J. E. Grusec \& L. Kuczynski (Eds.), Parenting and children's internalization of values: A handbook of contemporary theory (pp. 259-282). New York: Wiley.

Guerra, N. G., Nucci, L., \& Huesmann, L. R. (1994). Moral cognition and childhood aggression. In L. R. Huesmann (Ed.), Aggressive behavior: Current perspectives (pp. 13-33). New York: Plenum Press.

*Gunnoe, M. L., \& Mariner, C. L. (1997). Toward a developmentalcontextual model of the effects of parental spanking on children's aggression. Archives of Pediatric and Adolescent Medicine, 151, 768775 .

*Hall, E. C. (1995). A correlational analysis of parental conflict resolution practices and 4- and 5-year-old children's interpersonal problem solving skills and verbal abilities in a preschool setting (Doctoral dissertation, University of San Francisco, 1994). Dissertation Abstracts International, 55(12), 3785B.

*Hällström, T. (1987). Major depression, parental mental disorder, and early family relationships. Acta Psychiatrica Scandinavica, 75, 259263.

*Harvey, O. J., Gore, E. J., Frank, H., \& Batres, A. R. (1997). Relationship of shame and guilt to gender and parenting practices. Personality and Individual Differences, 23, 135-146.

Hashima, P. Y., \& Amato, P. R. (1994). Poverty, social support, and parental behavior. Child Development, 65, 394-403.

Hastings, P. D., \& Grusec, J. E. (1998). Parenting goals as organizers of responses to parent-child disagreement. Developmental Psychology, 34, 465-479.

Hedges, L. V. (1981). Distribution theory for Glass's estimator effect size and related estimators. Journal of Educational Statistics, 6, 107-128.

Hedges, L. V. (1982). Fitting categorical models to effect sizes from a series of experiments. Journal of Educational Statistics, 7, 119-137.

Hedges, L. V., \& Olkin, I. (1985). Statistical methods for meta-analysis. New York: Academic Press.

Heffer, R. W., \& Kelley, M. L. (1987). Mothers' acceptance of behavioral interventions for children: The influence of parent race and income. Behavior Therapy, 2, 153-163.

*Hemenway, D., Solnick, S., \& Carter, J. (1994). Child-rearing violence. Child Abuse \& Neglect, 18, 1011-1020. 
Herrenkohl, E. C., Herrenkohl, R. C., \& Toedter, L. J. (1983). Perspectives on the intergenerational transmission of abuse. In D. Finkelhor, R. J. Gelles, G. T. Hotaling, \& M. A. Straus (Eds.), The dark side of families: Current family violence research (pp. 305-316). Newbury Park, CA: Sage.

*Herzberger, S. D., Potts, D. A., \& Dillon, M. (1981). Abusive and nonabusive parental treatment from the child's perspective. Journal of Consulting and Clinical Psychology, 49, 81-90.

Hetherington, E. M., Cox, M., \& Cox, R. (1982). Effects of divorce on parents and children. In M. E. Lamb (Ed.), Nontraditional families: Parenting and child development (pp. 233-288). Mahwah, NJ: Erlbaum.

Hetherington, E. M., Stouwie, R. J., \& Ridberg, E. H. (1971). Patterns of family interaction and child-rearing attitudes related to three dimensions of juvenile delinquency. Journal of Abnormal Psychology, 78, 160-176.

Hirschi, T. (1969). Causes of delinquency. Berkeley, CA: University of California Press.

Hoff-Ginsberg, E., \& Tardif, T. (1995). Socioeconomic status and parenting. In M. H. Bornstein (Ed.), Handbook of parenting: Vol. 2. Biology and ecology of parenting (pp. 161-188). Mahwah, NJ: Erlbaum.

Hoffman, M. L. (1983). Affective and cognitive processes in moral internalization. In E. T. Higgins, D. N. Ruble, \& W. W. Hartup (Eds.), Social cognition and social development (pp. 236-274). New York: Cambridge University Press.

Holden, G. W., Coleman, S. M., \& Schmidt, K. L. (1995). Why 3-year-old children get spanked: Parent and child determinants as reported by college-educated mothers. Merrill-Palmer Quarterly, 41, 431-452.

Holden, G. W., \& Miller, P. C. (1997, April). Cognitive versus emotional parenting: Alignments between child-rearing cognitions, emotions, and reported behavior. In C. Tamis-LeMonda (Chair), The cognitive and affective sides of parenting: The roles of parenting views, emotions, and expectations in parenting interactions and children's development. Paper presented at the biennial meeting of the Society for Research in Child Development, Washington, DC.

Holden, G. W., \& Miller, P. C. (1999). Enduring and different: A metaanalysis of the similarity in parents' child rearing. Psychological Bulletin, 125, 223-254.

Holden, G. W., Miller, P. C., \& Harris, S. D. (1999). The instrumental side of corporal punishment: Parents' reported practices and outcome expectancies. Journal of Marriage and the Family, 61, 908-919.

Holden, G. W., Thompson, E. E., Zambarano, R. J., \& Marshall, L. A. (1997). Child effects as a source of change in maternal attitudes toward corporal punishment. Journal of Social and Personal Relationships, 14, $481-490$.

*Holmes, S. J., \& Robins, L. N. (1987). The influence of childhood disciplinary experience on the development of alcoholism and depression. Journal of Child Psychology and Psychiatry, 28, 399-415.

${ }^{+}$Holmes, S. J., \& Robins, L. N. (1988). The role of parental disciplinary practices in the development of depression and alcoholism. Psychiatry, 51, 24-35.

Huesmann, L. R. (1997). No simple relation. Psychological Inquiry, 8, 200-204.

Hunter, J. E., \& Schmidt, F. L. (1990). Methods of meta-analysis. Newbury Park, CA: Sage.

Huston, A. C. (1983). Sex-typing. In P. H. Mussen (Series Ed.) \& E. M. Hetherington (Vol. Ed.), Handbook of child psychology: Vol. 4. Socialization, personality, and social development (pp. 388-467). New York: Wiley.

Hutchings, B., \& Mednick, S. A. (1975). Registered criminality in the adoptive and biological parents of registered male criminal adoptees. In R. R. Fieve, D. Rosenthal, \& H. Brill (Eds.), Genetic research in psychiatry (pp. 105-116). Baltimore: Johns Hopkins University Press.

Hyman, I. A. (1995). Corporal punishment, psychological maltreatment, violence, and punitiveness in America: Research, advocacy, and public policy. Applied and Preventive Psychology, 4, 113-130.
Hyman, I. A. (1997). The case against spanking: How to discipline your child without hitting. San Fransisco: Jossey-Bass.

Ingraham v. Wright, 430 U.S. 651, 51 L.Ed.2d 711 (1977).

Izard, C. E. (1991). The psychology of emotions. New York: Plenum Press.

Jackson, A. P., Gyamfi, P., Brooks-Gunn, J., \& Blake, M. (1998). Employment status, psychological well-being, social support, and physical discipline practices of single Black mothers. Journal of Marriage and the Family, 60, 894-902.

Jackson, S., Thompson, R. A., Christiansen, E. H., Colman, R. A., Wyatt, J., Buckendahl, C. W., et al. (1999). Predicting abuse-prone parental attitudes and discipline practices in a nationally representative sample. Child Abuse \& Neglect, 23, 15-29.

Jennings, K. D., Stagg, V., \& Connors, R. E. (1991). Social networks and mothers' interactions with their preschool children. Child Development, 62, 966-978.

*Johannesson, I. (1974). Aggressive behavior among school children related to maternal practices in early childhood. In J. DeWit \& W. W. Hartup (Eds.), Determinants and origins of aggressive behavior (pp. 347-425). The Hague, the Netherlands: Mouton.

Johnson, B. T. (1993). DSTAT: Software for the meta-analytic review of research literatures (Rev. ed.) [Computer software]. Hillsdale, NJ: Erlbaum.

Jones, S. M. (2000). Youth exposure to community violence: Neighborhood and familial risk. Unpublished predissertation, Yale University.

*Joubert, C. E. (1991). Self-esteem and social desirability in relation to college students' retrospective perceptions of parental fairness and disciplinary practices. Psychological Reports, 69, 115-120.

Kadushin, A., \& Martin, J. A. (1981). Child abuse: An interactional event. New York: Columbia University Press.

*Kahn, M. W., \& Fua, C. (1995). Children of South Sea island immigrants to Australia: Factors associated with adjustment problems. International Journal of Social Psychiatry, 41, 55-73.

*Kandel, D. B. (1990). Parenting styles, drug use, and children's adjustment in families of young adults. Journal of Marriage and the Family, 52, 183-196.

Kandel, D. B., \& Wu, P. (1995). Disentangling mother-child effects in the development of antisocial behavior. In J. McCord (Ed.), Coercion and punishment in long-term perspectives (pp. 106-123). New York: Cambridge University Press.

Kazdin, A. E. (1997). Parent management training: Evidence, constructs, and issues. Journal of the Academy of Child and Adolescent Psychiatry, 36, 1349-1356.

Kelder, L. R., McNamara, J. R., Carlson, B., \& Lynn, S. J. (1991). Perceptions of physical punishment: The relation to childhood and adolescent experiences. Journal of Interpersonal Violence, 6, 432-445.

Kelley, M. L., Power, T. G., \& Wimbush, D. D. (1992). Determinants of disciplinary practices in low-income Black mothers. Child Development, 63, 573-582.

Kelley, M. L., Sanchez-Hucles, J., \& Walker, R. R. (1993). Correlates of disciplinary practices in working-to-middle-class African-American mothers. Merrill-Palmer Quarterly, 39, 252-264.

Knight, G. P., Fabes, R. A., \& Higgins, D. A. (1996). Concerns about drawing causal inferences from meta-analyses: An example in the study of gender differences in aggression. Psychological Bulletin, 119, 410421.

Knight, G. P., Kagan, S., \& Buriel, R. (1982). Perceived parental practices and prosocial development. Journal of Genetic Psychology, 141, 57-65.

Kochanska, G. (1991). Socialization and temperament in the development of guilt and conscience. Child Development, 62, 1379-1392.

Kochanska, G. (1993). Toward a synthesis of parental socialization and child temperament in early development of conscience. Child Development, 64, 325-347.

Kochanska, G. (1994). Beyond cognition: Expanding the search for the 
early roots of internalization and conscience. Developmental Psychology, 30, 20-22.

Kochanska, G. (1995). Children's temperament, mothers' discipline, and security of attachment: Multiple pathways to emerging internalization. Child Development, 66, 597-615.

Kochanska, G. (1997a). Multiple pathways to conscience for children with different temperaments: From toddlerhood to age 5. Developmental Psychology, 33, 228-240.

Kochanska, G. (1997b). Mutually responsive orientation between mothers and their young children: Implications for early socialization. Child Development, 68, 94-112.

Kochanska, G., \& Thompson, R. A. (1997). The emergence and development of conscience in toddlerhood and early childhood. In J. E. Grusec \& L. Kuczynski (Eds.), Parenting and children's internalization of values: A handbook of contemporary theory (pp. 53-77). New York: Wiley.

Kohlberg, L. (1969). Stage and sequence: The cognitive-developmental approach to socialization. In D. A. Goslin (Ed.), Handbook of socialization theory and research (pp. 347-480). Chicago: Rand McNally.

Kohn, M. L. (1977). Class and conformity: A study in values (2nd ed.). Chicago: University of Chicago Press.

Kuczynski, L. (1984). Socialization goals and mother-child interaction: Strategies for long-term and short-term compliance. Developmental Psychology, 20, 1061-1073.

Kuczynski, L., \& Hildebrandt, N. (1997). Models of conformity and resistance in socialization theory. In J. E. Grusec \& L. Kuczynski (Eds.), Parenting and children's internalization of values: A handbook of contemporary theory (pp. 227-256). New York: Wiley.

Kuczynski, L., Marshall, S., \& Schell, K. (1997). Value socialization in a bidirectional context. In J. E. Grusec \& L. Kuczynski (Eds.), Parenting and children's internalization of values: A handbook of contemporary theory (pp. 23-49). New York: Wiley.

*Lahey, B. B., Conger, R. D., Atkeson, B. M., \& Treiber, F. A. (1984). Parenting behavior and emotional status of abusive mothers. Journal of Consulting and Clinical Psychology, 52, 1062-1071.

Larzelere, R. E. (1986). Moderate spanking: Model or deterrent of children's aggression in the family? Journal of Family Violence, 1, 27-36.

Larzelere, R. E. (1996). A review of the outcomes of parental use of nonabusive or customary physical punishment. Pediatrics, 98(4, Pt. 2), $824-828$

Larzelere, R. E. (2000). Child outcomes of non-abusive and customary physical punishment by parents: An updated literature review. Unpublished manuscript, University of Nebraska Medical Center, Omaha, and Father Flanagan's Boys' Home, Boys Town, NE.

*Larzelere, R. E., Klein, M., Schumm, W. R., \& Alibrando, S. A., Jr. (1989). Relations of spanking and other parenting characteristics to self-esteem and perceived fairness of parental discipline. Psychological Reports, 64, 1140-1142.

Larzelere, R. E., Kuhn, B. R., \& Johnson, B. (2000). The intervention selection bias. Unpublished manuscript, University of Nebraska Medical Center, Omaha, and Father Flanagan's Boys' Home, Boys Town, NE.

*Larzelere, R. E., \& Merenda, J. A. (1994). The effectiveness of parental discipline for toddler misbehavior at different levels of child distress. Family Relations, 43, 480-488.

Larzelere, R. E., Sather, P. R., Schneider, W. N., Larson, D. B., \& Pike, P. L. (1998). Punishment enhances reasoning's effectiveness as a disciplinary response to toddlers. Journal of Marriage and the Family, 60, $388-403$.

${ }^{+}$Larzelere, R. E., Schneider, W. N., Larson, D. B., \& Pike, P. L. (1996). The effects of discipline responses in delaying toddler misbehavior recurrences. Child and Family Behavior Therapy, 18, 35-57.

Lasky, M. R. (1993). Family genesis of aggression. Psychiatric Annals, 23, 494-499.

Laub, J. H., \& Sampson, R. J. (1995). The long-term effect of punitive discipline. In J. McCord (Ed.), Coercion and punishment in long-term perspectives (pp. 247-258). New York: Cambridge University Press.

*LaVoie, J. C. (1973). Punishment and adolescent self-control. Developmental Psychology, 8, 16-24.

Lay, K., Waters, E., \& Park, K. A. (1989). Maternal responsiveness and child compliance: The role of mood as a mediator. Child Development, 60, 1405-1411.

Lazarus, R. S. (1991). Emotions and adaptation. New York: Oxford University Press.

Lee, C. L., \& Bates, J. E. (1985). Mother-child interaction at age two years and perceived difficult temperament. Child Development, 56, 13141325.

Lefkowitz, M. M., Eron, L. D., Walder, L. O., \& Huesmann, L. R. (1977). Growing up to be violent: A longitudinal study of the development of aggression. New York: Pergamon Press.

*Lefkowitz, M. M., Walder, L. O., \& Eron, L. D. (1963). Punishment, identification, and aggression. Merrill-Palmer Quarterly, 9, 1159-1174.

Lepper, M. R. (1973). Dissonance, self-perception, and honesty in children. Journal of Personality and Social Psychology, 25, 65-74.

Lepper, M. R. (1983). Social control processes and the internalization of social values: An attributional perspective. In E. T. Higgins, D. N. Ruble, \& W. W. Hartup (Eds.), Social cognition and social development (pp. 294-330). New York: Cambridge University Press.

*Lester, D. (1991). Physical abuse and physical punishment as precursors of suicidal behavior. Stress Medicine, 7, 255-256.

*Levin, H., \& Sears, R. R. (1956). Identification with parents as a determinant of doll play aggression. Child Development, 27, 135-153.

Lewis, C. C. (1981). The effects of parental firm control: A reinterpretation of findings. Psychological Bulletin, 90, 547-563.

Light, R. J., \& Pillemer, D. B. (1984). Summing up: The science of reviewing research. Cambridge, MA: Harvard University Press.

Loeber, R., Drinkwater, M., Yin, Y., Anderson, S. J., Schmidt, L. C., \& Crawford, A. (2000). Stability of family interaction from ages 6 to 18 . Journal of Abnormal Child Psychology, 28, 353-369.

Lohrmann-O'Rourke, S., \& Zirkel, P. A. (1998). The case law on aversive interventions for students with disabilities. Exceptional Children, 65, $101-123$.

Londerville, S., \& Main, M. (1981). Security of attachment, compliance, and maternal training methods in the second year of life. Developmental Psychology, 17, 289-299.

Luster, T., Rhoades, K., \& Haas, B. (1989). The relation between parental values and parenting behavior: A test of the Kohn hypothesis. Journal of Marriage and the Family, 51, 139-147.

Lynch, D. L., Stern, A. E., Oates, R. K., \& O'Toole, B. I. (1993). Who participates in child sexual abuse research? Journal of Child Psychology and Psychiatry, 34, 935-944.

${ }^{+}$Lytton, H. (1977). Correlates of compliance and the rudiments of conscience in two-year-old boys. Canadian Journal of Behavioral Science, 9, 242-251.

Lytton, H. (1997). Physical punishment is a problem, whether conduct disorder is endogenous or not. Psychological Inquiry, 8, 211-214.

Lytton, H., \& Romney, D. M. (1991). Parents' differential socialization of boys and girls: A meta-analysis. Psychological Bulletin, 109, 267-296.

*Lytton, H., \& Zwirner, W. (1975). Compliance and its controlling stimuli observed in a natural setting. Developmental Psychology, 11, 769-779.

Maccoby, E. E. (1980). Social development: Psychological growth and the parent-child relationship. New York: Harcourt Brace Jovanovich.

Maccoby, E. E., \& Jacklin, C. N. (1974). The psychology of sex differences. Stanford, CA: Stanford University Press.

Maccoby, E. E., \& Martin, J. A. (1983). Socialization in the context of the family: Parent-child interaction. In P. H. Mussen (Series Ed.) \& E. M. Hetherington (Vol. Ed.), Handbook of child psychology: Vol. 4. Socialization, personality, and social development (pp. 1-101). New York: Wiley. 
*MacKinnon, D. W. (1938). Violation of prohibitions. In H. A. Murray (Ed.), Explorations in personality (pp. 491-501). New York: Oxford University Press.

MacKinnon-Lewis, C., Volling, B. L., Lamb, M. E., Dechman, K., Rabiner, D., \& Curtner, M. E. (1994). A cross-contextual analysis of boys' social competence: From family to school. Developmental Psychology, 30, 325-333.

*Magai, C., Distel, N., \& Liker, R. (1995). Emotion socialization, attachment, and patterns of adult emotional traits. Cognition and Emotion, 9, 461-481.

*Mahoney, A., Donnelly, W. O., Lewis, T., \& Maynard, C. (2000). Mother and father self-reports of corporal punishment and severe physical aggression toward clinic-referred youth. Journal of Clinical Child Psychology, 29, 266-281.

Margolin, G., \& Patterson, G. R. (1975). Differential consequences provided by mothers and fathers for their sons and daughters. Developmental Psychology, 11, 537-538.

Mason, C. A., Cauce, A. M., Gonzalez, N., \& Hiraga, Y. (1996). Neither too sweet nor too sour: Problem peers, maternal control, and problem behavior in African American adolescents. Child Development, 67, 2115-2130.

Mason, M. A., \& Gambrill, E. (Eds.). (1994). Debating children's lives: Current controversies on children and adolescents. Thousand Oaks, CA: Sage.

*McCabe, K. M., Clark, R., \& Barnett, D. (1999). Family protective factors among urban African American youth. Journal of Clinical Child Psychology, 28, 137-150.

McCord, J. (1979). Some child-rearing antecedents of criminal behavior in adult men. Journal of Personality and Social Psychology, 37, 14771486 .

*McCord, J. (1988a). Parental aggressiveness and physical punishment in long-term perspective. In G. T. Hotaling, D. Finkelhor, J. T. Kirkpatrick, \& M. A. Straus (Eds.), Family abuse and its consequences: New directions in research (pp. 91-98). Newbury Park, CA: Sage.

${ }^{+}$McCord, J. (1988b). Parental behavior in the cycle of aggression. Psychiatry, 51, 14-23.

*McCord, J. (1991). Questioning the value of punishment. Social Problems, 38, 167-179.

McCord, J. (1997). On discipline. Psychological Inquiry, 8, 215-217.

McCord, W., \& McCord, J. (1959). Origins of crime. New York: Columbia University Press.

McCord, W., McCord, J., \& Howard, A. (1961). Familial correlates of aggression in nondelinquent male children. Journal of Abnormal and Social Psychology, 62, 79-93.

*McCranie, E. W., \& Simpson, M. E. (1986). Parental child-rearing antecedents of Type A behavior. Personality and Social Psychology Bulletin, 12, 493-501.

McLeod, J. D., Kruttschnitt, C., \& Dornfeld, M. (1994). Does parenting explain the effects of structural conditions on children's antisocial behavior? A comparison of Blacks and Whites. Social Forces, 73, 575604

*McLeod, J. D., \& Shanahan, M. J. (1993). Poverty, parenting, and children's mental health. American Sociological Review, 58, 351-366.

McLoyd, V. C. (1990). The impact of economic hardship on Black families and children: Psychological distress, parenting, and socioemotional development. Child Development, 61, 311-346.

McLoyd, V. C., Jayaratne, T. E., Ceballo, R., \& Borquez, J. (1994). Unemployment and work interruption among African American single mothers: Effects on parenting and adolescent socioemotional functioning. Child Development, 65, 562-589.

Mikulas, W. L. (1978). Behavior modification. New York: Harper \& Row. Miller, B. C., McCoy, J. K., Olson, T. D., \& Wallace, C. M. (1986). Parental discipline and control attempts in relation to adolescent sexual attitudes and behavior. Journal of Marriage and the Family, 48, 503512.

Miller, D. R., \& Swanson, G. E. (1958). The changing American parent. New York: Wiley.

*Minton, C., Kagan, J., \& Levine, J. A. (1971). Maternal control and obedience in the two-year-old. Child Development, 42, 1873-1894.

Mosby, L., Rawls, A. W., Meehan, A. J., Mays, E., \& Pettinari, C. J. (1999). Troubles in interracial talk about discipline: An examination of African American child rearing narratives. Journal of Comparative Family Studies, 30, 489-521.

${ }^{+}$Muller, R. T. (1994). Shame and aggressive behavior in corporal punishment (Doctoral dissertation, Michigan State University, 1993). Dissertation Abstracts International, 54(10), 5398B.

${ }^{+}$Muller, R. T. (1996). Family aggressiveness factors in the prediction of corporal punishment: Reciprocal effects and the impact of observer perspective. Journal of Family Psychology, 10, 474-489.

*Muller, R. T., Hunter, J. E., \& Stollak, G. (1995). The intergenerational transmission of corporal punishment: A comparison of social learning and temperament models. Child Abuse \& Neglect, 19, 1323-1335.

National Clearinghouse on Child Abuse and Neglect Information. (2000). What is child maltreatment? Retrieved June 30, 2001, from http:// www.calib.com/nccanch/pubs/factsheets/childmal.cfm

National Coalition to Abolish Corporal Punishment in the Schools. (2001). Facts about corporal punishment. Retrieved June 30, 2001, from http:// www.stophitting.com/disatschool/facts.php

*Nettelbladt, P., Svenson, C., \& Serin, U. (1996). Background factors in patients with schizoaffective disorder as compared with patients with diabetes and healthy individuals. European Archives of Psychiatry and Neurosciences, 246, 213-218.

Newsom, C., Flavell, J. E., \& Rincover, A. (1983). The side effects of punishment. In S. Axelrod \& J. Apsche (Eds.), The effects of punishment on human behavior (pp. 285-316). New York: Academic Press.

Nix, R. L., Pinderhughes, E. E., Dodge, K. A., Bates, J. E., Pettit, G. S., \& McFaden-Ketchum, S. A. (1999). The relation between mothers' hostile attribution tendencies and children's externalizing behavior problems: The mediating role of mothers' harsh discipline practices. Child Development, 70, 896-909.

Nobes, G., Smith, M., Upton, P., \& Heverin, A. (1999). Physical punishment by mothers and fathers in British homes. Journal of Interpersonal Violence, 14, 887-902.

O'Connor, T. G., Deater-Deckard, K., Fulker, D., Rutter, M., \& Plomin, R. (1998). Genotype-environment correlations in late childhood and early adolescence: Antisocial behavioral problems and coercive parenting. Developmental Psychology, 34, 970-981.

Ogbu, J. U. (1981). Origins of human competence: A cultural-ecological perspective. Child Development, 32, 413-429.

* Oldershaw, L., Walters, G. C., \& Hall, D. K. (1986). Control strategies and noncompliance in abusive mother-child dyads: An observational study. Child Development, 57, 722-732.

Olds, D. L., Eckenrode, J., Henderson, C. R., Jr., Kitzman, H., Powers, J., Cole, R., et al. (1997). Long-term effects of home visitation on maternal life course and child abuse and neglect. Journal of the American Medical Association, 278, 637-643.

Olweus, D. (1980). Familial and temperamental determinants of aggressive behavior in adolescent boys: A causal analysis. Developmental Psychology, 16, 644-660.

Pagliocca, P. M., Melton, G. B., Wiesz, V., \& Lyons, P. M., Jr. (1995). Parenting and the law. In M. H. Bornstein (Ed.), Handbook of parenting: Vol. 3. Status and social conditions of parenting (pp. 437-457). Mahwah, NJ: Erlbaum.

Paquette, D., Bolté, C., Tucotte, G., Dubeáu, D., \& Bouchard, C. (2000). A new typology of fathering: Defining and associated variables. Infant and Child Development, 9, 213-230.

Parke, R. D. (1977). Some effects of punishment on children's behavior- 
Revisited. In E. M. Hetherington \& R. D. Parke (Eds.), Contemporary readings in child psychology (pp. 208-220). New York: McGraw-Hill.

Parke, R. D., \& Buriel, R. (1998). Socialization in the family: Ethnic and ecological perspectives. In W. Damon (Series Ed.) \& N. Eisenberg (Vol. Ed.), Handbook of child psychology: Vol. 3. Social, emotional, and personality development (5th ed., pp. 463-552). New York: Wiley.

Parke, R. D., \& Lewis, N. G. (1981). The family in context: A multilevel interactional analysis of child abuse. In R. W. Henderson (Ed.), Parentchild interaction (pp. 169-204). New York: Academic Press.

Parke, R. D., \& Slaby, R. G. (1983). The development of aggression. In P. H. Mussen (Series Ed.) \& E. M. Hetherington (Vol. Ed.), Handbook of child psychology: Vol. 4. Socialization, personality, and social development (pp. 547-641). New York: Wiley.

Parke, R. D., \& Walters, R. H. (1967). Some factors determining the efficacy of punishment of inducing response inhibition. Monographs of the Society for Research in Child Development, 32(1, Serial No. 109).

Parpal, M., \& Maccoby, E. E. (1985). Maternal responsiveness and subsequent child compliance. Child Development, 56, 1326-1334.

Patterson, G. R. (1982). Coercive family process. Eugene, OR: Castalia.

Patterson, G. R. (1997). Performance models for parenting: A social interactional perspective. In J. E. Grusec \& L. Kuczynski (Eds.), Parenting and children's internalization of values (pp. 193-226). New York: Wiley.

Patterson, G. R., Dishion, T. J., \& Bank, L. (1984). Family interaction: A process model of deviancy training. Aggressive Behavior, 10, 253-267.

Patterson, G. R., Reid, J. B., \& Dishion, T. J. (1992). Antisocial boys. Eugene, OR: Castalia.

Patterson, G. R., \& Stouthamer-Loeber, M. (1984). The correlation of family management practices and delinquency. Child Development, 55, 1299-1307.

Pearce, L. D., \& Axinn, W. G. (1998). The impact of family religious life on the quality of mother-child relations. American Sociological Review, 63, 810-828.

Peisner, E. S. (1989). To spare or not to spare the rod: A cultural-historical view of child discipline. In J. Valsiner (Ed.), Child development in cultural context (pp. 111-141). Lewiston, NY: Hogrefe \& Huber.

Pervin, L. A. (Ed.). (1997). Psychological Inquiry, 8(3).

Peterson, L., Ewigman, B., \& Vandiver, T. (1994). Role of parental anger in low-income women: Discipline strategy, perceptions of behavior problems, and the need for control. Journal of Clinical Child Psychology, 23, 435-443.

Pettit, G. S., Bates, J. E., \& Dodge, K. A. (1993). Family interaction patterns and children's conduct problems at home and school: A longitudinal perspective. School Psychology Review, 22, 403-420.

Piaget, J. (1965). The moral judgment of the child (M. Gabain, Trans.). New York: Free Press. (Original work published 1932)

Pianta, R. C., \& Egeland, B. (1990). Life stress and parenting constructs in a disadvantaged sample: Results of the mother-child interaction project. Journal of Clinical Child Psychology, 19, 329-336.

Pinderhughes, E. E., Dodge, K. A., Bates, J. E., Pettit, G. S., \& Zelli, A. (2000). Discipline responses: Influences of parents' socioeconomic status, ethnicity, beliefs about parenting, stress, and cognitive-emotional processes. Journal of Family Psychology, 14, 380-400.

Plomin, R., DeFries, J. C., \& Loehlin, J. C. (1977). Genotype-environment interaction and correlation in the analysis of human behavior. Psychological Bulletin, 84, 309-322.

*Power, T. G., \& Chapieski, M. L. (1986). Childrearing and impulse control in toddlers: A naturalistic observation. Developmental Psychology, 22, 271-275.

Putnam, F. W., Liss, M. B., \& Landsverk, J. (1996). Ethical issues in maltreatment research with children and adolescents. In K. Hoagwood, P. S. Jensen, \& C. B. Fisher (Eds.), Ethical issues in mental health research with children and adolescents (pp. 113-132). Mahwah, NJ: Erlbaum.
*Radke-Yarrow, M. R., Campbell, J. D., \& Burton, R. V. (1968). Child rearing: An inquiry into research and methods. San Francisco: JosseyBass.

Redd, W. H., Morris, E. K., \& Martin, J. A. (1975). Effects of positive and negative adult-child interactions on children's social preference. Journal of Experimental Child Psychology, 19, 153-164.

Reiss, D. (1995). Genetic influence on family systems: Implications for development. Journal of Marriage and the Family, 57, 543-560.

*Riggs, D. S., \& O'Leary, K. D. (1996). Aggression between heterosexual dating partners: An examination of a causal model of courtship aggression. Journal of Interpersonal Violence, 11, 519-540.

Ritchie, J., \& Ritchie, J. (1981). Spare the rod. Boston: George Allen \& Unwin.

Ritchie, K. L. (1999). Maternal behaviors and cognitions during discipline episodes: A comparison of power bouts and single acts of noncompliance. Developmental Psychology, 35, 580-589.

*Roberts, M. W., \& Powers, S. W. (1990). Adjusting chair timeout enforcement procedures for oppositional children. Behavior Therapy, 21, 257-271.

Rodriguez, C. M., \& Sutherland, D. (1999). Predictors of parents' physical disciplinary practices. Child Abuse \& Neglect, 23, 651-657.

Rohner, R. P., Bourque, S. L., \& Elordi, C. A. (1996). Children's perceptions of corporal punishment, caretaker acceptance, and psychological adjustment in a poor, biracial Southern community. Journal of Marriage and the Family, 58, 842-852.

Rohner, R. P., Kean, K. J., \& Cournoyer, D. E. (1991). Effects of corporal punishment, perceived caretaker warmth, and cultural beliefs on the psychological adjustment of children in St. Kitts, West Indies. Journal of Marriage and the Family, 53, 681-693.

Rosemond, J. K. (1994). To spank or not to spank. Kansas City, MO: Andrews \& McMeel.

Rosén, L. A., O’Leary, S. G., Joyce, S. A., Conway, G., \& Pfiffner, L. J. (1984). The importance of prudent negative consequences for maintaining the appropriate behavior of hyperactive students. Journal of Abnormal Child Psychology, 12, 581-604.

Rosenthal, R. (1979). The "file-drawer problem" and tolerance for null results. Psychological Bulletin, 86, 638-641.

Rosenthal, R. (1991). Meta-analytic procedures for social research (Rev. ed.). Newbury Park, CA: Sage.

Rothbaum, F., \& Weisz, J. R. (1994). Parental caregiving and child externalizing behavior in nonclinical samples: A meta-analysis. Psychological Bulletin, 116, 55-74.

*Roy, A. (1978). Self-mutilation. British Journal of Medical Psychology, 51, 201-203.

Ruble, D. N., \& Martin, C. L. (1998). Gender development. In W. Damon (Series Ed.) \& N. Eisenberg (Vol. Ed.), Handbook of child psychology: Vol. 3. Social, emotional, and personality development (5th ed., pp. 933-1016). New York: Wiley.

Rutter, M., Giller, H., \& Hagell, A. (1998). Antisocial behavior by young children. New York: Cambridge University Press.

Saarni, C. (1999). The development of emotional competence. New York: Guilford.

Saarni, C., Mumme, D. L., \& Campos, J. J. (1998). Emotional development: Action, communication, and understanding. In W. Damon (Series Ed.) \& N. Eisenberg (Vol. Ed.), Handbook of child psychology: Vol. 3. Social, emotional, and personality development (5th ed., pp. 237-309). New York: Wiley.

Sampson, R. J., \& Laub, J. H. (1994). Urban poverty and the family context of delinquency: A new look at structure and process in a classic study. Child Development, 65, 523-540.

Sanson, A., \& Rothbart, M. K. (1995). Child temperament and parenting. In M. H. Bornstein (Ed.), Handbook of parenting: Vol. 4. Applied and practical parenting (pp. 299-321). Mahwah, NJ: Erlbaum. 
Scarr, S. (1992). Development theories for the 1990s: Development and individual differences. Child Development, 63, 1-19.

Scarr, S., \& McCartney, K. (1983). How people make their own environments: A theory of genotype $\rightarrow$ environment effects. Child Development, 54, 424-435.

*Schwermer, J. H. (1995). Physical punishment as purposive behavior (Doctoral dissertation, University of Maryland Baltimore County, 1994). Dissertation Abstracts International, 55(07), 2144B.

*Seagull, E. A. W., \& Weinshank, A. B. (1984). Childhood depression in a selected group of low-achieving seventh graders. Journal of Clinical Child Psychology, 13, 134-140.

* Sears, R. R. (1961). Relation of early socialization experiences to aggression in middle childhood. Journal of Abnormal and Social Psychology, 63, 466-492.

*Sears, R. R., Maccoby, E. E., \& Levin, H. (1957). Patterns of child rearing. New York: Harper \& Row.

Sheeber, L. B., \& Johnson, J. H. (1994). Evaluation of a temperamentfocused, parent-training program. Journal of Clinical Child Psychology, 23, 249-259.

Shumow, L., Vandell, D. L., \& Posner, J. K. (1998). Harsh, firm, and permissive parenting in low-income families: Relations to children's academic achievement and behavioral adjustment. Journal of Family Issues, 19, 483-507.

Siegal, M., \& Cowen, J. (1984). Appraisals of intervention: The mother's versus the culprit's behavior as determinants of children's evaluations of discipline techniques. Child Development, 55, 1760-1766.

Sigelman, C. K., Berry, C. J., \& Wiles, K. A. (1984). Violence in college students' dating relationships. Journal of Applied Social Psychology, 5, $530-548$.

Simons, R. L., Beaman, J., Conger, R. D., \& Chao, W. (1993). Stress, support, and antisocial behavior trait as determinants of emotional wellbeing and parenting practices among single mothers. Journal of Marriage and the Family, 55, 385-398.

*Simons, R. L., Johnson, C., Beaman, J., \& Conger, R. D. (1993). Explaining women's double jeopardy: Factors that mediate the association between harsh treatment as a child and violence by a husband. Journal of Marriage and the Family, 55, 713-723.

*Simons, R. L., Johnson, C., \& Conger, R. D. (1994). Harsh corporal punishment versus quality of parental involvement as an explanation of adolescent maladjustment. Journal of Marriage and the Family, 56, 591-607.

*Simons, R. L., Lin, K., \& Gordon, L. C. (1998). Socialization in the family of origin and male dating violence: A prospective study. Journal of Marriage and the Family, 60, 467-478.

Simons, R. L., Lorenz, F. O., Wu, C., \& Conger, R. D. (1993). Social network and marital support as mediators and moderators of the impact of stress and depression on parental behavior. Developmental Psychology, 29, 368-381.

Simons, R. L., Whitbeck, L. B., Conger, R. D., \& Wu, C. (1991). Intergenerational transmission of harsh parenting. Developmental Psychology, 27, 159-171.

Simons, R. L., Whitbeck, L. B., Melby, J. N., \& Wu, C. (1994). Economic pressure and harsh parenting. In R. D. Conger \& G. H. Elder Jr. (Eds.), Families in troubled times: Adapting to change in rural America (pp. 207-222). New York: Aldine de Gruyter.

*Singer, J. L., Singer, D. G., \& Rapaczynski, W. S. (1984). Family patterns and television viewing as predictors of children's beliefs and aggression. Journal of Communication, 34, 73-89.

Smetana, J. G. (1997). Parenting and the development of social knowledge reconceptualized: A social domain analysis. In J. E. Grusec \& L. Kuczynski (Eds.), Parenting and children's internalization of values: A handbook of contemporary theory (pp. 162-192). New York: Wiley.

Smith, J. R., \& Brooks-Gunn, J. (1997). Correlates and consequences of harsh discipline for young children. Archives of Pediatric and Adolescent Medicine, 151, 777-786.

Snyder, J. J. (1995). Coercion: A two-level theory of antisocial behavior. In W. O'Donohue \& L. Krasner (Eds.), Theories of behavior therapy: Exploring behavior change (pp. 313-348). Washington, DC: American Psychological Association.

Snyder, J., \& Patterson, G. R. (1986). The effects of consequences on patterns of social interaction: A quasi-experimental approach to reinforcement in natural interaction. Child Development, 57, 1257-1268.

Socolar, R. R. S., \& Stein, R. E. K. (1995). Spanking infants and toddlers: Maternal belief and practice. Pediatrics, 95, 105-111.

Spieker, S. J., Larson, N. C., Lewis, S. M., Keller, T. E., \& Gilchrist, L. (1999). Developmental trajectories of disruptive behavior problems in preschool children of adolescent mothers. Child Development, 70, 443458.

Staples, R., \& Johnson, L. B. (1993). Black families at the crossroads. San Fransisco: Jossey-Bass.

Stark, R., \& McEvoy, J. (1970). Middle-class violence. Psychology Today, 4, 52-54, 110-112.

*Stattin, J., Janson, H., Klackenberg-Larsson, I., \& Magnusson, D. (1995). Corporal punishment in everyday life: An intergenerational perspective. In J. McCord (Ed.), Coercion and punishment in long-term perspectives (pp. 315-347). New York: Cambridge University Press.

Stayton, D. J., Hogan, R., \& Ainsworth, M. D. S. (1971). Infant obedience and maternal behavior: The origins of socialization reconsidered. Child Development, 42, 1057-1069.

Steinmetz, S. K. (1979). Disciplinary techniques and their relationship to aggressiveness, dependency, and conscience. In W. R. Burr, R. Hill, F. I. Nye, \& I. L. Reiss (Eds.), Contemporary theories about the family: Vol. 1. Research based theories (pp. 405-438). New York: Free Press.

Stevens-Long, J. (1973). The effect of behavioral context on some aspects of adult disciplinary practice and affect. Child Development, 44, 476484.

Stolley, K. S., \& Szinovacz, M. (1997). Caregiving responsibilities and child spanking. Journal of Family Violence, 12, 99-112.

${ }^{+}$Strassberg, Z., Dodge, K. A., Pettit, G. S., \& Bates, J. E. (1994). Spanking in the home and children's subsequent aggression toward kindergarten peers. Development and Psychopathology, 6, 445-461.

Straus, M. A. (1974). Some social antecedents of physical punishment: A linkage theory interpretation. In S. K. Steinmetz \& M. A. Straus (Eds.), Violence in the family (pp. 159-166). New York: Harper \& Row.

Straus, M. A. (1990a). The Conflict Tactics Scale and its critics: An evaluation and new data on validity and reliability. In M. A. Straus \& R. J. Gelles (Eds.), Physical violence in American families: Risk factors and adaptations to violence in 8,145 families (pp. 49-73). New Brunswick, NJ: Transaction.

*Straus, M. A. (1990b). Ordinary violence, child abuse, and wife beating: What do they have in common? In M. A. Straus \& R. J. Gelles (Eds.), Physical violence in American families: Risk factors and adaptations to violence in 8,145 families (pp. 403-424). New Brunswick, NJ: Transaction.

*Straus, M. A. (1994a). Beating the devil out of them: Corporal punishment in American families. New York: Lexington Books.

Straus, M. A. (1994b). Should the use of corporal punishment by parents be considered child abuse? Yes. In M. A. Mason \& E. Gambrill (Eds.), Debating children's lives: Current controversies on children and adolescents (pp. 197-203). Thousand Oaks, CA: Sage.

${ }^{+}$Straus, M. A. (1995). Corporal punishment of children and adult depression and suicidal ideation. In J. McCord (Ed.), Coercion and punishment in long-term perspectives (pp. 59-77). New York: Cambridge University Press.

Straus, M. A. (1999). Child-report, adult-recall, and sibling versions of the Revised Conflict Tactics Scale. Durham, NC: Family Research Laboratory. 
Straus, M. A., \& Kantor, G. K. (1987). Stress and child abuse. In R. E. Helfer \& R. S. Kempe (Eds.), The battered child (4th ed., pp. 42-59). Chicago: University of Chicago Press.

*Straus, M. A., \& Kantor, G. K. (1994). Corporal punishment of adolescents by parents: A risk factor in the epidemiology of depression, suicide, alcohol abuse, and wife beating. Adolescence, 29, 543-561.

*Straus, M. A., \& Mouradian, V. E. (1998). Impulsive corporal punishment by mothers and antisocial behavior and impulsiveness of children. Behavioral Sciences and the Law, 16, 353-374.

Straus, M. A., \& Stewart, J. H. (1999). Corporal punishment by American parents: National data on prevalence, chronicity, severity, and duration, in relation to child and family characteristics. Clinical Child and Family Psychology Review, 2, 55-70.

*Straus, M. A., Sugarman, D. B., \& Giles-Sims, J. (1997). Spanking by parents and subsequent antisocial behavior of children. Archives of Pediatric and Adolescent Medicine, 151, 761-767.

Straus, M. A., \& Yodanis, C. L. (1996). Corporal punishment in adolescence and physical assaults on spouses later in life: What accounts for the link? Journal of Marriage and Family, 58, 825-841.

Swinford, S. P., DeMaris, A., Cernkovich, S. A., \& Giordano, P. C. (2000). Harsh physical disicpline in childhood and violence in later romatic involvements: The mediating role of problem behaviors. Journal of Marriage and the Family, 62, 508-519.

Thomas, A., \& Chess, S. (1977). Temperament and development. New York: Brunner/Mazel.

Thompson, R. W., Ruma, P. R., Brewster, A. L., Besetsney, L. K., \& Burke, R. V. (1997). Evaluation of an Air Force child physical abuse prevention project using the Reliable Change Index. Journal of Child and Family Studies, 6, 421-434.

Thyer, B. A. (1987). Punishment-induced aggression: A possible mechanism of child abuse? Psychological Reports, 60, 129-130.

Tremblay, R. E. (1995). Kindergarten behavioral patterns, parental practices, and early adolescent antisocial behavior. In J. McCord (Ed.), Coercion and punishment in long-term perspectives (pp. 139-153). New York: Cambridge University Press.

*Trickett, P. K., \& Kuczynski, L. (1986). Children's misbehaviors and parental discipline strategies in abusive and nonabusive families. Developmental Psychology, 22, 115-123.

Turner, H. A., \& Finkelhor, D. (1996). Corporal punishment as a stressor among youth. Journal of Marriage and the Family, 58, 155-166.

Ulrich, R. (1966). Pain as a cause of aggression. American Zoologist, 6, 643-662.

United Nations Children's Fund. (1999). The Convention on the Rights of the Child: Frequently asked questions, Who has not ratified and why not? Retrieved February 5, 2000, from http://www.unicef.org/crc/crc. htm

United Nations Committee on the Rights of the Child, Report on the seventh session, U.N. Document CRC/C/34, Annex IV, at 63 (November, 1994). Geneva, Switzerland: Author.

United Nations Convention on the Rights of the Child, G.A. Res. 44/25, U.N. GAOR, 44th Sess., at 3, U.N. Doc. A/RES/44/25 (1989, Nov. 20). Retrieved February 5, 2000, from http://www.unicef.org/crc/crc.htm

U.S. Department of Health and Human Services. (2001). Child maltreatment 1999: Reports from the states to the National Child Abuse and Neglect Data System. Washington, DC: U.S. Government Printing Office. Retrieved June 30, 2001, from http://www.acf.dhhs.gov/programs/ cb/publications/cm99/cm99.pdf

Van Houten, R. (1983). Punishment: From the animal laboratory to the applied setting. In S. Axelrod \& J. Apsche (Eds.), The effects of punishment on human behavior (pp. 13-14). New York: Academic.

Vasta, R. (1982). Physical child abuse: A dual-component analysis. Developmental Review, 2, 125-149.

Vissing, Y. M., Straus, M. A., Gelles, R. J., \& Harrop, J. W. (1991). Verbal aggression by parents and psychosocial problems of children. Child Abuse \& Neglect, 15, 223-238.

Walters, G. C., \& Grusec, J. E. (1977). Punishment. San Francisco: W. H. Freeman.

*Watson, D. G. (1990). Parenting styles and child behavior: A study of retrospective reports from parents of 2500 high school students (Doctoral dissertation, State University of New York at Buffalo, 1989). Dissertation Abstracts International, 50(07), 3181B.

Webster-Stratton, C. (1984). Randomized trial of two parent training programs for families with conduct-disordered children. Journal of Consulting and Clinical Psychology, 52, 666-678.

*Webster-Stratton, C. (1985). Comparison of abusive and nonabusive families with conduct-disordered children. American Journal of Orthopsychiatry, 55, 59-69.

Webster-Stratton, C. (1988a). Mothers' and fathers' perceptions of child deviance: Roles of parent and child behaviors and parent adjustment. Journal of Consulting and Clinical Psychology, 56, 909-915.

Webster-Stratton, C. (1988b). Preventing conduct problems in Head Start children: Strengthening parenting competencies. Journal of Consulting and Clinical Psychology, 66, 715-730.

Webster-Stratton, C. (1990). Stress: A potential disruptor of parent perceptions and family interactions. Journal of Clinical Child Psychology, 19, 302-312.

Webster-Stratton, C., Hollinsworth, T., \& Kolpacoff, M. (1989). The long-term effectiveness and clinical significance of three cost-effective training programs for families with conduct-problem children. Journal of Consulting and Clinical Psychology, 57, 550-553.

Weiss, B., Dodge, K. A., Bates, J. E., \& Pettit, G. S. (1992). Some consequences of early harsh discipline: Child aggression and a maladaptive social information processing style. Child Development, 63, 13211335.

West, D. J., \& Farrington, D. P. (1973). Who becomes delinquent? London: Heinemann.

Whaley, A. L. (2000). Sociocultural differences in the developmental differences in the developmental consequences of the use of physical discipline during childhood for African Americans. Cultural Diversity and Ethnic Minority Psychology, 6, 5-12.

*Whipple, E. E. (1990). The role of parental stress in physically abusive families (Doctoral dissertation, University of Washington, 1989). Dissertation Abstracts International, 50(10), 3364A.

Whipple, E. E., \& Richey, C. A. (1997). Crossing the line from physical discipline to child abuse: How much is too much? Child Abuse \& Neglect, 21, 431-444.

White, S. O., \& Straus, M. A. (1981). The implications of family violence for rehabilitation strategies. In S. E. Martin, L. B. Sechrest, \& R. Redner (Eds.), New directions in the rehabilitation of criminal offenders (pp. 255-288). Washington, DC: National Academy Press.

Widom, C. S. (1989). Does violence beget violence? A critical examination of the literature. Psychological Bulletin, 106, 3-28.

*Wiederhold, P. (1997). Family structure, family value, parental style, and discipline in the lives of gang members (Doctoral dissertation, Brigham Young University, 1997). Dissertation Abstracts International, 58(02), 964B.

Wiehe, V. R. (1990). Religious influence on parental attitudes toward the use of corporal punishment. Journal of Family Violence, 5, 173-186.

Wilcox, W. B. (1998). Conservative Protestant childrearing: Authoritarian or authoritative? American Sociological Review, 63, 796-809.

Wilson, J. Q., \& Herrnstein, R. J. (1985). Crime and human nature. New York: Simon \& Schuster.

Wissow, L. S. (2001). Ethnicity, income, and parenting contexts of physical punishment in a national sample of families with young children. Child Maltreatment, 6, 118-129.

Wolfe, D. A. (1987). Child abuse: Implications for child development and psychopathology. Newbury Park, CA: Sage. 
Wolfe, D. A. (1991). Preventing physical and emotional abuse of children. New York: Guilford Press.

Wolfe, D. A., Sandler, J., \& Kaufman, K. (1981). A competency-based parent training program for child abusers. Journal of Consulting and Clinical Psychology, 49, 633-640.

Wong, E. (1999, January 27). Oakland panel rejects no-spanking proposal. The Los Angeles Times, p. 3.

Xu, X., Tung, Y., \& Dunaway, R. G. (2000). Cultural, human, and social capital as determinants of corporal punishment: Toward an integrated theoretical model. Journal of Interpersonal Violence, 15, 603-630.

Yodanis, C. L., Hill, K. A., \& Straus, M. A. (2001). Tabular summaries of methodological characteristics of research using the Conflict Tactics Scale. Durhan, NC: Family Research Laboratory.

Youssef, R. M., Attia, M. S., \& Kamel, M. I. (1998). Children experiencing violence: I. Parental use of corporal punishment. Child Abuse \& Neglect, 22, 959-973.

Zahn-Waxler, C., \& Chapman, M. (1982). Immediate antecedents of care- takers' methods of discipline. Child Psychiatry and Human Development, 12, 179-192.

Zahn-Waxler, C., Cole, P. M., \& Barrett, K. C. (1991). Guilt and empathy: Sex differences and implications for the development of depression. In J. Garber \& K. A. Dodge (Eds.), The development of emotion regulation and dysregulation (pp. 243-272). New York: Cambridge University Press.

*Zahn-Waxler, C., Radke-Yarrow, M., \& King, R. A. (1979). Child rearing and children's prosocial initiations toward victims of distress. Child Development, 50, 319-330.

Zigler, E., \& Hall, N. (1989). Physical child abuse in America. In D. Cicchetti \& V. Carlson (Eds.), Child maltreatment (pp. 38-75). New York: Cambridge University Press.

Received October 3, 1997 Revision received July 30, 2001

Accepted August 14, 2001

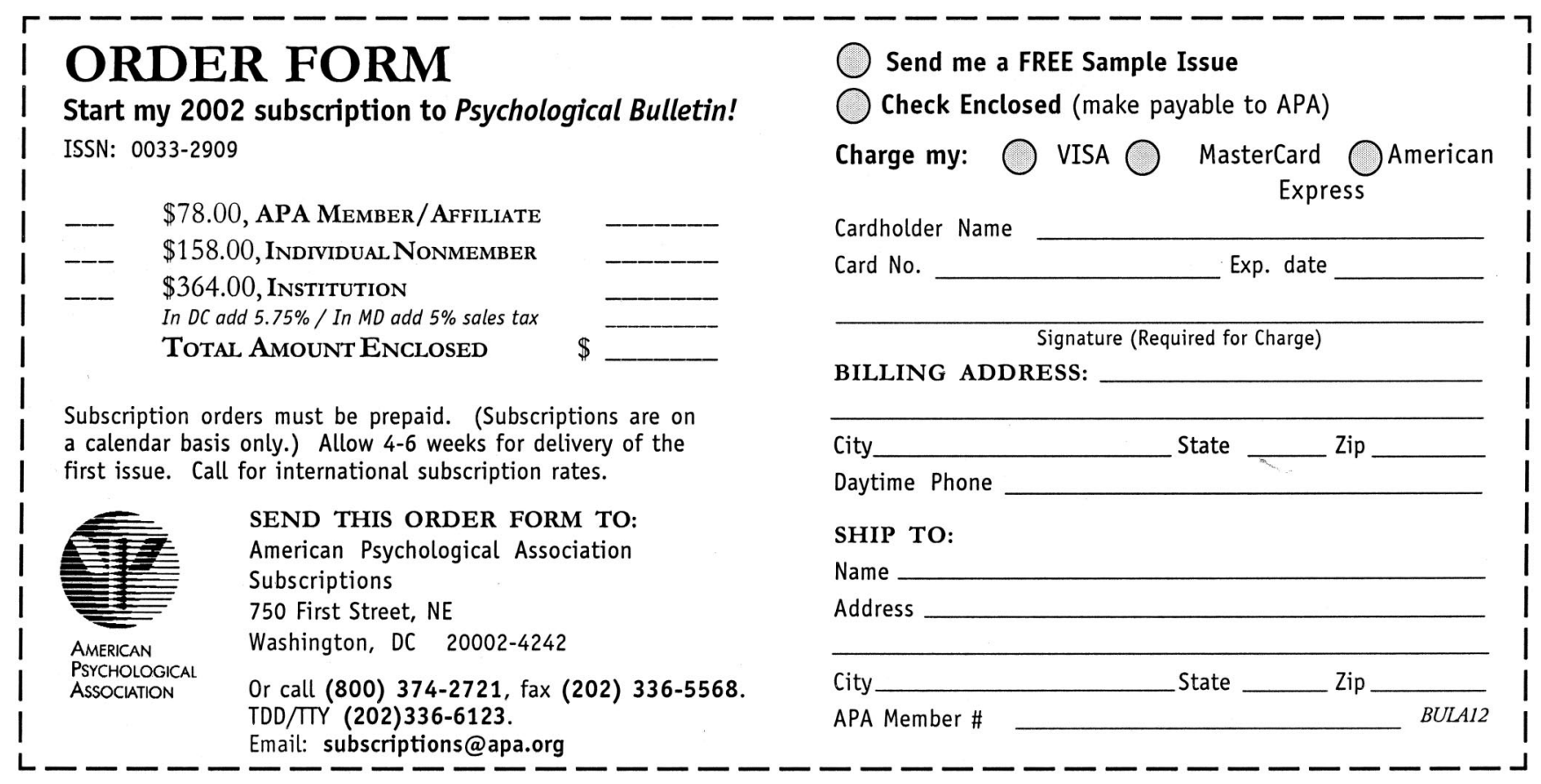

